\title{
Sustainable Development: Rural Poverty and Climate Change in Agriculture
}

\author{
Dissertation \\ to obtain the Dr. rer. pol. degree \\ in the International Ph. D. Program for Agricultural Sciences \\ in Göttingen (IPAG) \\ at the Faculty of Agricultural Sciences, \\ Georg-August-University Göttingen, Germany
}

presented by Hanjie Wang

born in Fujian, China

Göttingen, October 2020 

D7

1. Name of supervisor: Prof. Xiaohua Yu, Ph.D.

2. Name of co-supervisor: Prof. Dr. Jan-Henning Feil

3. Name of 2nd co-supervisor: Prof. Dr. Matin Qaim

Date of dissertation: October $19^{\text {th }}, 2020$ 



\section{Contents}

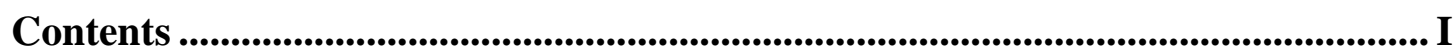

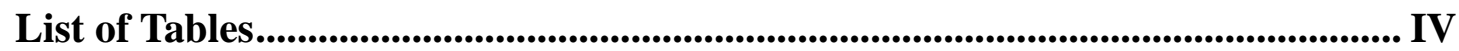

List of Figures...................................................................................................................................... V

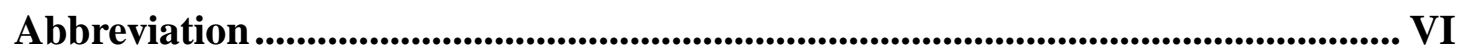

Acknowledgement ................................................................................................... VIII

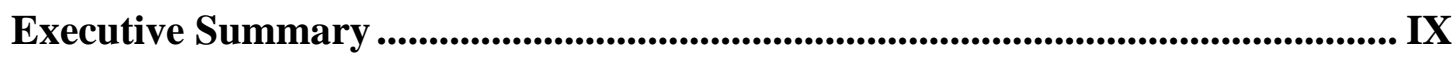

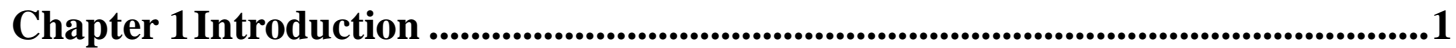

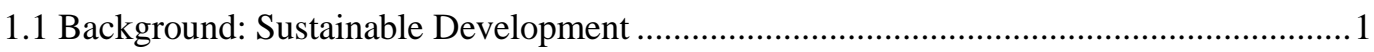

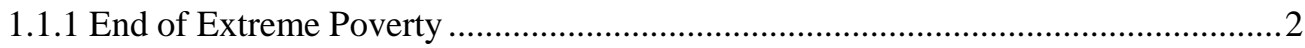

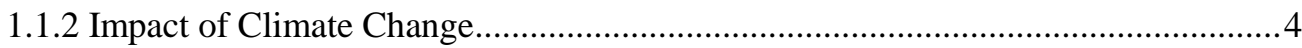

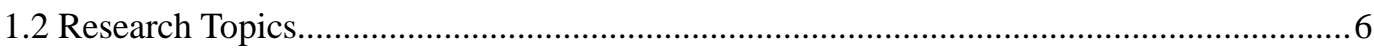

1.2.1 Poverty and Subjective Poverty in Rural China .......................................................6

1.2.2 Disagreement on Sunspots and Soybeans Futures Prices........................................

1.2.3 Climate Change and Agricultural Trade ................................................................ 8

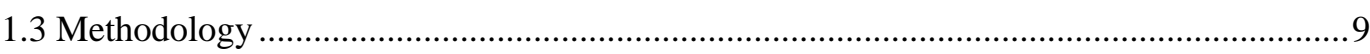

1.3.1 Subjective Poverty and Subjective Measure Approach............................................

1.3.2 Soybeans Futures Prices Volatility and the GARCH Models................................. 10

1.3.3 Agricultural Trade and the Gravity Model ……………..................................... 11

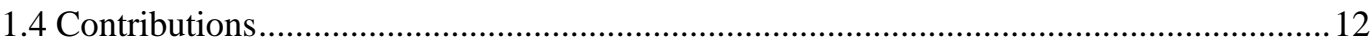

1.4.1 Reveal the Subjective Poverty in Rural China ……………………...................... 12

1.4.2 Provide a New Perspective to Understand the Impact of Sunspots.........................13

1.4.3 Substantiate the Impact of Climate Change on Agricultural Trade ........................ 15

Chapter 2Poverty and Subjective Poverty in Rural China ......................................17

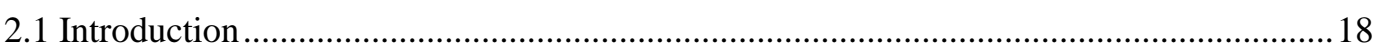

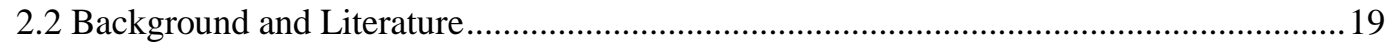

2.2.1 Objective Poverty and Its Limitations .................................................................. 19

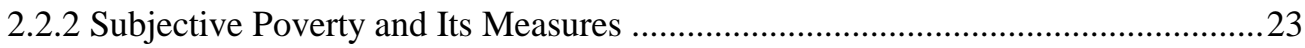




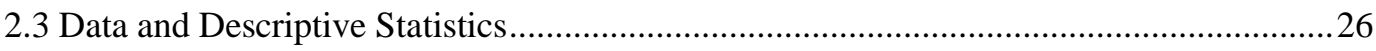

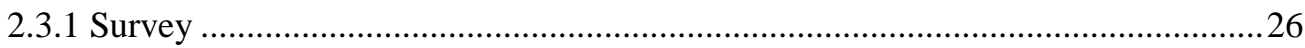

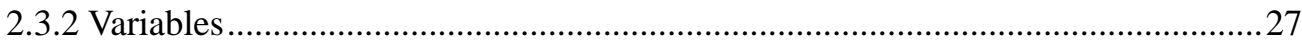

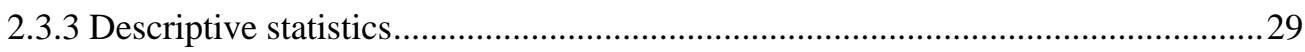

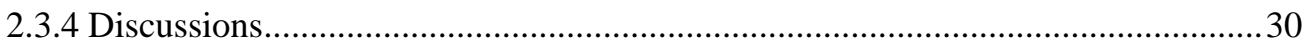

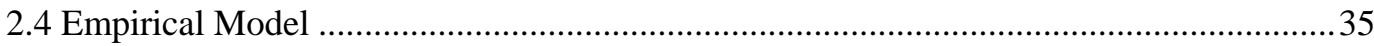

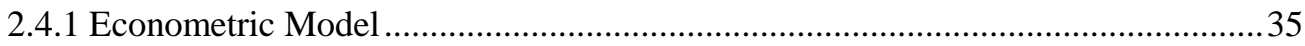

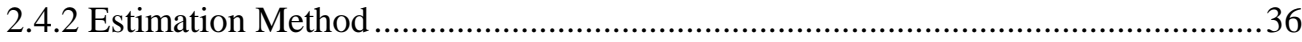

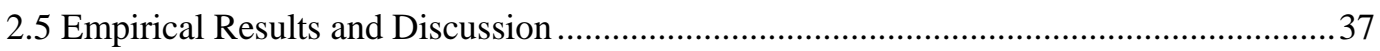

2.5.1 Determinants of the subjective poverty standard ...................................................37

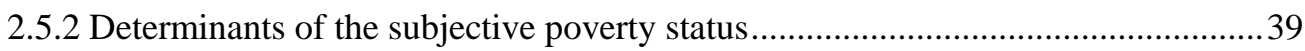

2.5.3 Determinants of the depth of subjective poverty..................................................4

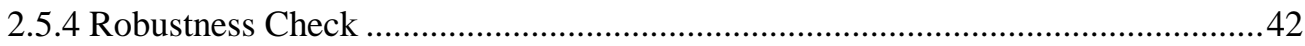

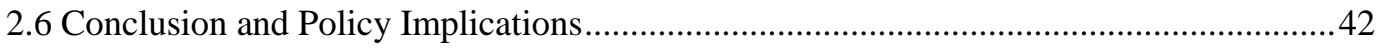

\section{Chapter 3Disagreement on Sunspots and Soybeans Futures Prices......................55}

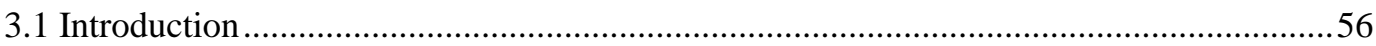

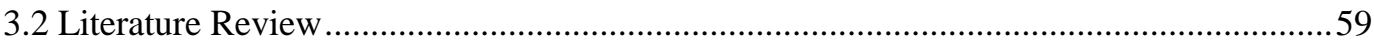

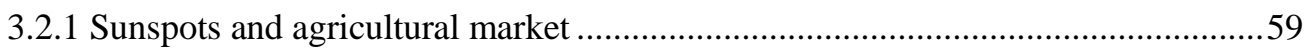

3.2.2 Sunspots and economic cycle ...........................................................................6

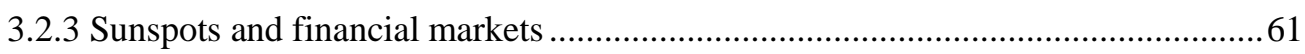

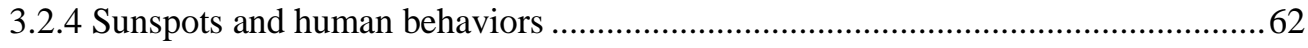

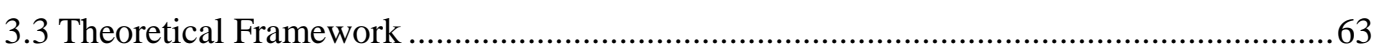

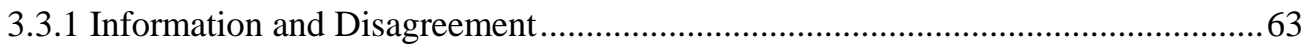

3.3.2 Information of Sunspots and Disagreement ........................................................66

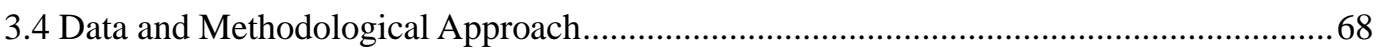

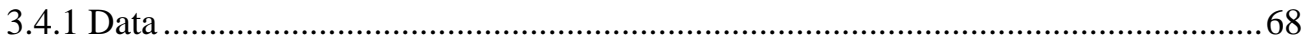

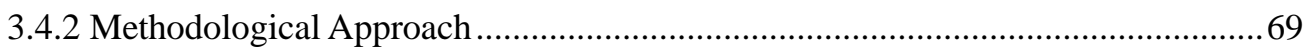

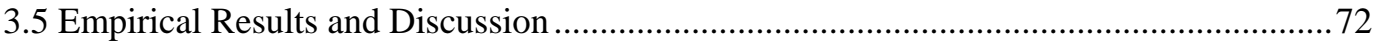

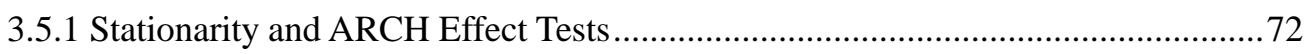

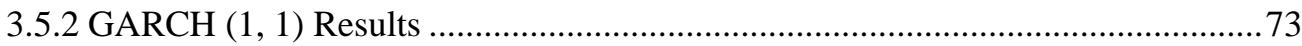


3.5.4 Markov-switching GARCH Results..................................................................

3.5.5 Discussion of Economic Mechanism ..................................................................77

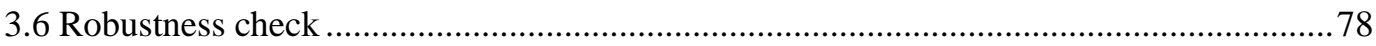

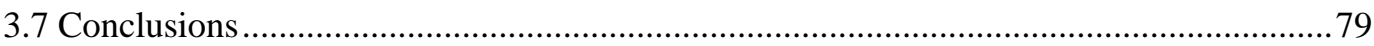

Chapter 4Climate Change and Agricultural Trade in Central Asia: Evidence

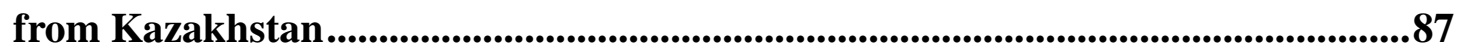

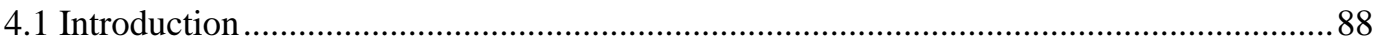

4.2 Background: Cereal trade and climate change in Kazakhstan ........................................91

4.3 Data and Descriptive Statistics......................................................................................93

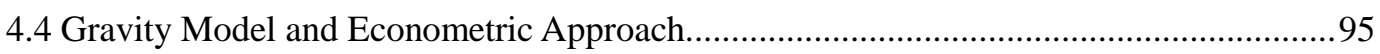

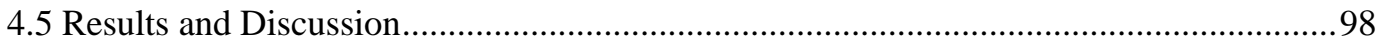

4.5.1 Climate Change and Cereal Exports in Kazakhstan................................................98

4.5.2 Climate Change and Cereal Imports in Kazakhstan............................................. 100

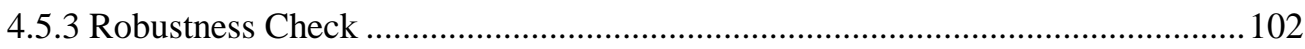

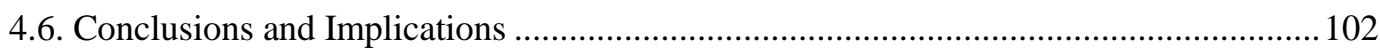

Chapter 5 General Conclusion.................................................................................................... 111

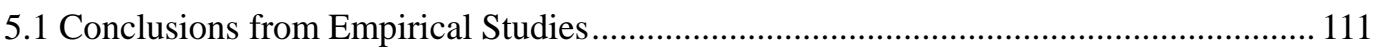

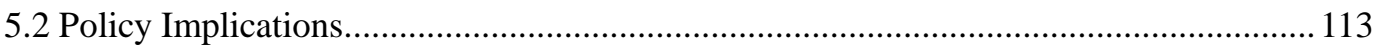

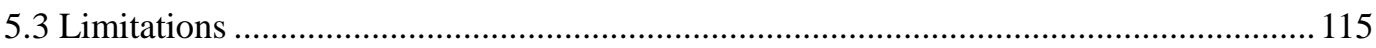

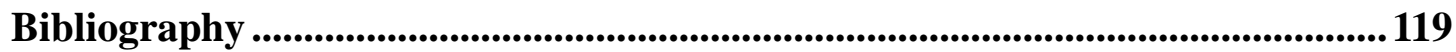




\section{List of Tables}

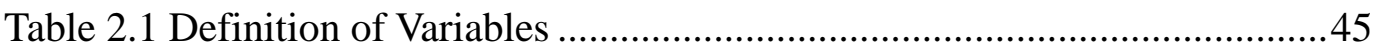

Table 2.2 Descriptive statistics of variables......................................................46

Table 2.3 Subjective poverty standard in rural China.......................................47

Table 2.4 Incidence of subjective poverty in rural China ..................................47

Table 2.5 Subjective poverty of the objective poor in rural China ......................47

Table 2.6 Comparison between the subjective poor and the non-subjective poor 48

Table 2.7 Determinants of the subjective poverty standard ...............................49

Table 2.8 Determinants of the subjective poverty status ...................................50

Table 2.9 Determinants of the poverty depth of the subjective poor ...................51

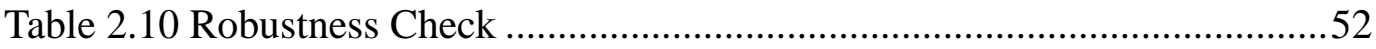

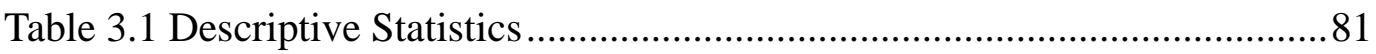

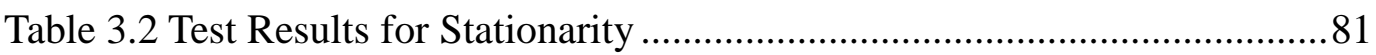

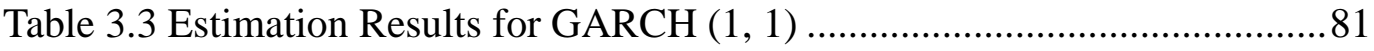

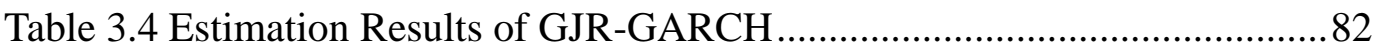

Table 3.5 Estimation Results of Markov-switching GARCH.............................83

Table 3.6 Robust Check between Sunspots and Volatility ..................................8

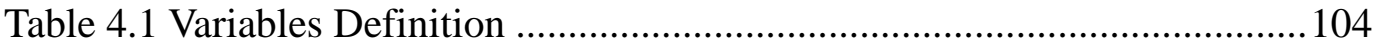

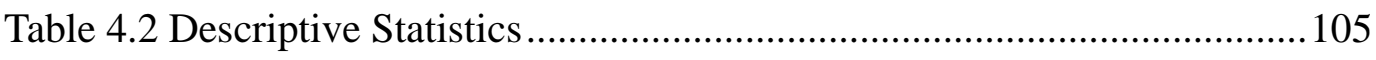

Table 4.3 the Impact of Climate Change on Cereal Exports..............................106

Table 4.4 the Impact of Climate Change on Cereal Imports..............................107

Table 4.5 Robustness Check of Cereal Exports .................................................108

Table 4.6 Robustness Check of Cereal Imports ................................................109 


\section{List of Figures}

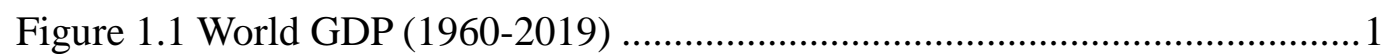

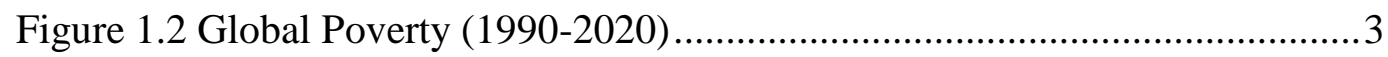

Figure 1.3 Global Temperature Change (1880-2019) ..........................................4

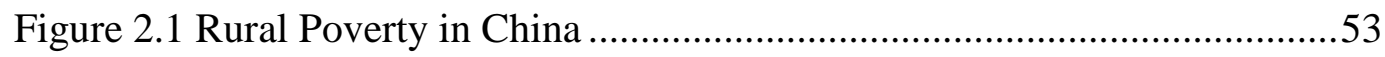

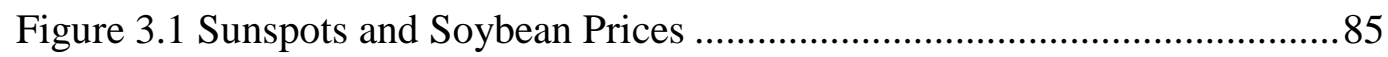

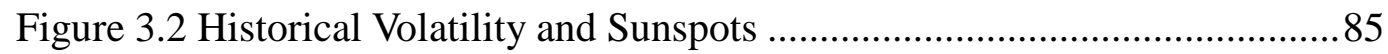

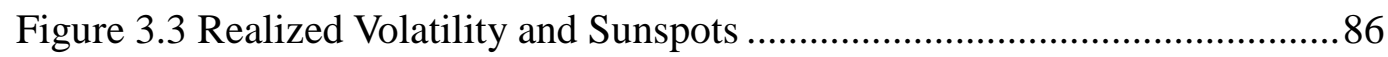

Figure 4.1 Precipitation and Wheat Exports .................................................. 110

Figure 4.2 Temperature and Wheat Exports .................................................. 110 


\section{Abbreviation}

\begin{tabular}{|c|c|}
\hline SDGs & Sustainable Development Goals \\
\hline GDP & Gross Domestic Product \\
\hline NBS & National Bureau of Statistics \\
\hline GISS & NASA's Goddard Institute for Space Studies \\
\hline MIQ & Minimum Income Question \\
\hline GARCH & Generalized Autoregressive Conditional Heteroskedasticity \\
\hline PPP & Purchasing Power Parity \\
\hline $\mathrm{ICP}$ & International Comparison Program \\
\hline MPI & Multidimensional Poverty Index \\
\hline UNDP & United Nations Development Programme \\
\hline IEQ & Income Evaluation Question \\
\hline CSP & Centre for Social Policy Question \\
\hline MSQ & Minimum Spending Question \\
\hline SIPP & Survey of Income and Program Participation \\
\hline CHIP & Chinese Household Income Project \\
\hline GVIO & Gross Value of Industrial Output \\
\hline DJIA & Dow Jones Industrial Average \\
\hline NASA & National Aeronautics and Space Administration \\
\hline NOAA & National Oceanic and Atmospheric Administration \\
\hline $\mathrm{ARCH}$ & Autoregressive Conditional Heteroscedasticity \\
\hline
\end{tabular}




\begin{tabular}{|l|l|}
\hline BRI & the Belt and Road Initiative \\
\hline IPCC & the Intergovernmental Panel on Climate Change \\
\hline FAO & Food and Agriculture Organization of the United Nations \\
\hline GPM & Global Precipitation Measurement \\
\hline JAXA & the Japan Aerospace Exploration Agency \\
\hline MERRA2 & the Second Modern-Era Retrospective Analysis for Research and \\
\hline OLS & Applications \\
\hline PPML & Ordinary Least Squares \\
\hline TRA & Poisson Pseudo Maximum Likelihood \\
\hline NTB & Regional Trade Agreement \\
\hline EPA & Non-Tariff Barriers to Trade \\
\hline
\end{tabular}




\section{Acknowledgement}

Throughout the writing of this dissertation, I have received a great deal of support from my supervisors, colleagues, and friends.

I would first like to express my sincere gratitude to my supervisor Prof. Xiaohua Yu for his patience, motivation, and excellent guidance during my Ph.D. study. His immense knowledge enables me to develop a deep understanding on my research topic, which is extremely valuable for my academic career. I also appreciate his countless help for my personal lives. Besides, I would like to thank the rest of my thesis committee: Prof. Dr. Jan-Henning Feil and Prof. Dr. Matin Qaim, for their insightful comments and encouragement.

My sincere thanks also go to my colleagues at the University of Göttingen: Ms. Jana Nowakowsky, Ms. Lucie Louise Maruejols, Dr. Yuquan Chen, Dr. Hengrong Luo, and Dr. Zhenhua Wang, who provide me a great help to conduct my research. I really appreciate for their precious support.

Last but not least, I am very grateful to my girlfriend, Dr. Jiali Han, for her companionship. Thank you so much for all of the happy memories. Also, I would like to thank my parents and my brother for supporting me spiritually throughout my $\mathrm{Ph} . \mathrm{D}$. study.

Hanjie Wang

August 2020, Göttingen, Germany 


\section{Executive Summary}

How to achieve sustainable development is an important issue all over the world. In 2015, all United Nations Member States adopted the 17 Sustainable Development Goals (SDGs) as a universal action to ensure social, economic, and environmental sustainability. Notably, rural poverty and climate change are the most significant challenges for the agricultural economy and rural development as it relates to the basic living needs of rural households and agricultural production activities. Therefore, this dissertation aims to better understand rural poverty and the impact of climate change on agriculture so as to provide some theoretical and empirical evidence for policy-making.

Concerning the rural poverty and climate change issues, this dissertation sheds light on three topics: poverty and subjective poverty in rural China, disagreement on sunspots and soybeans futures prices, and the impact of climate change on agricultural trade in Central Asia. Each topic is studied both theoretically and empirically.

The first topic uses a subjective measure approach to reveal the subjective poverty in rural China and then employs several econometric models to analyze the determinants of subjective poverty. We collect a nationally representative sample of 2025 households to conduct the research. Our results indicate that the mean subjective poverty line of the rural households is 8297 yuan per capita, which is far higher than the national poverty line (2800 yuan). Statistically, $29 \%$ of the surveyed rural households who are not objectively poor feel subjectively poor. Thus, we conclude 
that the objective poverty line cannot fully reflect the subjective poverty perception.

The second topic analyzes the impact of sunspots on the volatility of soybeans futures prices in a framework of the disagreement theory. Empirically, we use the monthly time series datasets of soybeans futures prices and sunspot activities from 1988-2018 to investigate how sunspots affect the volatilities of soybeans futures price by estimating the GARCH, GJR-GARCH, and Markov-switching GARCH models. Our findings can be summarized as (1) extremely low sunspot activity could lead to both a high level and high volatility for soybeans futures price; and (2) when considering regime changes, the disagreement level is nonlinear in the high volatility regime in which the high price volatility exists on both extremely low and high sunspot activities.

The third topic takes Kazakhstan as an example to empirically analyze the impact of climate change on cereal trade by including them as determinants in the gravity model. Our results show that climate changes in Kazakhstan, measured by precipitation and temperature, could increase the export of wheat and rice and the import of maize, and decrease the import of wheat. Specifically, as a major crop in Kazakhstan, increasing precipitation by 1 millimeter during the major cropping season from May to August, will significantly enhance export of wheat by $0.7 \%$ and reduce the import by $1.7 \%$; increasing temperature by $1{ }^{\circ} \mathrm{C}$ during the same cropping season will significantly increase export of wheat by $21.9 \%$ and reduce the import by $49.4 \%$.

Based on these findings, this dissertation offers some policy implications as follows. First, compared with the objective poverty line, the measurement of 
subjective poverty is a more flexible method to reflect the poverty perception particularly when extreme poverty is not an important issue. Thus, it is necessary to integrate subjective poverty into the policy evaluation system and combine both subjective and objective poverty to show a full picture of poverty reduction in rural China. Second, projecting food prices and making food policies should consider sunspots. A better forecast of market price could help traders make better investment strategies, and help governments make better food security policies. Third, under the increased challenges of climate change, international cereal trade could be an effective adaption to ensuring food supply. Thus, a well-functioning international cereal trade system should be taken into consideration so as to support the adaption to climate change. Nevertheless, as an important cereal trade country around the world, the dramatic adjustments of cereal trade patterns resulting from climate change in Kazakhstan may affect global food security. For this reason, it is necessary to integrate international food trade into the other climate change adaption approaches in the future. 



\section{Chapter 1 Introduction}

\subsection{Background: Sustainable Development}

How to achieve sustainable development is an important issue all over the world. Although the world economic development has experienced a remarkable upward trend over the past few decades, rising from 11.36 trillion in 1960 to 84.99 trillion in 2019 (See Figure 1.1), we still face a lot of global challenges, including poverty and inequality, climate change, environmental degradation, and so on. In such a scenario, in 2015, all United Nations Member States adopted the 17 Sustainable Development Goals (SDGs) as a universal action to ensure social, economic, and environmental sustainability by 2030 . Thence, a number of studies attach great attention to sustainable development worldwide, trying to understand the underlying mechanism of sustainable development and then find a feasible way to achieve the Sustainable Development Goals.

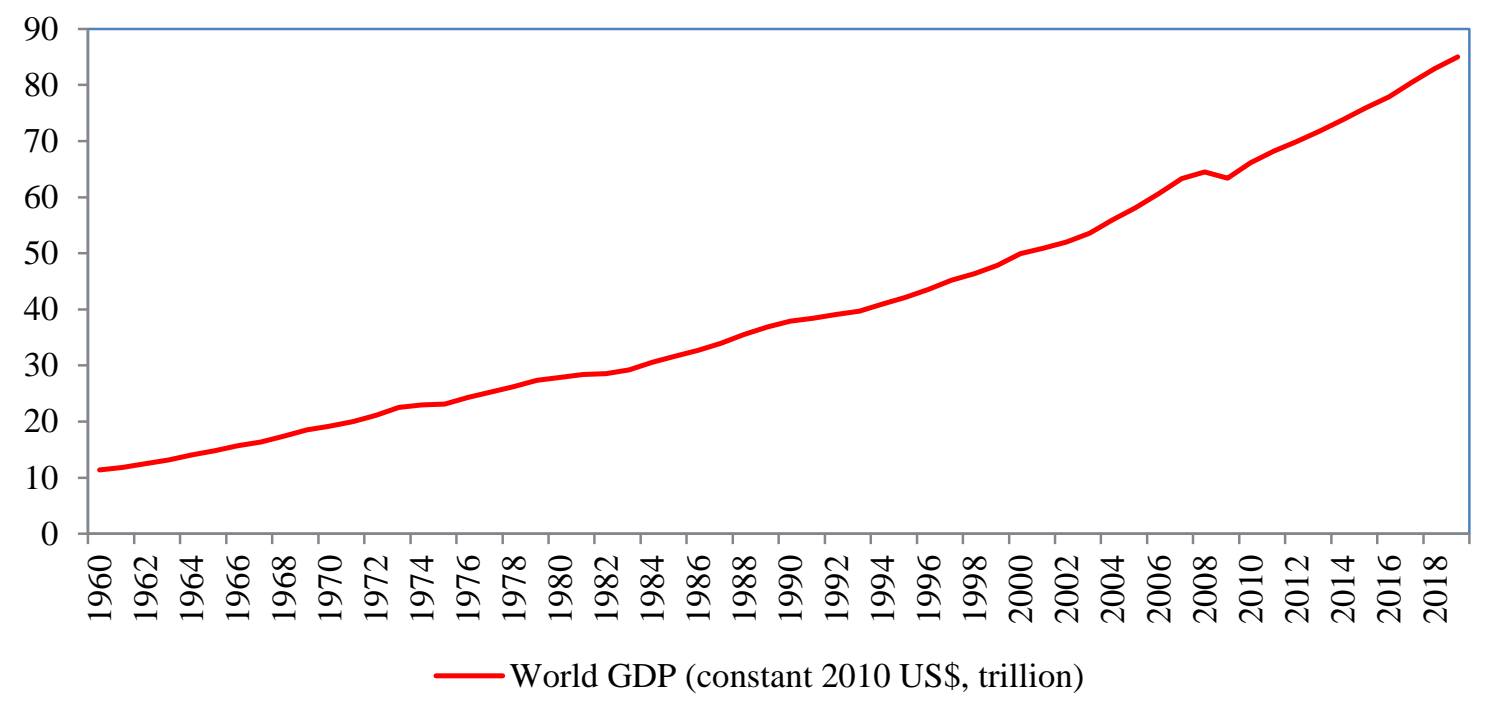

Figure 1.1 World GDP (1960-2019)

Source: The World Bank 
Among all of the 17 Sustainable Development Goals, the first goal is to end poverty in all its forms everywhere, including extreme poverty, the greatest challenge for sustainable development, especially in developing countries. Notably, many developing countries are experiencing acute food insecurity. Most of the poor are extremely vulnerable as they face low coverage of social protection, job losses, and insufficient education resources. Worse still, climate change could even attack the poor. The natural hazards induced by climate change, such as floods, droughts, and wildfires, worsen extreme poverty due to the fact that most of the poor's livelihood mainly relies on agricultural production activities. Therefore, this dissertation aims to better understand rural poverty and the impact of climate change on agriculture so as to provide some theoretical and empirical evidence for policy-making.

\subsubsection{End of Extreme Poverty}

Nowadays, there are nearly 10 percent of the world's population lives in extreme poverty, which is measured by the World Bank's poverty line of $1.90 \$$ per day. As shown in Figure 1.2, over the past few decades, there has been marked progress in reducing extreme poverty. The proportion of people living below $1.90 \$$ a day declined from 35.9 percent in 1990 to 9.9 percent in 2015. However, the progress had slowed in these few years, especially after the outbreak of COVID-19. It is projected that the extreme poverty rate will reach 8.8 percent in 2020 , rising from 8.2 percent in 2019 , which indicates that an estimated 71 million additional population will fall into 
extreme poverty due to the COVID- $19^{1}$.

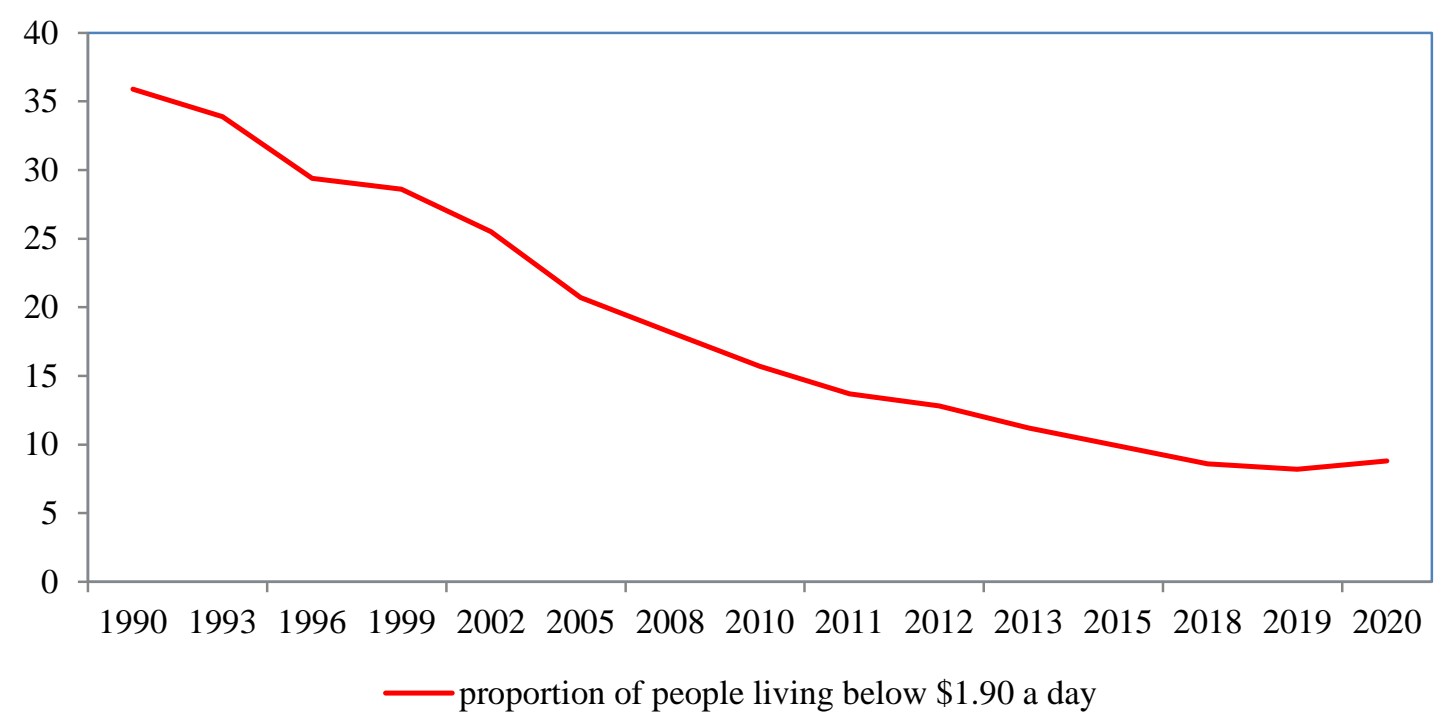

Figure 1.2 Global Poverty (1990-2020)

Source: The World Bank; the Sustainable Development Goals Report 2020

Although the outbreak of COVID-19 significantly challenges the SGDs, it is widely admitted that China has made a great contribution to global poverty reduction, which have largely driven the 2030 Agenda for Sustainable Development process. According to the World Bank, more than 730 million people have been lifted out of extreme poverty from 1990 to 2015 , contributing over 70 percent to worldwide poverty reduction ${ }^{2}$. This spectacular achievement not only comes as a result of pro-poor economic growth but also the comprehensive poverty reduction policies, such as cash transfers, rural infrastructure investment, education and healthcare services, etc.. Currently, the Chinese government is aiming to eradicate extreme poverty by 2020. According to the National Bureau of Statistics of China (NBSC), the extreme poverty rate declines to 0.6 percent at the end of 2019 , which indicates that it is promising to achieve the goal of eradicating extreme poverty by 2020 . Therefore,

${ }^{1}$ Source: the Sustainable Development Goals Report 2020

${ }^{2}$ Shttps://www.chinadaily.com.cn/a/201911/15/WS5dce6bc4a310cf3e35577b6e.html 
numerous studies start to shed light on the issue of rural poverty in China after 2020 (Liu, Guo, and Zhou 2018; Guo, Zhou, and Cao 2018; Liu et al. 2020; Wang et al. 2020).

\subsubsection{Impact of Climate Change}

Another significant challenge we now face is climate change. According to the IPCC (Intergovernmental Panel on Climate Change), the decade, 2010-2019, is the warmest on record. As depicted in Figure 1.3, the global surface temperature has experienced a dramatic upward trend in the past few decades, which is relative to the average temperatures from 1951-1980. The year 2016 and 2019 rank as the first and second warmest on record (source: NASA/GISS). Consequently, the increasing temperature induces massive natural disasters worldwide, including droughts, floods, wildfires, etc. (the Sustainable Development Goals Report 2020).

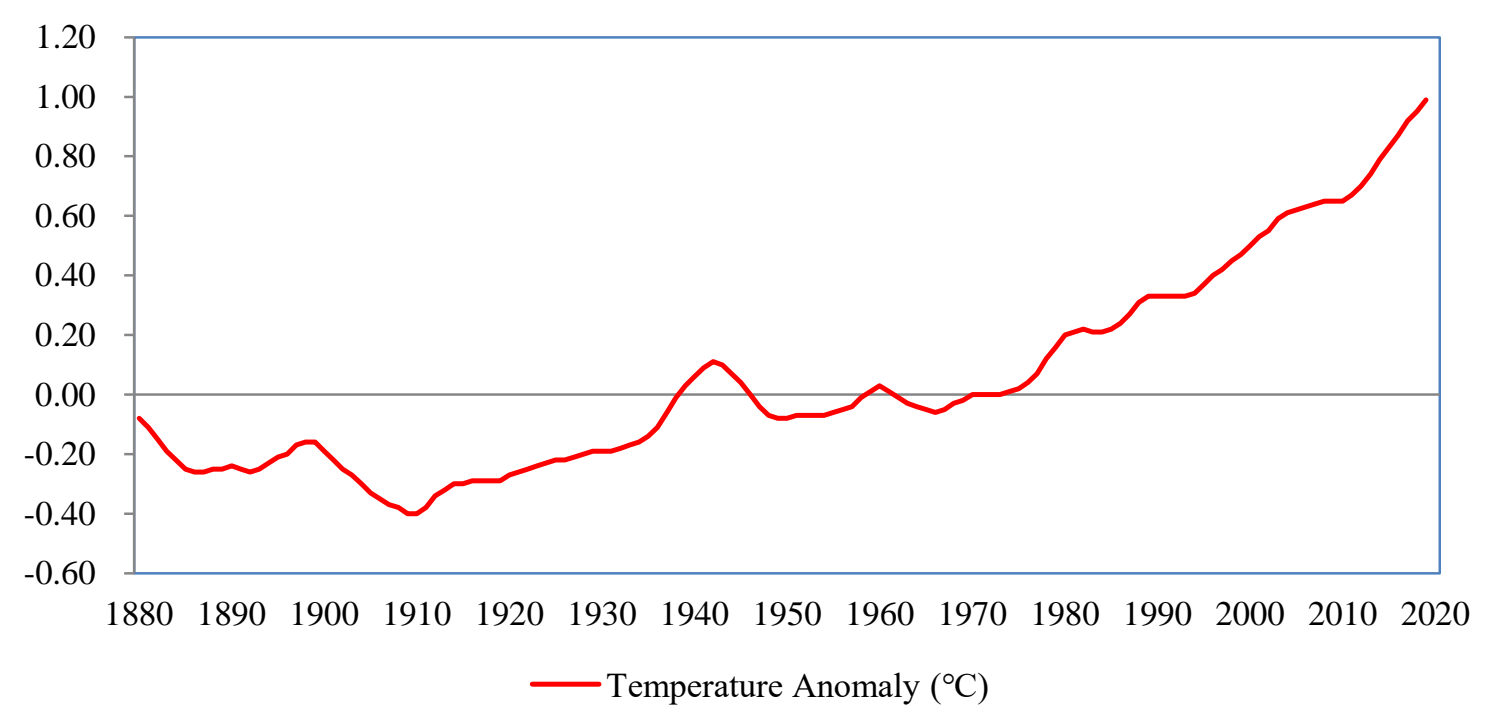

Figure 1.3 Global Temperature Change (1880-2019)

Source: NASA's Goddard Institute for Space Studies (GISS).

Agriculture is an essential sector of the economy as it ensures the food supply. 
However, the changing climate has far-reaching impacts on agriculture, which would challenge food security (Yu et al. 2020). Although several studies have concluded that, in some cases, warming may increase the production for some crops as such temperature condition could meet the optimal temperature for growth and reproduction (Pryor et al. 2014), the continuously increasing temperature would harm crops and then cause decreases in agricultural production. One clear example is that the 2010 Russia heat wave due to natural variability had caused considerable crop yield losses in many important agricultural production countries such as Russia, Kazakhstan, Ukraine, etc., contributing to the dramatic increase in global food prices. Also, changing precipitation patterns may lead to floods and droughts, which could threaten agricultural production due to the fact that such abnormal water supply cannot meet the optimal water requirement for crops. Generally, it is a consensus that climate change would contribute to food insecurity in the future by decreasing food production and increasing food price volatility, which particularly worsens the welfare of the poor.

As mentioned above, rural poverty and climate change seriously challenge sustainable development worldwide. Regarding the rural poverty issue, this dissertation tends to shed light on subjective poverty in rural China beyond 2020, when extreme poverty is expected to be eliminated entirely. In terms of the impact of climate change, we reveal the impact from two perspectives. First, high food price volatility could incur severe welfare loss, especially for the poor (Bellemare, Barrett, and Just 2013; Yu 2014). Thus, we reveal the impact of sunspots on soybeans futures 
prices volatility from the behavioral finance perspective by using the disagreement theory. Second, international agricultural trade is a potential adaption to climate change, which could help ensure food security of a country. Accordingly, this dissertation empirically substantiates the impact of climate change on agricultural trade in Central Asia so as to provide some insightful policy implications.

\subsection{Research Topics}

\subsubsection{Poverty and Subjective Poverty in Rural China}

In response to SDGs, the Chinese government is currently undertaking a policy campaign which is so-called "The Targeted Poverty Alleviation", aiming to eliminate extreme poverty in rural China by 2020, ten years ahead of the agenda of SDGs. According to China's National Bureau of Statistics, at the end of 2019, the extreme poverty rate has decreased to 0.6 percent. Given the ongoing rapid economic growth and affluent fiscal resources, it is promising to achieve the goal of eradicating extreme poverty by 2020 (Zhou et al. 2018).

Then, does it imply no poverty in rural China any more after 2020? Obviously, the answer is no. It is widely known that the definition of poverty has many dimensions. Even when absolute poverty can be eliminated in rural China, relative poverty still exists in the long run. More importantly, poverty can not only be measured by a wealth status but also a subjective feeling. Mahmood, Yu, and Klasen (2018) show a difference between objective and subjective poverty in Pakistan, as they are determined by different factors. 
Beyond promoting material wealth mainly measured by GDP, the Chinese government starts to shed light on welfare improvement for its citizens (Zhou and $\mathrm{Yu}$ 2017). Along this line, the concept of "subjective poverty" is going to then move to the center of policy arena, as it is linked to those who have a perception of deprivation.

The first topic of this dissertation is to study subjective poverty in rural China and provide policy implications for poverty reduction in China beyond 2020 when extreme poverty is expected to be completely eliminated.

\subsubsection{Disagreement on Sunspots and Soybeans Futures Prices}

High food price volatility could incur severe welfare loss (Bellemare et al. 2013; Yu 2014b), while solar phenomena, often measured by sunspots, are regarded as a fundamental factor that drives the volatility. Considerable literature points out that sunspots activity significantly affects weather changes (Ormes 2018; Gupta 2019; Yang et al. 2019), economic consequences (Gu et al. 2013; Novy-Marx 2014; Sun et al. 2017; Benhabib and Spiegel 2018; Fehr et al. 2019; Ascari et al. 2019), and social individuals' behaviors (Kashiwagi 2014; Ho 2015; Arifovic et al. 2019). By and large, the linkage between the information of sunspots and food price volatility is quite complicated, as people may have different perceptions for them.

The third topic of this dissertation aims to understand the impact of sunspots on the volatility of financial markets and its mechanism both theoretically and empirically. Specifically, we focus on the soybeans futures market. As we know, the 
agricultural commodity futures market plays a vital role in the development of the agriculture sector and traders' decision-making. Capturing the volatility of agricultural commodity futures price enables policymakers to stabilize the domestic agricultural commodity market in time so as to protect agriculture sectors.

\subsubsection{Climate Change and Agricultural Trade}

Climate plays a vital role in agricultural production activities (Brown and Funk 2008; Crost et al. 2018; Holst, Yu, and Gruen 2013). According to the OECD-FAO Agricultural Outlook (2016-2025), the global cereal use will grow by $14 \%$, reaching 2818 Mt by 2025. Given the fundamental function of agriculture in food security, there is a growing concern on the potential impact of climate change on agricultural productivity (Adams et al. 1998; Olesen and Bindi 2002; Baldos and Hertel 2014). Specifically, climate change would certainly change the natural conditions of crop growth, such as temperature and precipitation (Rosenzweig and Parry 1994; Huang, von Lampe, and van Tongeren 2011; Zhang, Zhang, and Chen 2017).

Theoretically, adaption is one of the effective approaches in respond to climate change in the agriculture sector (Chen et al. 2015). Extensive studies show that climate change would be problematic for agricultural production without adaption, while the vulnerability of agricultural production could be alleviated with adaption (Mendelsohn, Nordhaus, and Shaw 1994; Wheaton and Maciver 1999; Burke and Emerick 2016). Such a scenario, international agriculture trade, accompanying the transfer of virtual water, could be an effective adaptation to reduce climate-induced 
environmental stress (Konar et al. 2011).

Thus, the third topic of this dissertation is that we use the gravity model, a widely used trade model in the field of international trade (Hasiner and $\mathrm{Yu}$ 2019), to empirically reveal the relationship between climate change and cereal trade, providing the empirical evidence for the impact of climate change on cereal trade.

\subsection{Methodology}

\subsubsection{Subjective Poverty and Subjective Measure Approach}

How to measure subjective poverty is a key issue in Chapter 2. Different people have a different understanding of poverty. Consequently, some who are not objective poverty may feel poor, while some who are objective poverty may not feel poor (Mahmood, Yu, and Klasen 2018). Meanwhile, the information, provided from the objective poverty, is very limited for the policymakers, particularly in an affluent society, which requires additional subjective information from the polls (Veenhoven 2002; Klasen et al. 2016). Hence, Deaton (2010) directly suggests that "why don't we just ask people?" since the people themselves have a very good idea of whether or not they are poor.

We assume that farmers may have better information for themselves than any others, even economists. Thus, this study adopts the Minimum Income Question, which is a prevalent method to measure subject poverty (e.g., Van Praag et al. 1980; Gustafsson et al. 2004; Bishop et al. 2006), to identify the subjective poverty in rural China. Explicitly, the survey question reads: "Please offer an income amount below 
which you will feel poor for a household as yours". It is reasonable that such a number offered by the respondents entails all information about their individual living conditions, subjective well-being, and regional development level. This is a typical MIQ for estimating a subjective poverty line for this household.

\subsubsection{Soybeans Futures Prices Volatility and the GARCH Models}

A central issue of Chapter 3 is to analyze the impact of sunspots on soybeans futures price volatility. In this case, the GARCH (Generalized Autoregressive Conditional Heteroskedasticity) models serve very well for this purpose, as it could capture the volatility by variance function. This econometric approach is proposed by Bollerslev (1986) to describe the volatility in financial markets, which can be formulated by, i.e., $\operatorname{GARCH}(\mathrm{p}, \mathrm{q})$ :

$$
\sigma_{t}^{2}=\alpha_{0}+\alpha_{1} \varepsilon_{t-1}^{2}+\alpha_{2} \varepsilon_{t-2}^{2}+\ldots+\alpha_{p} \varepsilon_{t-q}^{2}+\beta_{1} \sigma_{t-1}^{2}+\beta_{2} \sigma_{t-2}^{2}+\ldots+\beta_{p} \sigma_{t-p}^{2}
$$

Where $\beta_{i}$ are the coefficients for the variances.

In practice, the $\operatorname{GARCH}(1,1)$ is the most prevalent model in the time series analysis of the financial market. That is:

$$
\sigma_{t}^{2}=\alpha_{0}+\alpha_{1} \varepsilon_{t-1}^{2}+\beta_{1} \sigma_{t-1}^{2}
$$

Though the negative correlation between the shocks and the returns has been widely observed, the sign and the magnitude of the shocks might be asymmetric. Glosten, Jagannathan, and Runkle (1993) introduce a GARCH model (GJR-GARCH) which considers different effects of negative and positive shocks. That is:

$$
\sigma_{t}^{2}=\alpha_{0}+\left(\alpha_{1}+r_{1} I_{t-1}\right) \varepsilon_{t-1}^{2}+\beta_{1} \sigma_{t-1}^{2}
$$


Where $I_{t-1}=1$ if $\varepsilon_{t-1} \leq 0 ; I_{t-1}=0$ if $\varepsilon_{t-1}>0$.

$I_{t-1}$ is an index function. Particularly, when the shock is negative, $I_{t-1}=1$ and its coefficient $r_{1}$ then captures the asymmetric effect.

Moreover, recent studies find that when regime changes in the volatility dynamics, the GARCH-type models might fail to capture the true variation of volatility (Bauwens, Backer, and Dufays 2014). In this case, Markov- switching GARCH model provides a solution to this problem, as it allows the parameters to vary over time. The conditional variance dynamics can be formulated as:

$$
h_{k, t}=h\left(y_{t-1}, h_{k, t-1}, \boldsymbol{\delta}_{k}\right)
$$

Where $h(\bullet)$ defines the filter for the conditional variance and ensures its positive, $y_{t-1}$ is the variable of interest at the time $t-1, k$ denotes regimes, $h_{k, t-1}$ denotes past variance, and $\boldsymbol{\delta}_{k}$ is the regime-dependent vector of parameters.

Considering the different assumptions of volatility patterns, this study employs three econometric methods to capture the soybeans futures price volatility: the GARCH, GJR-GARCH, and Markov-switching GARCH models, which could ensure the robustness of empirical results.

\subsubsection{Agricultural Trade and the Gravity Model}

In Chapter 4, we aim to reveal the impact of climate change on agricultural trade. Thus, the gravity model provides an optimal approach to study international agricultural trade. Specifically, the gravity model of international trade, inspired by Newton's gravity equation, relates bilateral trade flows to the economic size and 
distance of two trade partners. This model was first proposed by Isard (1954) in the field of economics. The basic model for two partners' trade can be formulated by the following equation:

$$
Y_{i j}=C \frac{E_{i} E_{j}}{D_{i j}}
$$

Where $Y_{i j}$ denotes trade flows (export or import) from country $i$ to country $j$; $E_{i}$ and $E_{j}$ denote the economic size of two countries, respectively, measured by their GDP's; $D_{i j}$ is the geographical distance between the two countries; and $C$ is constant. Theoretically, this model indicates that trade flows are determined by the exporter's productivity, the importer's purchasing power, and also the trade cost measured by geographical and economic distance. In addition, Linnemann (1996), Bergstrand (1989), and Tian and Yu (2017) further consider a set of bilateral trade covariates as trade costs, mainly including contiguous border, common language, and so on. Empirically, for the sake of econometric analyses, we can simply transfer the gravity model to a linear form by taking logarithms, that is:

$$
\ln Y_{i j}=\alpha+\beta_{1} \ln E_{i}+\beta_{2} \ln E_{j}+\beta_{3} \ln D_{i j}+\varepsilon_{i j}
$$

\subsection{Contributions}

\subsubsection{Reveal the Subjective Poverty in Rural China}

The most prevalent measurement of poverty is to set an objective absolute poverty line by the government, scholars, or some organizations. Traditionally, absolute poverty measurement is based on a comparison of resources to needs. However, the 
objective poverty measures often ignore individual heterogeneities of wellbeing, resulting in large deviations in poverty headcounts, and have been subject to much criticism (Deaton 2010; Deaton and Heston 2010; Ravallion 2015). Consequently, some who are not objective poverty may feel poor, while some who are objective poverty may not feel poor (Mahmood, Yu, and Klasen 2018). Meanwhile, the information provided from the objective poverty is very limited for policymakers, particularly in an affluent society, which requires additional subjective information from the polls (Veenhoven, 2002; Klasen et al. 2016). Hence, Deaton (2010) directly suggests that "why don't we just ask people?", since the people themselves have an excellent idea of whether or not they are poor.

Poverty is also a subjective feeling. On a background that China promises to eliminate absolute poverty by 2020 , the concept of subjective poverty should become increasingly important for poverty policymaking in rural China. However, little attention has been paid to the research of subjective poverty in rural China. In order to fill in the research gap, Chapter 2 employs a nationally representative survey of rural households in China, and particularly shed light on the situation of subjective poverty in rural China and then empirically analyzes the determinants.

\subsubsection{Provide a New Perspective to Understand the Impact of Sunspots}

Existing literature attempts to reveal the role of sunspots on the volatility of financial markets. For instance, Kang (2015) reveals price volatility in an incomplete market with sunspots by equilibrium analysis. After that, Kang (2019) further considers the 
welfare cost of excess volatility with sunspots. Similarly, Benhabib and Wang (2015) find that sunspot shocks would generate variations in asset prices by using an equilibrium model. In addition, Farmer (2015) employs the global sunspot equilibria to capture the volatility of assets price caused by sunspots. However, there is very limited evidence on how the information of sunspots affects investors' behaviors, which is a key issue to better understand the underlying mechanism of the volatility of financial markets. Furthermore, to the best of our knowledge, recent literature does not provide direct empirical evidence for the impact of sunspots on the volatility of financial markets.

Chapter 3 of this dissertation fills in the research gap and makes several contributions to the existing literature. First, while most studies use equilibrium analyses to deduce the impact of sunspots on the volatility of price (e.g., Farmer 2015; Benhabib and Wang 2015; Kang 2019), this study is different from them. A central issue of this study is to employ disagreement theory to analyze investors' behaviors, given the complicated information of sunspots. Theoretically, disagreements could change market price trends and volatilities. Disagreement on the information of sunspots would shape investors' behavior. In the hypothesis of an efficient market, individuals are assumed as rational, and market prices capture all information (Marinescu et al. 2018). It indicates no need to consider any behavioral or psychological bias. Over the past decades and especially in the course of the last financial crisis, the field of behavioral finance has been of great concern for researchers and traders (Malmendier and Nagel 2016; Ruan et al. 2019; Lan, Huang, 
and Yan 2020). In a real financial market, the beliefs of investors are heterogeneous (Hong and Stein 2007; Aouadi, Arouri, and Teulon 2013; Thaler 2016; Andrade et al. 2019). Thus, the disagreement problem always exists among investors, especially when they receive complicated information. We employ the disagreement theory from behavioral finance to reveal investors' behaviors, given the complicated information of sunspots, providing new insights on the underlying mechanism of the impact of sunspots on the volatility of soybeans futures price.

Second, to the best of our knowledge, this is the first study empirically investigating the impact of sunspots on the volatility of soybeans futures price. Soybean is an important traded agricultural product in the global market as it provides affluent proteins for human and livestock needs. We use three econometric methodologies: the GARCH, GJR-GARCH, and Markov- switching GARCH models with exogenous covariates of sunspots. Each of these methods assumes different patterns of price volatility, which could ensure the robustness of empirical results.

This study could help better understand the mechanism of soybean prices from a theoretical perspective and better forecast market prices from an empirical perspective. A better forecast of agricultural market price could help investors make better investment strategies, and help governments make better food security policies ( $\mathrm{Yu}$ 2014a).

\subsubsection{Substantiate the Impact of Climate Change on Agricultural Trade}

Central Asia, an important agricultural production area, its agriculture development 
faces tremendous challenges from climate change. Climate change could certainly increase natural risk and uncertainty in agriculture sectors. Using SRES scenarios from IPCCAR4, 23 models, the Intergovernmental Panel on Climate Change (IPCC) points out that projected increases in temperature could exacerbate the water shortage in Central Asia ${ }^{3}$. Thus, how to cope with climate change is prior of policy agenda in Central Asia.

Although a few studies have realized the potential adaptation of agriculture trade, to the best of our knowledge, far too little attention has been paid to the impact of climate change on cereal trade in Central Asia. Given the importance of the potential adaptation of international agriculture trade, it is necessary to understand how climate change affects the agriculture trade patterns in Central Asia. Particularly, agriculture plays an important role in their livelihood, but food production particularly suffered from political and economic turmoil after the collapse of the Soviet Union even though these countries traditionally had a favorable endowment of natural resources and well-organized facilities for agricultural production. How to incorporate themselves into the global food trade system, particularly after the transition from a planned economy to a market system, has not been well studied.

Thus, the main contribution of Chapter 4 is that we use the gravity model, a widely used trade model in the field of international trade (Hasiner and Yu 2019), to empirically reveal the relationship between climate change and cereal trade, which provide the empirical evidence for the impact of climate change on agricultural trade.

\footnotetext{
${ }^{3}$ Source: www.ipcc.ch
} 


\section{Chapter 2 Poverty and Subjective Poverty in Rural}

\section{China $^{4}$}

Abstract: China is undergoing a campaign which is called "The Targeted Poverty Alleviation Policy" to eradicate extreme poverty from rural China until 2020. Though poverty in rural China has been studied intensively in different objective dimensions, little attention has been paid to poverty line settings and subjective poverty, which are hinged to the policy effects. In order to fill in the research gap, this study employs a nationally representative survey of rural households in 2016, to measure subjective poverty in rural China, and analyze the determinants as well. Our results indicate that the mean subjective poverty line of the rural households is 8297 yuan per capita, which is far higher than the national poverty line (2800 yuan). Statistically, $29 \%$ of the surveyed rural households who are not objectively poor feel subjectively poor. The objective poverty line cannot fully reflect the subjective poverty perception. Thus, how to reduce the subjective poverty perception could be a major policy agenda in rural China after 2020, when extreme poverty is no longer a problem.

Keywords: rural China, poverty lines, subjective poverty, objective poverty, the Targeted Poverty Alleviation Policy

JEL: D63, I32, I38

\footnotetext{
${ }^{4}$ This chapter has been published in Social Indicators Research. I contributed to the data analysis and results discussion, and took the lead in writing the manuscript under the guidance of Prof. Yu. All authors provided critical feedback and contributed to the research.

Wang, H., Zhao, Q., Bai, Y., Zhang, L., \& Yu, X. (Corresponding Author) (2020). Poverty and Subjective Poverty in Rural China. Social Indicators Research, 150, 219-242. https://doi.org/10.1007/s11205-020-02303-0
} 


\subsection{Introduction}

Poverty is globally regarded as a serious challenge, and poverty reduction is put in a prior position in the policy agenda of many developing countries. The United Nations' Sustainable Development Goals (SDGs), which was passed in 2015, put "No Poverty" as the first goal, specifically to "End poverty in all its forms everywhere" by 2030. China is no exception. Over the past 40 years, since the economic reform launched in 1978, rapid economic growth has lifted millions of people out of poverty in China. The Human Development Report in 2016 indicates that the global extreme poverty prevalence rate, measured by the poverty line of the US $\$ 1.90$ per day, was less than 11 percent in 2013, and China has made a significant contribution to global poverty reduction efforts. Figure 2.1 shows, according to the national poverty line of China, the extreme poverty rate had been reduced from 97.5 percent in 1978 to 4.5 percent in 2016. Most of the poor live in rural areas, and their livelihood depends on agriculture. In comparison, the urban residents in China could enjoy a well-established social security system that protects them from extreme poverty.

In response to SDGs, the Chinese government is currently undertaking a policy campaign which is so-called "The Targeted Poverty Alleviation", aiming to eliminate extreme poverty in rural China by 2020, 10 years ahead of the agenda of SDGs. According to China's National Bureau of Statistics, at the end of 2018, the extreme poverty rate has decreased to 1.7 percent. Given ongoing rapid economic growth and affluent fiscal resources, it is promising to achieve the goal of eradicating extreme poverty by 2020 (Zhou et al. 2018). 
Then, does it imply no poverty in rural China any more after 2020? Obviously, the answer is no. It is widely known that the definition of poverty has many dimensions. Even when absolute poverty can be eliminated in rural China, relative poverty still exists in the long run. In addition, poverty can not only be measured by a wealth status but also a subjective feeling. Mahmood, Yu, and Klasen (2018) show a difference between objective and subjective poverty in Pakistan, as they are determined by different factors.

Beyond promoting material wealth mainly measured by GDP, the Chinese government starts to shed light on welfare improvement for its citizens (Zhou and $\mathrm{Yu}$ 2017). Along this line, the concept of "subjective poverty" is going to then move to the center of policy arena, as it is linked to those who have a perception of deprivation.

The main objective of this study is to study subjective poverty in rural China and provides policy implications for poverty reduction in China beyond 2020 when extreme poverty is expected to be completely eliminated.

[Place Figure 2.1 here]

\subsection{Background and Literature}

\subsubsection{Objective Poverty and Its Limitations}

The most prevalent measurement of poverty is to set an objective absolute poverty line by the government, scholars, or some organizations. Traditionally, absolute poverty measurement is based on a comparison of resources to needs. Thus, a family 
is identified as the poor if its resources short of the poverty threshold (Foster 1998). For instance, the most recent global poverty line recommended by the World Bank is US \$ 1.90 expenditure per day per person (2011 purchasing power parity (PPP) price). Through the purchasing power parity (PPP), the global poverty line can be compared between different countries. However, the concept of global poverty line has been strongly criticized by Deaton (2010). First, the poverty line is set by some experts which do not capture full information of the poor; Second, the prices collected by the International Comparison Program (ICP) are national average prices, which are different from those the poor face, as the expenditure patterns of the poor often differ the aggregate patterns; Third, each country (region) has different consumption patterns due to different food, culture, and traditions (Deaton 2010; Deaton and Dupriez 2011; Kim et al. 2018).

In addition to the global poverty line, many countries and areas are prone to set a national poverty line (an income or a consumption poverty line) based on their economic and social reality. The poverty lines are often adjusted according to economic development levels. Likewise, this type of traditional poverty line, mainly measuring absolute poverty, is very sensitive to different research designs. On the one hand, the household surveys, which are the primary information sources for the poverty line setting, often cannot obtain accurate income or consumption information from the surveyed families. One typical example was the national sample survey of India in 1998. The Indian government replaced the traditional survey of 30-days food consumption with one of 7-days food consumption, which resulted in a sharp increase 
in food consumption expenditure per month. Due to the survey method change, the poor population in India is reduced by nearly 175 million. Besides, according to Deaton (2001), the estimated deviation would be higher if we use the standard nutritional approach in which the poverty line is calculated by the costs of minimum nutrition requirement. Deaton and Drèze (2009) discuss the India poverty line by estimating the demand for calories, and the result showed that a family would prefer not to undertake heavy-labor work when the economic condition of the family improves, and hence the demand for calories declines. Thus, if the poverty line is based on calorie demand, the incidence of poverty, on the contrary, would increase. On the other hand, if there are a lot of poor people live near the poverty line, a slight change in the poverty line would incur a significant impact on the heads counting of the poor (Deaton and Heston 2010; Ravallion 2015). In addition, the cross-sectional survey data entail statistical errors. For instance, there is always a difference between the household's consumption population and the survey population (Yu and Abler 2016). In most cases, the survey population is higher than the consumption population, and it leads to an underestimation of food consumption per capita.

Besides, the relative poverty line is also one of the most important objective poverty lines, which is widely used in developed countries. Compared with the absolute poverty line, the relative poverty line mainly focuses on the people who have some money but still no enough money to afford anything above the basics. Conventionally, it is useful for showing the percentage of the population who has been relatively left behind. 
Apart from the several poverty measurements mentioned above, some literature focuses on the multidimensional poverty based on the "capability poverty" theory of Sen (1999), and presents a multidimensional poverty index that included education, health, living conditions, and so on (Alkire and Foster 2011; Alkire and Seth 2015). In practice, the multidimensional poverty index (MPI) is also widely used for measuring economic development levels globally, and the Human Development Index of the United Nations Development Programme (UNDP) is a typical application.

Income (consumption) or multidimensional poverty measurements belong to the category of objective poverty and often measured by an objective poverty line threshold set by politicians, scholars, or other authorized organizations. However, these objective poverty measures often ignore individual heterogeneities of wellbeing, result in large deviations in poverty headcounts, and have been subject to much criticism due to the aforementioned reasons.

Townsend (1979) further points out that the fundamental flaw of objective poverty is that it is difficult to scientifically define the non-material needs. Van Praag (1968) suggests that objective poverty is a patriarchal style measure, as the poverty line is decided by bureaucrats or experts, ignoring the real perception of the poor. Different people have a different understanding of poverty. Consequently, some who are not objective poverty may feel poor, while some who are objective poverty may not feel poor (Mahmood, Yu, and Klasen 2018). Meanwhile, the information, provided from the objective poverty, is very limited for the policymakers particularly in an affluent society, which requires additional subjective information from the polls 
(Veenhoven 2002; Klasen et al. 2016). Hence, Deaton (2010) directly suggests that "why don't we just ask people?", since the people themselves have a very good idea of whether or not they are poor.

\subsubsection{Subjective Poverty and Its Measures}

There is a call for subjective poverty. The meaning of utility, a basic concept in economics, is defined as the subjective perception of self-welfare, but this is largely neglected in many studies, particularly in poverty measurement. Thus, some studies start to shed light on subjective poverty. They believe that social individuals possess the most fruitful information for themselves so that they can be the best persons who can judge whether they are in poverty status or not. Combined with several drawbacks of objective poverty, the subjective poverty concept is beneficial to poverty identification and policy design (Ravallion and Lokshin 2002; Deaton 2010; Allen 2017; Zhou and Yu 2017; Deaton 2018). For example, Pradhan and Ravallion (2000) use the satisfaction of consumption to measure the subjective poverty status; Mahmood, Yu, and Klasen (2018) compare the subjective poverty and objective poverty of Pakistan and find that the objective poverty cannot fully reflect the subjective poverty.

Empirically, subjective poverty is mainly identified through questionnaire surveys, evaluating social individuals for their welfare condition and minimum needs. According to the different identifications, there are three main types of questionnaire settings: namely, Income Evaluation Question (IEQ) (Van Praag 1968), Minimum 
Income Question (MIQ) (Goedhart et al. 1977) and Centre for Social Policy Question $(\mathrm{CSP})^{5}$ (Deleeck and Van den Bosch 1992). Early applications of the subjective poverty questions are mainly conducted in some Western industrial countries and regions. Van Praag et al. (1982) analyze the subjective poverty line for eight EU countries by the Income Evaluation Question (IEQ), and they find that the subjective poverty line of city residents is relatively higher than others. Danziger et al. (1984) and Colasanto et al. (1984) use the Minimum Income Question (MIQ) to study the subjective poverty of the United States, and the finding shows that the subjective poverty line is higher than the objective poverty line set by the government. Based on the Minimum Income Question (MIQ), Garner and Short (2003) propose the Minimum Spending Question (MSQ) to study the subjective poverty of the United States with use of the data of Survey of Income and Program Participation (SIPP), and suggest that the subjective poverty line based on MIQ is higher than MSQ.

However, subjective poverty in rural China has not been well studied though it is increasingly important from the policy perspective. There are a few exceptions or related studies in urban China. The earliest study is conducted by Gustafsson et al. (2004). They use the Minimum Income Question (MIQ) to investigate the subjective poverty in urban China and find that the subjective poverty line is close to the objective poverty line set by the Chinese government. Bishop et al. (2006) also use

\footnotetext{
${ }^{5}$ Income Evaluation Question is often defined as "Please try to indicate what you consider to be an appropriate amount for your household for each of the following cases. __ very bad; __ bad; __ insufficient; __ sufficient; ___ good; __ very good". Minimum Income Question is defined as "What do you consider as an absolute minimum net income for a household as yours?" or "We would like to know an income amount below which you won't be able to make both ends meet". CSP question is defined as "Can you make ends meet with the actual net income of your household: with great difficulty; with difficulty; with some difficulty; rather easily; easily; very easily". The above definitions are provided by Filk \& Van Praag (1991).
} 
the Minimum Income Question (MIQ) to study the subjective poverty of different areas of China based on the data of the Chinese Household Income Project (CHIP). However, the CHIP does not directly contain the Minimum Income Questions, and the MIQ used in their study is estimated through alternative indicators. Zuo and Yang (2013) discuss the implications of subjective poverty measurement for anti-poverty policy in China theoretically, suggesting that subjective poverty possesses both instrumental value and intrinsic value. However, there are no direct studies for subjective poverty in rural China, though more than $90 \%$ of the poor live in rural areas in China.

Currently, poverty counting in rural China is still mainly based on an objective poverty line: the national poverty line. The current national poverty line is 3000 yuan net income per year (equals 2.3 USD per day ${ }^{6}$ ) set in 2016. The Chinese government is campaigning for eliminating absolute poverty by 2020 . Beyond then, the subjective poverty measurement would be a better way to reflect the poverty perception of people in rural China. Therefore, in order to fill the gap in the research of subjective poverty, this study adopts the method of MIQ to measure subjective poverty in rural China and attempts to provide implications for poverty-reduction policies for China beyond 2020 .

\footnotetext{
${ }^{6}$ Source: Poverty Monitoring Report of Rural China (2017)
} 


\subsection{Data and Descriptive Statistics}

\subsubsection{Survey}

The data used in this study is a nationally representative survey of 2025 rural households in five provinces of China (Jiangsu, Sichuan, Shannxi, Jilin, Hebei) in 2016, collected by the Center for Chinese Agricultural Policy, Chinese Academy of Science. The sample was selected as the following steps. First, we selected five provinces to represent the five major agro-ecological zones in China: Jiangsu is a representative sample province of the eastern coastal region; Sichuan is a sample of the south-west region; Shannxi is a sample of the north-west region; Jilin is a sample of the north-east region; Hebei is a sample of the central region. Second, according to the per capita gross value of industrial output $(\mathrm{GVIO})^{7}$, we divided all counties into five groups for each province, and then randomly selected one from each group. Following this procedure, we randomly selected two towns from each county, and two villages from each town, and then selected 20 sample households from each village. Finally, we collected a nationally representative sample of $2025^{8}$ households' information for the year of 2015.

\footnotetext{
7 The reason why we select the GVIO is that GVIO is one of the best indicators to reflect the standard of living and development potential as well as the income distribution within province (Rozelle, 1996).

${ }^{8}$ Theoretically, the total sample should be 2000 households. However, during the tracing investigation, one village of Jiangsu province was dismantled into two villages, thus, the final village sample is 101 . Besides, there are also 5 rural households was dismantled into two households. As a result, the household sample we finally get is 2025 .
} 


\subsubsection{Variables}

How to measure subjective poverty is a key issue in this study. As aforementioned, there are three main methods to identify the subjective poverty for social individuals: IEQ, MIQ, and CPS. Compared with IEQ and CPS methods, MIQ is more easily for the respondents to understand and more feasible in the survey. Due to these advantages, Minimum Income Question (MIQ) is widely used in the subject poverty research all over the world (e.g., Van Praag et al. 1980; Gustafsson et al. 2004; Bishop et al. 2006). Thus, this study adopts the Minimum Income Question to identify subjective poverty in rural China. The survey question reads: "Please offer an income amount below which you will feel poor for a household as yours". We believe such a number offered by the respondents entails all information about their individual living conditions, subjective well-being, and regional development level. This is a typical MIQ for estimating a subjective poverty line for this household.

In order to control for the effect of family size, the subjective poverty line per capita is computed by dividing the self-reported minimum income by the family size. Based on the mean value of individual subjective poverty standards, the subjective poverty status for each rural household can be identified: 1 if the per capita real income surpasses the subjective poverty standard and 0 otherwise. Besides, we could also define the depth of subjective poverty, which is computed by dividing the gap between the subjective poverty standard and per capita real income by the subjective poverty standard ${ }^{9}$. In addition, to reveal the difference between the subjective poverty

\footnotetext{
9 The depth of subjective poverty can be expressed by the following equation: subjective poverty depth $=$
} 
and objective poverty, this study measures the objective poverty by two means: the national poverty line (2800 yuan per year in 2015$)^{10}$ and the global poverty line (the US $\$ 1.90$ per day) ${ }^{11}$.

The explanatory variables mainly include the demographic and socioeconomic characteristics of the rural household (characteristics of the household head, characteristics of the household, human capital of the household, material capital of household, social capital, and major irregular expenditure of the household). Specifically, (1) the characteristics of a household head include head's age, head's gender, marital status, head's education level, whether the head is a village leader, and whether the head is a party member; (2) the characteristics of a household include per capita income, family size, number of elders, number of children and number of labor forces; (3) the human capital includes average health condition of family members and average education level of family members; (4) the material capital includes land size, house value, productive asset value, and consumption asset; (5) the social capital is measured by two questions: "how many friends or relatives working in the government" and "how many friends or relatives working as managers in the enterprise"; (6) the major irregular expenditure of a household includes education expenditure, medical expenditure, gift expenditure, and wedding expenditure. Table 2.1 presents the definitions of all variables involved in this study.

\section{[Place Table 2.1 here]}

\footnotetext{
(subjective poverty standard - per capita income) / subjective poverty standard.

${ }^{10}$ This is the national poverty line of 2015 in rural China, which is from "POVERTY MONITORING REPORT OF RURAL CHINA".

${ }^{11}$ Using Purchasing Power Parity (PPP) price, 1 \$ equals 3.696 RMB. (Source: Poverty Monitoring Report of Rural China (2017)). Based on that, the global poverty line equals 2563 RMB approximately.
} 


\subsubsection{Descriptive statistics}

Table 2.2 shows the descriptive statistics of the subjective poverty, objective poverty, and other information of the rural household. It is clear that the prevalence rate of subjective poverty is 0.44 , while the rates of objective poverty are 0.22 (National objective poverty line) and 0.20 (Global objective poverty line), respectively. It indicates that the objective poverty measurement cannot reflect the subjective poverty comprehensively in rural China. It highlights the importance of a study on subjective poverty in rural China.

Looking at characteristics of the household head, the average age of the household heads is 57.84 years old; $88 \%$ of the heads are male and married; Their average school years is only $6.84^{12} ; 16 \%$ of them are party member; only $8 \%$ are village leaders. This shows a general picture of the demography in rural China, and aging is a problem facing rural China.

Regarding the characteristics of the household, the average family size is 4.14. Both the average numbers of elders and children in a household are 0.64 , which shows that $36 \%$ are dependent population. The average number of labor forces is approximately 2.66 , but the average school year is only 6.73 , slightly lower than the household head.

The house value is the most precious asset in rural China, while the medical expenditure and the gift expenditure are the two largest irregular expenditures. As for

\footnotetext{
126.8 School years means almost household head only graduate from the primary school.
} 
social capital, more friends or relatives are working in government organizations (1.02) than acting as managers in enterprises (0.47).

\section{[Place Table 2.2 here]}

\subsubsection{Discussions}

The descriptive statistics clearly show some differences between subjective poverty and objective poverty. Table 2.3 reveals the subjective poverty lines in rural China, which are compared with national and global poverty lines. The average subjective poverty standard for rural households is 8297 yuan, which can be used as a nationally representative Subjective Poverty Line, much higher than the national (objective) poverty line (2800 yuan) and global (objective) poverty line (2563 yuan), respectively. Specifically, the subjective poverty line is about 2.96 and 3.23 times the national and global poverty lines, respectively. It implies that the objective poverty line in China and the World Bank cannot well mirror the welfare levels of rural households in China, given continuously high economic growth rates in the past 40 years.

Table 2.3 also shows the subjective poverty standards for the five sample provinces. We have a similar finding that the subjective poverty standards for all five provinces are all higher than the objective poverty lines. The gap of Jiangsu province is the largest though the differences within the five provinces are not substantial, all-around three times. It is possible that the Jiangsu province is the richest region within the five provinces. 
Besides, we also compared the subjective poverty standard with real per capita net income for each province and the nation as well. The result shows that the average subjective poverty standard is lower than the average per capita income, about $76 \%$ of the average real income. It shows that the gap between the subjective poverty line and the real net income is correlated with the income level again. The higher the income is, the larger the gap is. The largest gaps are from Shannxi and Jiangsu, with relatively higher income.

\section{[Place Table 2.3 here]}

Once we have a nationally representative Subjective Poverty Line, we can use it to count the subjective incidents. Table 2.4 compares the incidences of subjective poverty and objective poverty and their difference in rural China as well. Overall, the prevalence rate of subjective poverty is 0.44 , which means that almost half of rural households feel that they are in subjective poverty status. However, the prevalent rates of objective poverty are only 0.22 based on the national poverty line and 0.20 based on the global poverty line, respectively. It is clear that the prevalence of subjective poverty is twice as much as objective poverty with the national poverty line, indicating that even if China eliminates absolute poverty by 2020 , there are still plenty of rural households who fall into the subjective poverty.

After analyzing the subjective poverty for five provinces, we can draw a similar conclusion: there are more rural households in the status of subjective poverty than in the objective poverty. The gaps between the prevalence of subjective poverty and 
objective poverty for Jilin province are the largest $(0.29$ and 0.32 , respectively, for the national and global poverty lines).

\section{[Place Table 2.4 here]}

Table 2.5 specifically sheds light on the comparison between the poor households differently measured by the subjective and objective poverty standards. This would offer us a deeper understanding of the subjective poverty in rural China. As Table 2.5 shows, 449 rural households fall into the objective poverty based on the national poverty line, and 1576 households are non-poor. Among the 449 objective poor, 434 households also feel subjectively poor, about $96 \%$ of the objectively poor, which means that nearly all the objective poor fall into the subjective poor with a few exceptions. As the national poverty line is relatively low, it is comprehensible that these extremely poor subjectively feel they are poor as well. In this case, the target of the objective poor is also an ideal way to reduce subjective poverty, particularly for the extremely poor.

Nevertheless, 467 rural households who are not identified as the objective poor fall into the subjective poverty status, sharing $29 \%$ of the non-poor. Similar to Mahmood, Yu, and Klasen (2018), it reveals a reality that plenty of rural households who feel subjectively poor are not identified as the poor with the national poverty line. Thus, if we only focus on the objective poor, we ignore a large part of the subjective poor. A similar conclusion can be drawn from the objective poverty line measured by the global poverty line. Specifically, $97 \%$ of the objective poor who fall into the subjective poverty status while $31 \%$ of the non-objective-poor feel that they are in the 
subjective poverty status. Such a finding once again highlights the importance of the concept of subjective poverty for poverty reduction in rural China beyond 2020 .

Subjective poverty is measured by a subjective statement so that each individual has a different understanding of the subjective poverty line. Table 2.5 also compares the subjective poverty standards for the objective poor and non-poor. The subjective poverty standard for the objective poor is 7876.87 yuan, while the standard for the objective non-poor is 8416.92 yuan when we use the national poverty line. Clearly, the objective non-poor have a higher subjective poverty standard. A similar result is found when we use the global poverty line.

Furthermore, there is an asymmetry between subjective and objective poverty. In our sample, 449 households are identified as the objective poor according to the national poverty line. Within these 449 households, 369 (or 82\%) confirmed that they were also the subjective poor, and the rest $80(18 \%)$ thought they did not belong to the subjective poor. A similar result could be yielded even we use the global poverty line. There are some poor who are even below the national/global poverty line, but they do not think they are poor. It is possible that poverty could be transitionary, or they live a simple life.

\section{[Place Table 2.5 here]}

In order to further investigate the characteristics of the subjective poor, Table 2.6 presents the comparison of the demographic and socioeconomic characteristics between the subjective poor and non-poor. From the last column of Table 2.6, we can find that there are some significant differences in the demographic and socioeconomic 
characteristics between the subjective poor and non-poor. In particular, for the subjective non-poor, household head's age is younger, and their education level is higher than the subjective poor. In terms of the characteristics of the household, the per capita income of the subjective non-poor is higher than the subjective poor. Moreover, there are more family members, children, and labor forces in the subjectively non-poor households, while the (subjective) poor households have more elders to support. The human capital condition of the subjective non-poor is better than the subjective poor, having more healthy members, and higher education experience. The subjective non-poor households also have a higher value of the house, productive asset, consumption asset, and more land size than the subjective poor. Regarding the major irregular expenditure, the subjectively non-poor households spend more money in the area of gift and wedding expenditures, while the subjectively poor households spend more money on the medical expenditure. It shows that medical insurance is not well established in rural China, and the poor suffer from medical expenditure due to severe diseases. Finally, we do not find a significant difference between subjective non-poor and poor households in the aspect of social capital.

In the next section, we are going to exercise econometric models to study the determinants of subjective poverty in rural China.

[Place Table 2.6 here] 


\subsection{Empirical Model}

\subsubsection{Econometric Model}

In the previous sections, we designed a questionnaire to reveal each household's subjective poverty line and use the average value as the representative subjective poverty line for the nation to identify the subjective poverty status for each household. In order to study the determinants of subjective poverty in rural China, econometric models are specified as follows:

$$
\begin{gathered}
\log \left(S S_{i}\right)=\alpha_{1}+\sum_{j=1}^{6} \beta_{j} H D_{i}+\sum_{j=1}^{5} \gamma_{j} H H_{i}+\sum_{j=1}^{2} \delta_{j} H C_{i} \\
+\sum_{j=1}^{4} \theta_{j} M C_{i}+\sum_{j=1}^{2} \rho_{j} S C_{i}+\sum_{j=1}^{4} \varphi_{j} M E_{i}+\varepsilon_{1 i} \\
S P_{i}=\alpha_{1}+\sum_{j=1}^{6} \beta_{j} H D_{i}+\sum_{j=1}^{5} \gamma_{j} H H_{i}+\sum_{j=1}^{2} \delta_{j} H C_{i} \\
+\sum_{j=1}^{4} \theta_{j} M C_{i}+\sum_{j=1}^{2} \rho_{j} S C_{i}+\sum_{j=1}^{4} \varphi_{j} M E_{i}+\varepsilon_{2 i} \\
S D_{i}=\alpha_{1}+\sum_{j=1}^{6} \beta_{j} H D_{i}+\sum_{j=1}^{5} \gamma_{j} H H_{i}+\sum_{j=1}^{2} \delta_{j} H C_{i} \\
+\sum_{j=1}^{4} \theta_{j} M C_{i}+\sum_{j=1}^{2} \rho_{j} S C_{i}+\sum_{j=1}^{4} \varphi_{j} M E_{i}+\varepsilon_{3 i}
\end{gathered}
$$

In Equation (2.1), Equation (2.2), and Equation (2.3), subscript $i$ denotes the $i$ th household. Specifically, Equation (2.1) is to study the determinants of subjective poverty standard, and $S S$ denotes the subjective poverty standard reported by each rural household; Equation (2.2) is to study the determinants of subjective poverty status, and $S P$ denotes the subjective poverty status of the rural household measured by whether the real income is higher than the nationally representative Subjective 
Poverty Line or not (0-higher, 1-lower). Meanwhile, Equation (2.3) is to study the determinants of the depth of subjective poverty, and $S D$ denotes the depth of subjective poverty of the rural household.

In terms of the independent variables, $H D, H H, H C, M C, S C$, and $M E$ respectively stand for the characteristics of household head, the characteristics of household, household human capital, household social capital, and irregular expenditures (including education expenditure, medical expenditure, gift expenditure, and wedding expenditure). The explanations for all the related variables are reported in Table 2.1. The terms $\varepsilon$ are error terms following normal distributions with zero mean.

\subsubsection{Estimation Method}

As SS (Subjective Poverty Standard) and $S D$ (Subjective Poverty Depth) are continuous variables, OLS can be used for estimating Equation (2.1) and (2.3). In contrast, for Equation (2.2), $S P$ is a dummy variable that denotes whether the rural household is subjectively poor ( $S P=1$ if the rural household is subjective poor; $S P=0$ if the household is not subjectively poor) with use of the subjective poverty line. Thus, the Probit model is used in the estimation of Equation (2.2). Besides, as the data used in this study is cross-sectional, we report the robust standard errors to remedy the heteroscedasticity problem. We also use the variance inflation factor (VIF) to check multicollinearity, and find that it is not an issue in the regressions (Mason et al. 1989). 


\subsection{Empirical Results and Discussion}

\subsubsection{Determinants of the subjective poverty standard}

Table 2.7 shows the results of the determinants of subjective poverty standard. Model 1 is the estimation of Equation (2.1), indicating that the head's age, per capita income, family size, human capital, material capital, and major irregular expenditure play significant effects on the subjective poverty standard reported by the rural household. However, the subjective poverty standard might be affected by regional policies, customs, cultures, and geographical environments. To remedy this problem, we add county dummy variables in Model 2 to control for the unobservable regional effect. The two results are very similar, and the following discussion is mainly based on the estimation results from Model 2.

First, the coefficients for the head's age and the family size within the category of demographic variables are statistically significant at $1 \%$ and are -0.007 and -0.164 , respectively. It implies that old household heads and large family sizes are less likely to feel subjectively poor. Specifically, when the age of a household head increases by one year, the subjective poverty line decreases by $0.7 \%$. It is possible that a young family demands more money, e.g., for building a new house and supporting the education of children. When the household size increases by one member, the subjective poverty line decreases by $16.4 \%$, perhaps due to the consumption of family public goods. 
Second, the coefficient for per capita income is 0.022 and statistically significant at $5 \%$, indicating the per capita income of a household would increase the subjective poverty standard significantly. It is easy to understand that the more money a rural household has, the higher life quality they pursue. As a result, the subjective poverty standard increases. Much literature points out that per capita income is an important factor that affects the subjective poverty standard (Kingdon and Knight 2006; Posel and Rogan 2014; Reyes-García et al. 2016; Mahmood, Yu, and Klasen 2018).

The socioeconomic characteristics also significantly affect the subjective poverty standard. Particularly, the coefficient for the average education level of family members is 0.024 and statistically significant. It can be explained by the fact that a person with more education often has a higher expectation of good life quality. Similarly, the material capital, the house value, and the value of consumption assets also enhance the subjective poverty standard significantly.

For the variables related to major irregular expenditures, the coefficients for almost all variables are positive and significant, specifically including education expenditure, medical expenditure, and gift expenditure. One plausible interpretation is that, due to imperfections of the social security system in rural China, rural households face high education and medical expenditures, and they wish a high income to compensate for these necessary expenditures. As a result, it increases the subjective poverty standard directly. Besides, in the traditional culture of rural China, when one's friends or relatives celebrate a variety of social events, such as wedding, funeral, childbirth and so on, it is conventional to give cash-gift to express their 
blessing, which has occupied a large chunk of the rural household income (Chen 2014). Thus, gift expenditure also could increase the subjective poverty standard significantly. In fact, the coefficient for the medical expenditure is 0.021 , greater than the other expenditures. Clearly, medical expenditure plays the most important role in the subjective poverty standard within the category of irregular expenditures.

From what we have discussed above, we can draw a conclusion that, except for the demographic characteristics, such as age, family size, and education, subjective poverty standards are linked to wealthy levels and irregular expenditures of a family. On the one hand, the wealthy level, measured by per capita income and house value, etc. can reflect the life quality, and it is comprehensible that wealthier families are expected to have high subjective poverty lines. On the other hand, irregular expenditures are linked to imperfections of the social security system in rural China (mainly medical and education expenditure), and the traditional culture of a cash gift. The government should enhance the coverage of medical insurance, increase the education expenditure, and change the culture of a cash gift, to reduce insecurity and enhance life satisfaction for rural households.

\section{[Place Table 2.7 here]}

\subsubsection{Determinants of the subjective poverty status}

We now use the average subjective poverty lines as the representative subjective poverty lines to categorize the subjective poverty status. If the per capita income for a household surpasses the representative subjective poverty line, they are categorized as 
subjectively non-poor households ( 0 in the Probit model); otherwise, they are subjectively poor households ( 1 in the Probit model). Table 2.8 presents the estimation results for Equation (2.2), to study the determinants of the subjective poverty status. Similarly, Model 1 does not control for regional effects, while Model 2 does. The estimation results of Model 2 show that the coefficients for head's age, head's gender, family size, and per capita income are negative and significant, while the coefficients for human capital, material capital, social capital, and major irregular expenditures are positive and statistically significant.

Specifically, the older the head is, the less chance the household falls into subjective poverty. Male heads seem to be beneficial to the subjective well-being of the rural household. Importantly, the coefficient for per capita income is negative and statistically significant, and it suggests that the growth of per capita income for rural households is an effective way to alleviate the subjective poverty, which is consistent with the findings of the current literature (Stevenson and Wolfers 2013; Mahmood, Yu, and Klasen 2018).

Furthermore, rural households with higher education levels, more material capital, and more social capital are more likely to fall into the status of subjective poverty. Perhaps these aspects increase their expectation for better life quality. When they did not reach it, they are more likely to feel subjectively poor.

Moreover, regarding the major irregular expenditures of the rural household, only the coefficient for medical expenditure is positive and significant, meaning that medical expenditure worsens the subjective poverty status. Mainly due to the 
imperfection of medical insurance, many households have to pay a large chunk of medical expenditures, particularly for extremely serious diseases by themselves.

\section{[Place Table 2.8 here]}

\subsubsection{Determinants of the depth of subjective poverty}

Finally, this study discusses the determinants of the depth of subjective poverty, specifically for the subsample of the subjective poor. Table 2.9 shows the estimation results of Equation (2.3). Similarly, we report both results without and with control for regional fixed effect in Model 1 and Model 2, respectively. From the estimated result of Model 2, we can find that, for the subjective poor, the coefficient for per capita income is negative and statistically significant, and it implies that the growth of per capita income can alleviate the subjective poverty depth for the subjective poor.

Meanwhile, the depth of subjective poverty decreases as rural households have more family members or more friends and relatives working in government organizations. Besides, the land size of the households plays a negative effect on the subjective poverty depth, and it indicates that households with more cultivated land are more likely to alleviate the subjective poverty depth. Agricultural land is a very important asset for rural households, and it could help reduce poverty.

On the other hand, the coefficients for head's gender and the value of the consumption asset are positive and statistically significant, and it suggests that male head and accumulation of the consumption asset would worsen the subjective poverty 
depth, perhaps males have more expenditure on addicted goods, such as cigarettes and alcohol.

It is particularly important to point out that education and medical expenditures could exacerbate the subjective poverty specifically for the subjective poor. Once again, as we mentioned above, under the context of the imperfect social security system in rural China, education and medical expenditures are two major heavy financial burdens for the rural households, especially for the poor.

\section{[Place Table 2.9 here]}

\subsubsection{Robustness Check}

In this part, we further check the robustness of empirical results by excluding $5 \%$ of the extreme values of the subjective poverty standard, and the estimation results are reported in Table 2.10. Specifically, Model 1 is the results of Equation (2.1), while Model 2 and Model 3 are the results for Equation (2.2) and Equation (2.3), respectively. It is clear that these results are consistent with our previous empirical results.

[Place Table 2.10 here]

\subsection{Conclusion and Policy Implications}

Poverty is also a subjective feeling. On a background that China promises to eliminate absolute poverty by 2020, the concept of subjective poverty should become increasingly important for poverty policymaking in rural China. However, little 
attention has been paid to the research of subjective poverty in rural China. We employ a nationally representative survey of rural households in China, and particularly shed light on the situation of subjective poverty in rural China and then analyze the determinants.

The results show that the mean subjective poverty standard for the rural households is 8297 yuan per capita, much higher than the national poverty line and the global poverty line. It implies that the objective poverty line cannot reflect the subjective poverty comprehensively. $82 \%$ of the objective poor in rural China report higher subjective poverty standards or feel subjectively poor, while $29 \%$ of the rural household who are not the objective poor feel subjectively poor.

The results of our empirical analysis show that the demographic and socioeconomic characteristics have significant effects on the subjective. Specifically, on the one hand, the wealthy level of a household, measured by per capita income and house value, etc. can reflect the life quality. It is understandable that wealthier families expect a better life quality so that a high subjective poverty line for them is comprehensible. On the other hand, irregular expenditures due to imperfections of social security systems in rural China (mainly medical and education expenditures) and traditional culture of a cash gift, are also positively correlated with the subjective poverty lines.

This study offers some policy implications as follows: First, compared with the objective poverty line, the measurement of subjective poverty is a more flexible method to reflect the poverty perception when extreme poverty is not an important 
issue, such as in China. This will be increasingly important for China's poverty and welfare policymaking beyond 2020 when extreme poverty is eliminated. Second, medical expenditure and education expenditure are found to play an important role in subjective poverty in rural China. The government should enhance the coverage of medical insurance, increase the education expenditure, and change the culture of a cash gift, to reduce insecurity and enhance life satisfaction for rural households ${ }^{13}$. Third, the subjective poverty standard is correlated with income level, and it should increase gradually if there is a national subjective poverty line. In order to evaluate the efficiency of the policies more scientifically, it is necessary to integrate subjective poverty into the policy evaluation system and combine both subjective and objective poverty to show a full picture of poverty reduction in rural China. Fourth, sustainable growth of income is an effective way to alleviate both subjective and objective poverty and to increase the life satisfaction of the citizens (Zhou and Yu 2017).

${ }^{13}$ Chinese government has issued several regulations for the culture of cash gift. For instance, No. 1 Central Document of 2018 has proposed the policies to restrict the culture of cash gift. 


\section{Tables}

Table 2.1 Definition of Variables

\begin{tabular}{|c|c|c|c|}
\hline \multicolumn{2}{|c|}{ Variables } & Definition & Unit \\
\hline \multirow{3}{*}{$\begin{array}{l}\text { Subjective } \\
\text { poverty }\end{array}$} & $\begin{array}{l}\text { Subjective poverty } \\
\text { standard }\end{array}$ & $\begin{array}{l}\text { Log of (self-report minimum income/family } \\
\text { size) }\end{array}$ & yuan \\
\hline & $\begin{array}{l}\text { Subjective poverty } \\
\text { status }\end{array}$ & $\begin{array}{l}\text { Whether per capita income surpass } \\
\text { subjective poverty standard? Yes }=0, \mathrm{No}=1\end{array}$ & dummy \\
\hline & $\begin{array}{l}\text { The depth of } \\
\text { subjective poverty }\end{array}$ & $\begin{array}{l}\text { (subjective poverty standard-per capita } \\
\text { income) / subjective poverty standard }\end{array}$ & ratio \\
\hline \multirow{2}{*}{$\begin{array}{l}\text { Objective } \\
\text { poverty }\end{array}$} & $\begin{array}{l}\text { Objective poverty } \\
\text { _c }\end{array}$ & $\begin{array}{l}\text { Below } 2800 \text { yuan per year is poor, above } \\
2800 \text { yuan is non-poor. Poor }=1 \text {, Non-poor }=0\end{array}$ & dummy \\
\hline & $\begin{array}{l}\text { Objective poverty } \\
\_\mathrm{g}\end{array}$ & $\begin{array}{l}\text { Below } \$ 1.90 \text { per day is poor, above } \$ 1.90 \\
\text { per day is non-poor. Poor }=1 \text {, Non-poor }=0\end{array}$ & dummy \\
\hline \multirow{6}{*}{$\begin{array}{c}\text { Head's } \\
\text { characteristics }\end{array}$} & Head's age & The age of household head & years old \\
\hline & Head's gender & $\begin{array}{l}\text { The gender of household hear Male }=1 \text {, } \\
\text { Female }=0\end{array}$ & dummy \\
\hline & Marital status & Married $=1$, otherwise $=0$ & dummy \\
\hline & Head's education & School years of household head & year \\
\hline & Village leader & Whether be a village leader? Yes $=1, \mathrm{No}=0$ & dummy \\
\hline & Party member & Whether be a party member? Yes $=1, \mathrm{No}=0$ & dummy \\
\hline \multirow{5}{*}{$\begin{array}{l}\text { Household's } \\
\text { characteristics }\end{array}$} & Per capita income & Log of per capita income of household & yuan \\
\hline & Family size & The number of family members & person \\
\hline & Number of elders & $\begin{array}{l}\text { The number of family members whose age } \\
\text { above } 65\end{array}$ & person \\
\hline & Number of children & $\begin{array}{l}\text { The number of family members whose age } \\
\text { below } 15\end{array}$ & person \\
\hline & $\begin{array}{l}\text { Number of labor } \\
\text { forces }\end{array}$ & The number of family labor forces & person \\
\hline \multirow[t]{2}{*}{ Human capital } & Health condition & $\begin{array}{l}\text { Average health condition of family members } \\
(1=\text { very good, } 2=\text { good, } 3=\text { general, } 4=\text { bad, } \\
5=\text { very bad })\end{array}$ & category \\
\hline & Education level & Average school years of family members & year \\
\hline \multirow{4}{*}{ Material capital } & Land Size & Log of the area of cultivated land & $\mathrm{mu}$ \\
\hline & House value & Log of the value of the house & yuan \\
\hline & $\begin{array}{l}\text { Productive asset } \\
\text { value }\end{array}$ & Log of the value of the productive asset & yuan \\
\hline & $\begin{array}{l}\text { Consumption asset } \\
\text { value }\end{array}$ & Log of the value of the consumption asset & yuan \\
\hline \multirow{2}{*}{ Social capital } & $\begin{array}{l}\text { Government } \\
\text { organization }\end{array}$ & $\begin{array}{l}\text { How many friends or relatives working on } \\
\text { the government organization? }\end{array}$ & person \\
\hline & $\begin{array}{l}\text { Enterprise's } \\
\text { manager }\end{array}$ & $\begin{array}{l}\text { How many friends or relatives working as a } \\
\text { manager in the enterprise? }\end{array}$ & person \\
\hline
\end{tabular}


Sustainable Development: Rural Poverty and Climate Change in Agriculture

\begin{tabular}{|c|c|c|c|}
\hline \multirow{4}{*}{$\begin{array}{c}\text { Major } \\
\text { expenditure }\end{array}$} & $\begin{array}{l}\text { Education } \\
\text { expenditure }\end{array}$ & Log of the total education expenditure & yuan \\
\hline & $\begin{array}{l}\text { Medical } \\
\text { expenditure }\end{array}$ & Log of the total medical expenditure & yuan \\
\hline & Gift expenditure & Log of the total gift expenditure & yuan \\
\hline & $\begin{array}{l}\text { Wedding } \\
\text { expenditure }\end{array}$ & Log of the total wedding expenditure & yuan \\
\hline
\end{tabular}

Table 2.2 Descriptive statistics of variables

\begin{tabular}{|c|c|c|c|c|c|}
\hline \multicolumn{2}{|r|}{ Variables } & Mean & S.D. & Min & Max \\
\hline \multirow{3}{*}{$\begin{array}{c}\text { Subjective } \\
\text { poverty }\end{array}$} & $\begin{array}{l}\text { Subjective poverty } \\
\text { standard }\end{array}$ & 8.77 & 0.74 & 5.81 & 10.82 \\
\hline & Subjective poverty status & 0.44 & 0.50 & 0.00 & 1.00 \\
\hline & $\begin{array}{l}\text { Depth of subjective } \\
\text { poverty }\end{array}$ & -1.12 & 3.52 & -71.00 & 1.00 \\
\hline \multirow{2}{*}{ Objective poverty } & Objective poverty_c & 0.22 & 0.42 & 0.00 & 1.00 \\
\hline & Objective poverty_g & 0.20 & 0.40 & 0.00 & 1.00 \\
\hline \multirow{6}{*}{$\begin{array}{c}\text { Head's } \\
\text { characteristics }\end{array}$} & Head's age & 57.84 & 10.26 & 23.00 & 88.00 \\
\hline & Head's gender & 0.88 & 0.32 & 0.00 & 1.00 \\
\hline & Marital status & 0.88 & 0.32 & 0.00 & 1.00 \\
\hline & Head's education & 6.84 & 3.42 & 0.00 & 16.00 \\
\hline & Village leader & 0.08 & 0.27 & 0.00 & 1.00 \\
\hline & Party member & 0.16 & 0.37 & 0.00 & 1.00 \\
\hline \multirow{5}{*}{$\begin{array}{l}\text { Household's } \\
\text { characteristics }\end{array}$} & Per capita income & 8.64 & 1.66 & 0.00 & 11.71 \\
\hline & Family size & 4.14 & 1.83 & 1.00 & 13.00 \\
\hline & Number of elders & 0.64 & 0.80 & 0.00 & 3.00 \\
\hline & Number of children & 0.64 & 0.83 & 0.00 & 6.00 \\
\hline & Number of labor forces & 2.66 & 1.27 & 0.00 & 9.00 \\
\hline \multirow{2}{*}{ Human capital } & Health condition & 2.15 & 0.85 & 1.00 & 5.00 \\
\hline & Education level & 6.73 & 2.61 & 0.00 & 15.67 \\
\hline \multirow{4}{*}{ Material capital } & Land Size & 1.02 & 2.49 & -4.61 & 6.11 \\
\hline & House value & 2.21 & 1.55 & -2.30 & 6.17 \\
\hline & Productive asset & -3.84 & 2.97 & -6.91 & 3.44 \\
\hline & Consumption asset & 0.09 & 1.68 & -6.91 & 4.03 \\
\hline \multirow{2}{*}{ Social capital } & Government organization & 1.02 & 3.14 & 0.00 & 70.00 \\
\hline & Enterprise's manager & 0.47 & 2.28 & 0.00 & 60.00 \\
\hline \multirow{4}{*}{$\begin{array}{c}\text { Major } \\
\text { expenditure }\end{array}$} & Education expenditure & 2.37 & 4.05 & 0.00 & 12.56 \\
\hline & Medical expenditure & 7.40 & 2.68 & 0.00 & 13.35 \\
\hline & Gift expenditure & 7.13 & 2.49 & 0.00 & 11.00 \\
\hline & Wedding expenditure & 0.28 & 1.78 & 0.00 & 13.60 \\
\hline
\end{tabular}


Table 2.3 Subjective poverty standard in rural China

\begin{tabular}{|c|c|c|c|c|c|c|c|}
\hline Province & $\begin{array}{c}(1) \\
\text { Subjective } \\
\text { poverty }\end{array}$ & $\begin{array}{c}\text { National } \\
\text { poverty } \\
\text { line }\end{array}$ & $(1) /(2)$ & $\begin{array}{c}(3) \\
\text { Global } \\
\text { poverty } \\
\text { line }\end{array}$ & (1)/(3) & $\begin{array}{c}\text { (4) } \\
\text { Per capita } \\
\text { income }\end{array}$ & $(1) /(4)$ \\
\hline Whole & 8297.18 & 2800 & 2.96 & 2563 & 3.23 & 10891.3 & 0.76 \\
\hline Jiangsu & 9387.75 & 2800 & 3.35 & 2563 & 3.66 & 13588.1 & 0.69 \\
\hline Sichuan & 7813.68 & 2800 & 2.79 & 2563 & 3.04 & 8637.38 & 0.90 \\
\hline Shannxi & 7432.38 & 2800 & 2.65 & 2563 & 2.89 & 11307.17 & 0.66 \\
\hline Jilin & 8371.67 & 2800 & 2.99 & 2563 & 3.26 & 10164.39 & 0.82 \\
\hline Hebei & 8476.76 & 2800 & 3.03 & 2563 & 3.30 & 10785.86 & 0.79 \\
\hline
\end{tabular}

Table 2.4 Incidence of subjective poverty in rural China

\begin{tabular}{|c|c|c|c|c|c|}
\hline Province & $\begin{array}{c}\text { (1) Subjective } \\
\text { poverty }\end{array}$ & $\begin{array}{c}\text { (2) National } \\
\text { poverty line }\end{array}$ & (1) - (2) & $\begin{array}{c}\text { (3) Global } \\
\text { poverty line }\end{array}$ & (1) - (3) \\
\hline Whole & 0.44 & 0.22 & 0.22 & 0.20 & 0.24 \\
\hline Jiangsu & 0.37 & 0.17 & 0.20 & 0.15 & 0.22 \\
\hline Sichuan & 0.49 & 0.27 & 0.22 & 0.25 & 0.24 \\
\hline Shannxi & 0.39 & 0.24 & 0.15 & 0.21 & 0.18 \\
\hline Jilin & 0.53 & 0.24 & 0.29 & 0.21 & 0.32 \\
\hline Hebei & 0.44 & 0.20 & 0.24 & 0.18 & 0.26 \\
\hline
\end{tabular}

Table 2.5 Subjective poverty of the objective poor in rural China

\begin{tabular}{|c|c|c|c|c|c|c|c|c|c|}
\hline \multirow[t]{2}{*}{ Group } & \multicolumn{2}{|c|}{ Subjective poor } & \multirow{2}{*}{$\begin{array}{l}\text { Subjective } \\
\text { poverty } \\
\text { standard }\end{array}$} & \multicolumn{3}{|c|}{$\begin{array}{c}\text { Subjective poverty } \\
\text { standard > Objective line }\end{array}$} & \multicolumn{3}{|c|}{$\begin{array}{c}\text { Subjective poverty } \\
\text { standard < Objective } \\
\text { line }\end{array}$} \\
\hline & Obs & Percent & & Obs & Perc & Mean & Obs & Percent & Mean \\
\hline \multicolumn{10}{|c|}{ Objective poverty based on national poverty line (Poor Obs=449; Non-poor Obs=1576) } \\
\hline Poor & 434 & $96 \%$ & 7876.87 & 369 & $82 \%$ & 9155.61 & 80 & $18 \%$ & 1978.65 \\
\hline Non-poor & 467 & $29 \%$ & 8416.92 & \multicolumn{3}{|c|}{---} & \multicolumn{3}{|c|}{---} \\
\hline \multicolumn{10}{|c|}{ Objective poverty based on global poverty line (Poor Obs=417; Non-poor Obs=1608) } \\
\hline Poor & 405 & $97 \%$ & 7902.71 & 340 & $84 \%$ & 9245.02 & 65 & $16 \%$ & 2012.84 \\
\hline Non-poor & 496 & $31 \%$ & 8399.47 & \multicolumn{3}{|c|}{--- } & \multicolumn{3}{|c|}{--- } \\
\hline
\end{tabular}


Table 2.6 Comparison between the subjective poor and the non-subjective poor

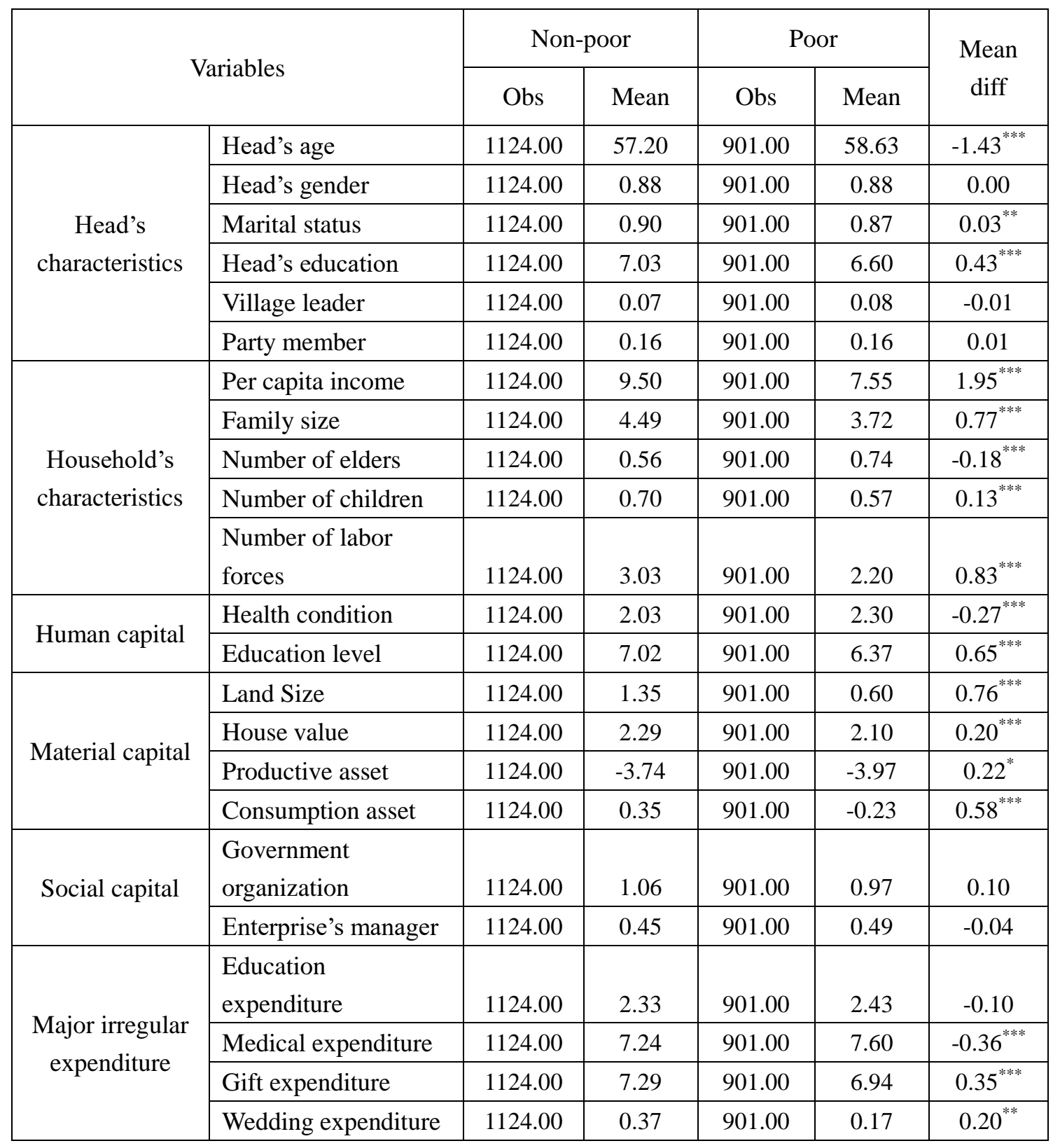

Notes: $* \mathrm{p}<0.1, * * \mathrm{p}<0.05, * * * \mathrm{p}<0.01$ 
Table 2.7 Determinants of the subjective poverty standard

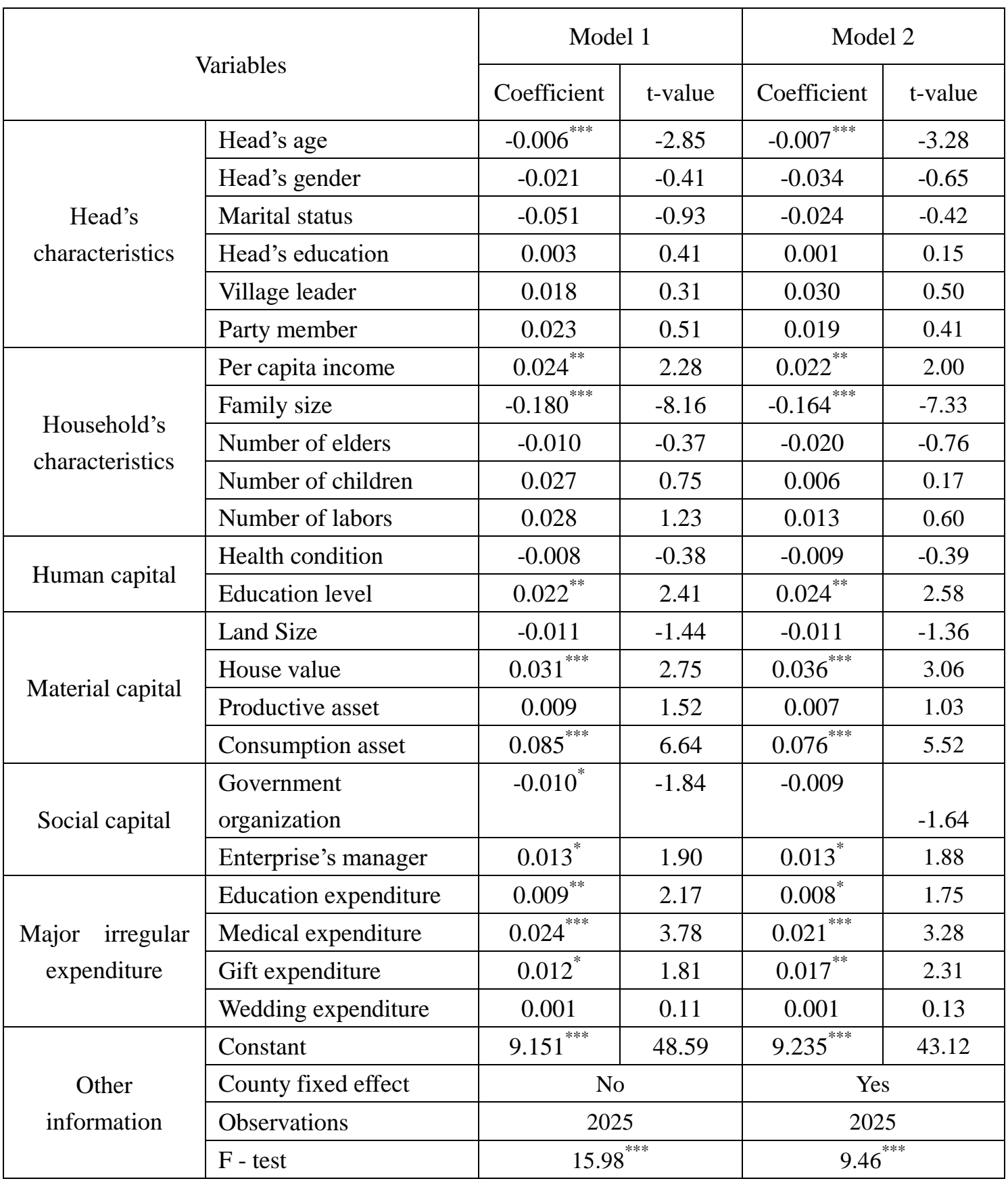

Notes: $* \mathrm{p}<0.1, * * \mathrm{p}<0.05, * * * \mathrm{p}<0.01$ 
Table 2.8 Determinants of the subjective poverty status

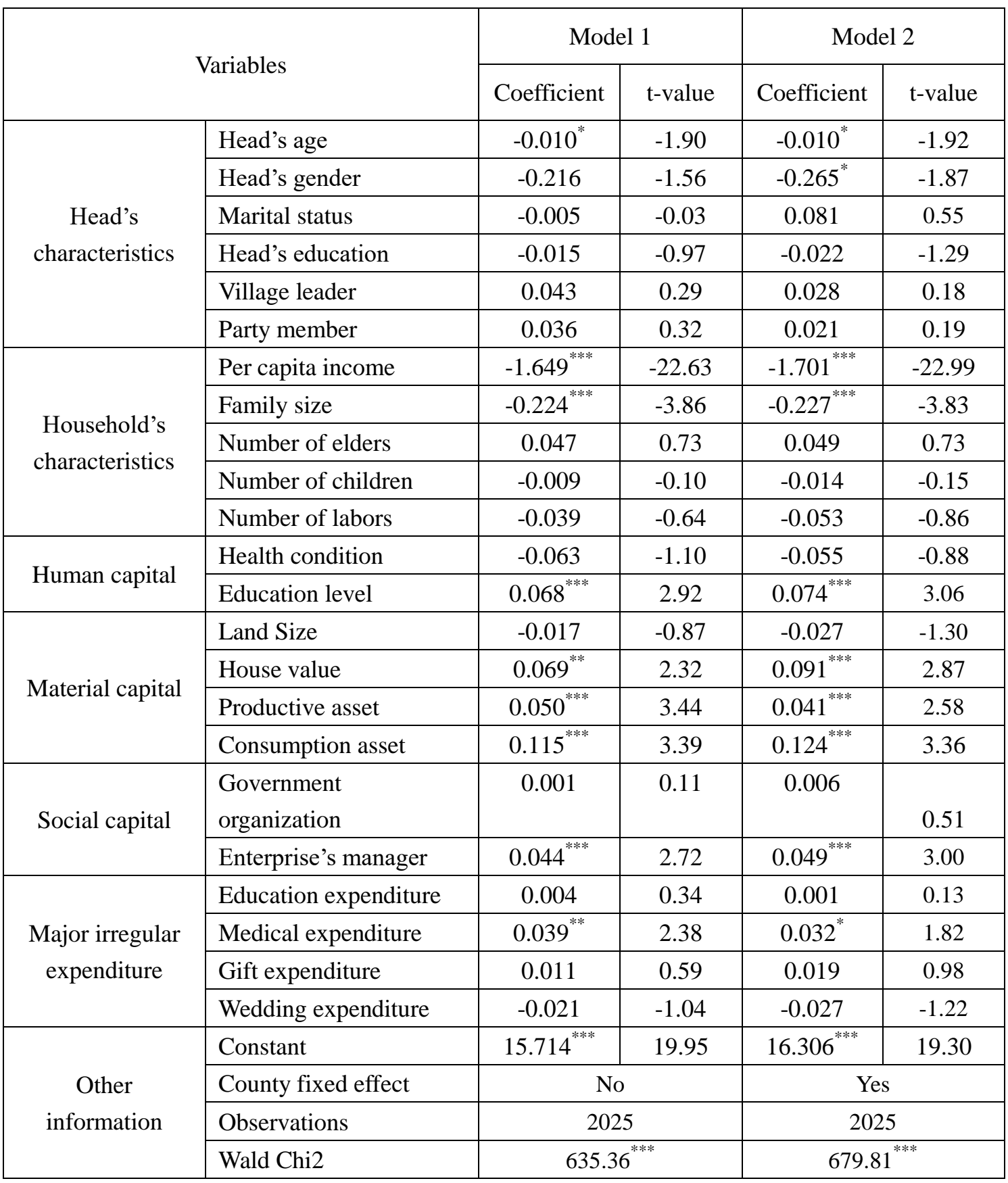

Notes: $* \mathrm{p}<0.1, * * \mathrm{p}<0.05, * * * \mathrm{p}<0.01$ 
Table 2.9 Determinants of the poverty depth of the subjective poor

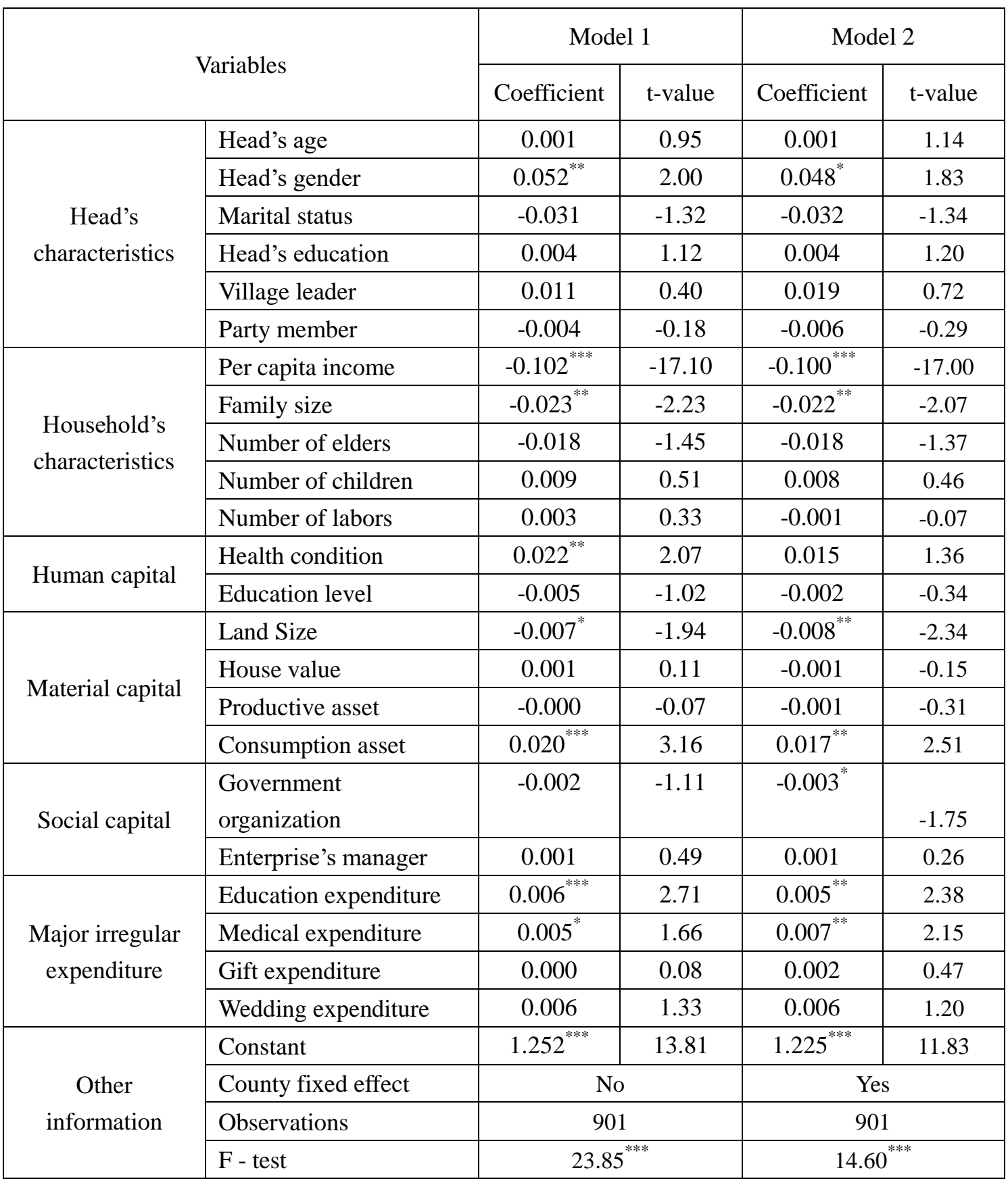

Notes: $* \mathrm{p}<0.1, * * \mathrm{p}<0.05, * * * \mathrm{p}<0.01$ 
Table 2.10 Robustness Check

\begin{tabular}{|c|c|c|c|c|}
\hline \multicolumn{2}{|c|}{ Variables } & Model 1 & Model 2 & Model 3 \\
\hline \multirow{6}{*}{$\begin{array}{c}\text { Head's } \\
\text { characteristics }\end{array}$} & Head's age & $\begin{array}{c}-0.006^{* \ldots * *} \\
(-3.24)\end{array}$ & $\begin{array}{l}-0.011^{*} \\
(-1.88)\end{array}$ & $\begin{array}{l}0.001 \\
(0.70)\end{array}$ \\
\hline & Head's gender & $\begin{array}{l}0.011 \\
(0.23)\end{array}$ & $\begin{array}{l}-0.213 \\
(-1.33)\end{array}$ & $\begin{array}{l}0.056^{* *} \\
(2.04)\end{array}$ \\
\hline & Marital status & $\begin{array}{l}-0.070 \\
(-1.46)\end{array}$ & $\begin{array}{l}0.091 \\
(0.54)\end{array}$ & $\begin{array}{l}-0.040 \\
(-1.60)\end{array}$ \\
\hline & Head's education & $\begin{array}{l}-0.001 \\
(-0.15)\end{array}$ & $\begin{array}{l}-0.021 \\
(-1.15)\end{array}$ & $\begin{array}{l}0.003 \\
(0.77)\end{array}$ \\
\hline & Village leader & $\begin{array}{l}0.031 \\
(0.60)\end{array}$ & $\begin{array}{l}0.024 \\
(0.14)\end{array}$ & $\begin{array}{l}0.033 \\
(1.18)\end{array}$ \\
\hline & Party member & $\begin{array}{l}0.016 \\
(0.39)\end{array}$ & $\begin{array}{l}0.026 \\
(0.21)\end{array}$ & $\begin{array}{l}-0.022 \\
(-0.94)\end{array}$ \\
\hline \multirow{5}{*}{$\begin{array}{l}\text { Household's } \\
\text { characteristics }\end{array}$} & Per capita income & $\begin{array}{c}0.030^{* 3 * * 1} \\
(3.07)\end{array}$ & $\begin{array}{c}-1.949^{* * * * *} \\
(-22.04)\end{array}$ & $\begin{array}{l}-0.108^{* * * * * *} \\
(-16.15)\end{array}$ \\
\hline & Family size & 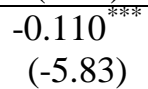 & $\begin{array}{c}-0.198^{* * * * * * * *} \\
(-3.02)\end{array}$ & $\begin{array}{l}-0.023^{* * *} \\
(-2.13)\end{array}$ \\
\hline & Number of elders & $\begin{array}{l}-0.003 \\
(-0.12)\end{array}$ & $\begin{array}{l}0.127^{*} \\
(1.72)\end{array}$ & $\begin{array}{l}-0.005 \\
(-0.40)\end{array}$ \\
\hline & Number of children & $\begin{array}{l}0.008 \\
(0.26)\end{array}$ & $\begin{array}{l}-0.010 \\
(-0.10)\end{array}$ & $\begin{array}{l}0.021 \\
(1.22)\end{array}$ \\
\hline & Number of labors & $\begin{array}{l}0.011 \\
(0.57) \\
\end{array}$ & $\begin{array}{l}-0.041 \\
(-0.59) \\
\end{array}$ & $\begin{array}{l}0.002 \\
(0.17) \\
\end{array}$ \\
\hline \multirow{2}{*}{ Human capital } & Health condition & $\begin{array}{l}0.006 \\
(0.28)\end{array}$ & $\begin{array}{l}-0.032 \\
(-0.47) \\
\end{array}$ & $\begin{array}{l}0.020^{*} \\
(1.75)\end{array}$ \\
\hline & Education level & $\begin{array}{l}0.014^{*} \\
(1.76)\end{array}$ & $\begin{array}{l}0.052^{* *} \\
(2.00)\end{array}$ & $\begin{array}{l}-0.002 \\
(-0.36)\end{array}$ \\
\hline \multirow{4}{*}{ Material capital } & Land Size & $\begin{array}{l}-0.007 \\
(-1.07)\end{array}$ & $\begin{array}{l}-0.028 \\
(-1.19)\end{array}$ & $\begin{array}{l}-0.009^{* * *} \\
(-2.35)\end{array}$ \\
\hline & House value & $\begin{array}{l}0.014 \\
(1.33)\end{array}$ & $\begin{array}{l}0.060^{*} \\
(1.74)\end{array}$ & $\begin{array}{l}-0.004 \\
(-0.68)\end{array}$ \\
\hline & Productive asset & $\begin{array}{l}0.006 \\
(1.04)\end{array}$ & $\begin{array}{c}0.042^{* * *} \\
(2.41)\end{array}$ & $\begin{array}{l}0.000 \\
(0.11)\end{array}$ \\
\hline & Consumption asset & $\begin{array}{c}0.064^{* * * *} \\
(5.29)\end{array}$ & $\begin{array}{c}0.132^{* * * *} \\
(3.28)\end{array}$ & $\begin{array}{c}0.018^{* * * *} \\
(2.60)\end{array}$ \\
\hline \multirow{2}{*}{ Social capital } & Government organization & $\begin{array}{l}-0.006 \\
(-1.33)\end{array}$ & $\begin{array}{l}0.021 \\
(1.63)\end{array}$ & $\begin{array}{l}-0.002 \\
(-1.59)\end{array}$ \\
\hline & Enterprise's manager & $\begin{array}{l}0.012^{* * *} \\
(2.17)\end{array}$ & $\begin{array}{l}0.046^{*} \\
(1.95) \\
\end{array}$ & $\begin{array}{l}-0.001 \\
(-0.56)\end{array}$ \\
\hline \multirow{4}{*}{$\begin{array}{l}\text { Major irregular } \\
\text { expenditure }\end{array}$} & Education expenditure & $\begin{array}{l}0.008^{* * *} \\
(2.18)\end{array}$ & $\begin{array}{l}0.002 \\
(0.12)\end{array}$ & $\begin{array}{c}0.006^{* * * *+1} \\
(2.78)\end{array}$ \\
\hline & Medical expenditure & $\begin{array}{c}0.015^{* * * * 4} \\
(2.79) \\
\end{array}$ & $\begin{array}{l}0.019 \\
(1.03)\end{array}$ & $\begin{array}{l}0.004 \\
(1.30) \\
\end{array}$ \\
\hline & Gift expenditure & $\begin{array}{c}0.011^{* * *} \\
(1.98) \\
\end{array}$ & $\begin{array}{l}0.010 \\
(0.50)\end{array}$ & $\begin{array}{l}0.001 \\
(0.42) \\
\end{array}$ \\
\hline & Wedding expenditure & $\begin{array}{l}0.001 \\
(0.12)\end{array}$ & $\begin{array}{l}-0.024 \\
(-0.95)\end{array}$ & $\begin{array}{l}0.007 \\
(1.40)\end{array}$ \\
\hline \multirow{3}{*}{ Other information } & Constant & $\begin{array}{c}9.016^{* 3 * * 4} \\
(49.78)\end{array}$ & $\begin{array}{c}18.568 \\
(19.45)\end{array}$ & 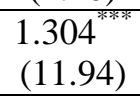 \\
\hline & County fixed effect & Yes & Yes & Yes \\
\hline & Observations & 1872 & 1872 & 822 \\
\hline
\end{tabular}

Notes: $\mathrm{t}$ statistics in parentheses. $* \mathrm{p}<0.1, * * \mathrm{p}<0.05, * * * \mathrm{p}<0.01$ 


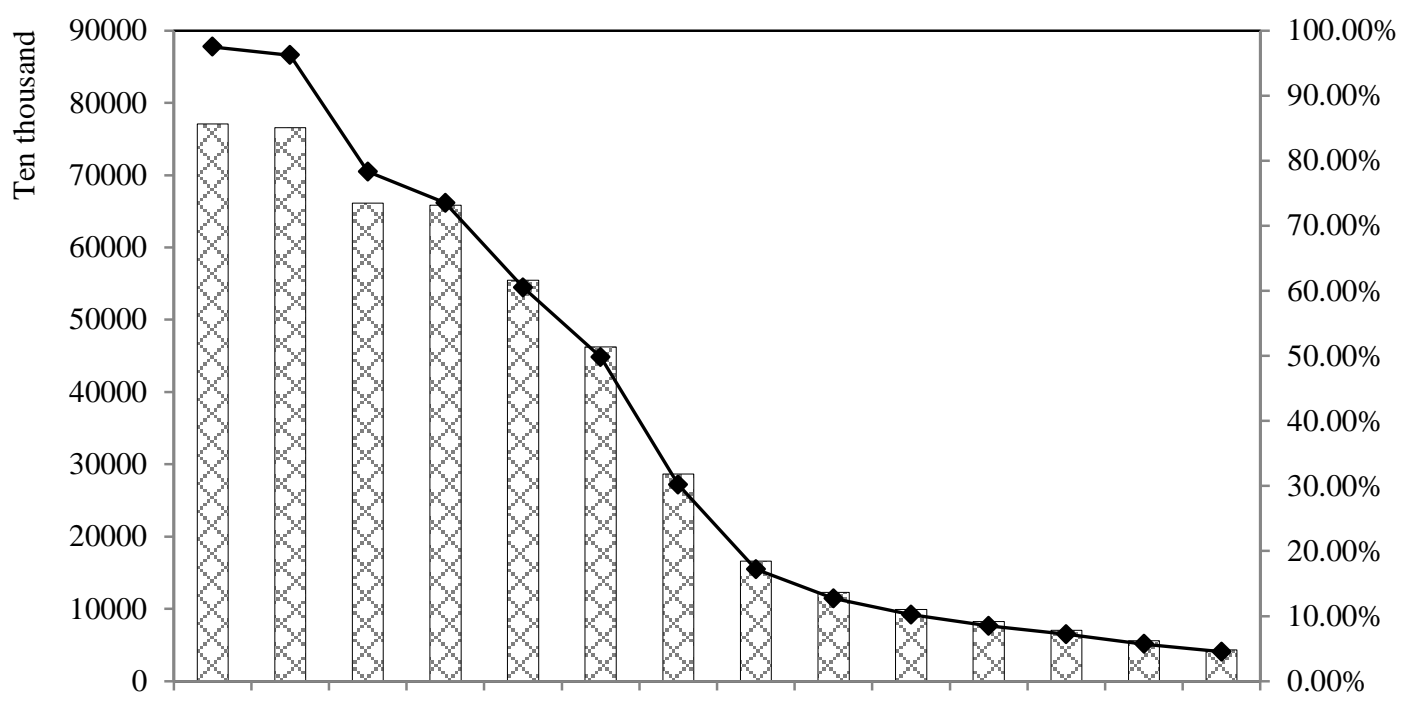

19781980198519901995199920052010201120122013201420152016

$\times X$ Amount $\multimap$ Rate

Figure 2.1 Rural Poverty in China

Source: Poverty Monitoring Report of Rural China (2017), National Bureau of Statistics (NBS) of

China (calculated by the national poverty line 2010) 


\section{Chapter 3 Disagreement on Sunspots and Soybeans}

\section{Futures Prices $^{14}$}

Abstract: Disagreement on information could cause market price volatilities through the channels of gradual information flow, limited attention, and heterogeneous priors. High food price volatilities could incur severe welfare loss. This study analyzes the effect of sunspots on the volatility of soybeans futures prices in a framework of the disagreement theory. Empirically, we use the monthly time series datasets of soybeans futures prices and sunspots activities from1988-2018 to investigate how sunspots affect the volatilities of soybeans futures prices by estimating the GARCH, GJR-GARCH, and Markov-switching GARCH models. Our findings are summarized as: (1) extremely low sunspot activity could lead to both high price and high volatility for soybeans futures prices; and (2) when considering regime changes, the disagreement level is nonlinear in the high volatility regime in which the high price volatility exists on both extremely low and high sunspot activities.

Keywords: disagreement, sunspots, investors' behaviors, soybeans futures prices

JEL: G12; G14; G41

\footnotetext{
${ }^{14}$ This chapter has been published in Economic Modelling. I contributed to the theoretical framework and empirical analysis, and took the lead in writing the manuscript under the guidance of Prof. Yu. All authors provided critical feedback and contributed to the research.

Wang, H., Feil, J. H., \& Yu, X. (Corresponding Author) (2020). Disagreement on Sunspots and Soybeans Futures Prices. Economic Modelling. https://doi.org/10.1016/j.econmod.2020.03.005
} 


\subsection{Introduction}

High food price volatility could incur severe welfare loss (Bellemare, Barrett, and Just 2013; Yu 2014b), while solar phenomena, often measured by sunspots ${ }^{15}$, are regarded as a fundamental factor that drives the volatility. Considerable literature points out that sunspot activity significantly affects the weather changes, including temperature, rainfall, cyclone, and so on (Ormes 2018; Gupta 2019; Yang et al. 2019). Some studies shed light on the economic consequences of sunspot activity and show that sunspot activity indeed affects economic growth, economic recession, unemployment, stock market, and agricultural production (e.g., Gu et al. 2013; Novy-Marx 2014; Sun et al. 2017; Benhabib and Spiegel 2018; Fehr et al. 2019; Ascari, Bonomolo, and Lopes 2019). Moreover, it is well-known that social individuals' behaviors are influenced by sunspot activity to some extension, such as animal spirits and self-fulfilling prophecies (Kashiwagi 2014; Ho 2015; Arifovic et al. 2019). By and large, the linkage between the information of sunspots and food price volatility is quite complicated, as people may have different perceptions for them.

The information has a significant effect on financial market trading (Yang and Li 2013), and investors are conducted based on different beliefs on the information. Given a piece of information, people may disagree on the market consequences. The information of sunspots is no exception. Some literature attempts to reveal the role of sunspots on the volatility of financial markets. For instance, Kang (2015) reveals price

\footnotetext{
${ }^{15}$ Sunspots form on the surface of the Sun due to strong magnetic field lines coming up from within the Sun trough the solar surface and appear visibly as dark spots compared to their surroundings (see www.spaceweatherlive.com).
} 
volatility in an incomplete market with sunspots by equilibrium analysis. After that, Kang (2019) further considers the welfare cost of excess volatility with sunspots. Similarly, Benhabib and Wang (2015) find that sunspot shocks would generate variations in asset prices by using an equilibrium model. In addition, Farmer (2015) employs the global sunspot equilibria to capture the volatility of assets price caused by sunspots. However, there is very limited evidence on how the information of sunspots affects investors' behaviors, which is a key issue to better understand the underlying mechanism of the volatility of financial markets. Furthermore, to the best of our knowledge, recent literature does not provide direct empirical evidence on the effect of sunspots on the volatility of financial markets. This study aims to understand the impact of sunspots on the volatility of financial markets and its mechanism both theoretically and empirically. Specifically, we focus on the soybeans futures market. It is widely known that the agricultural commodity futures market plays an essential role in the development of the agriculture sector and traders' decision-making. Capturing the volatility of agricultural commodity futures price enables policymakers to stabilize the domestic agricultural commodity market in time so as to protect agriculture sectors.

A central issue of this study is to employ the disagreement theory to analyze investors' behaviors, given the complicated information of sunspots. Theoretically, disagreements could change market price trends and volatilities. Disagreement on the information of sunspots would shape investors' behavior. In the hypothesis of an efficient market, individuals are assumed as rational, and market prices capture all 
information (Marinescu et al. 2018). It indicates no need to consider any behavioral or psychological bias. Over the past decades and especially in the course of the last financial crisis, the field of behavioral finance has been of great concern for researchers and traders (Malmendier and Nagel 2016; Ruan et al. 2019; Lan, Huang, and Yan 2020). In a real financial market, the beliefs of investors are heterogeneous (Hong and Stein 2007; Aouadi, Arouri, and Teulon 2013; Thaler 2016; Andrade et al. 2019). Thus, the disagreement problem always exists among investors, especially when they receive complicated information. As indicated above, sunspot activity could potentially affect investors' behaviors differently. Thus, market prices could eventually be affected by heterogeneous traders with different beliefs. However, little attention has been paid to the disagreement mechanism of sunspot information. One can expect that low sunspot activity could lead to high prices due to its correlated cold weather, but the effect on the volatility of the soybeans futures price cannot simply be inferred. Notably, both first- and second-order moments of food prices have important welfare effects for both farmers and consumers (Bellemare, Barrett, and Just 2013; Yu 2014a \& 2014b).

This study fills in the research gap and makes several contributions to the existing literature. First, while most studies use equilibrium analyses to deduce the effect of sunspots on the volatility of price (e.g., Farmer 2015; Benhabib and Wang 2015; Kang 2019), this study is different from them. We employ the disagreement theory from behavioral finance to reveal investors' behaviors, given the complicated information of sunspots, providing new insights on the underlying mechanism of the effect of 
sunspots on the volatility of soybeans futures prices. Second, to the best of our knowledge, this is the first study empirically investigating the impact of sunspots on the volatility of soybeans futures prices. Soybean is an important traded agricultural product in the global market as it provides affluent proteins for human and livestock needs. We use three econometric methodologies: the GARCH, GJR-GARCH, and Markov- switching GARCH models with exogenous covariates of sunspots. Each of these methods assumes different patterns of price volatility, which could ensure the robustness of empirical results. This study could help better understand the mechanism of soybean prices from a theoretical perspective and better forecast market prices from an empirical perspective. A better forecast of agricultural market price could help investors make better investment strategies, and help governments make better food security policies (Yu 2014a).

The study is organized as follows: Section 3.2 provides a literature review of the potential economic effects of sunspot activity; Section 3.3 presents the theory of disagreement as a theoretical framework; Section 3.4 applies the GARCH, GJR-GARCH, and Markov- switching GARCH models with exogenous covariates of sunspots; Section 3.5 concludes the study.

\subsection{Literature Review}

\subsubsection{Sunspots and agricultural market}

A number of previous studies have confirmed an association between sunspots and agricultural production. Dodamani et al. (2015) reveal a significant correlation 
between sunspot activity and crop yield using remote sensing. Some other studies adopt different econometric methods and then find similar conclusions in different countries, such as Europe, UK, India, and so on (Garnett et al. 2006; Huhtamaa et al. 2015). Recent literature further investigates the indirect mechanism between sunspots and crop yield. Major findings show that sunspots mainly affect agricultural production through the channel of the influence on climate changes, including temperature, rainfall, and geomagnetic fields (Lockwood 2012; Gupta et al. 2015).

In addition, some studies focus on the effect of sunspots on crop prices. For example, Herschel (1801) and Jevons (1879) reveal the positive relationship between sunspots and crop (wheat and corn) prices by using time series analysis, although this is somehow not consistent with the positive correlation between sunspots and crop output. Pustilnik and Yom Din (2013) further find that the effect of sunspots on agricultural commodity prices depends on the respective sensitivity of local weather, while Love (2013) claims that the effect of sunspots on wheat price is statistically insignificant. Burakov (2017) finds that, in the long run, sunspots and world wheat prices are related. This inconclusive scientific evidence provides a ground for disagreement in market trading.

\subsubsection{Sunspots and economic cycle}

Herschel (1801) conducts the earliest study on the relationship between sunspot activity and business activity. In light of this, Jevons (1879) points out the channel that sunspots affect the economic cycle is that the weather changes caused by sunspots 
influence the production of crops. This might be true when agricultural activities were dominating the economic system at that time. Things might be different in modern days, as the importance of the agricultural sector for the global economy has generally been reduced. Yet, the results of Garcia-Mata and Shaffner (1934) do not support it, and their conclusion shows that only the correlation between sunspot activity and the non-agricultural activity is statistically significant. Walsh (1993) further claims that the correlation coefficient between the solar cycle and economic performance is 65 percent. Harrison and Weder (2006) construct a dynamic general equilibrium model with sunspots, which can explain the Great Recession of the U.S. Recent studies suggest an association between the variation of sunspot and unemployment rate, that is, the rise in the sunspot number significantly increases the unemployment rate (Cherrier and Saïdi 2018; Ji and Xiao 2018).

\subsubsection{Sunspots and financial markets}

Considering the sunspots as non-fundamental uncertainty, Modis (2007) analyzes the correlation between the number of sunspots and the Dow Jones Industrial Average (DJIA), and the results showed that the DJIA pattern precedes the peaks of sunspots. Novy-Marx (2014) points out that a high level of sunspot activity might decrease the capacity of investors to receive information, with the potential result that the news cannot get incorporated into prices. Wall and Jenkins (2003) consider this correlation as folklore, as it would be very difficult to substantiate it. Still, they also admitted the possibility of this correlation because it is well-known that weather conditions affect 
the behaviors of investors, and sunspots again may change the weather. Recent studies of Kim (2017) and Fehr et al. (2019) re-confirm the significant relationship between sunspots and stock market performance.

\subsubsection{Sunspots and human behaviors}

A number of researchers have investigated whether sunspots affect human behaviors. The previous study of Tchijevsky (1971) analyzes the sunspot activity and the histories of 72 countries from 500 B.C to 1922 A.D, showing that nearly 80 percent of significant historical events, such as wars, revolutions, and migrations, occurred during the maximum sunspot activity. The inner mechanism could be explained by the theory of Withbroe (1989), which points out that the cosmic radiation caused by sunspot activity vitalize human and is the source of human evolution. There are also some experimental analyses on the effect of sunspots on human behaviors. For instance, Duffy and Fisher (2005) find that sunspots significantly affect human behaviors in a less informative market, while in a more informative market, this effect would decrease. Fehr and Heinemann (2018) measure how sunspots affect behavior, and the results show that highly correlated private signals might cause sunspot-driven behaviors.

According to the existing literature, we can conclude that sunspot activity affects both economic performance and human behaviors. As such, the information of sunspots is far more complicated beyond human understanding. Investors cannot always interpret this kind of complicated information unanimously, causing a 
disagreement problem in financial markets. It is well-known that information has a pivotal role in the volatility of price in financial markets, especially in future trading. The agricultural commodity futures market, one of the most important financial markets in the world, is extremely vital for price setting on agricultural spot markets. In light of this, a key issue is how the complicated information of sunspots affects the volatility of agricultural commodity futures prices. This study uses the disagreement theory to reveal the effect of sunspots on soybeans futures prices.

\subsection{Theoretical Framework}

Disagreement theory provides a useful account for behavioral finance. Following the theoretical framework of Hong and Stein (2007), there are three main channels that could lead to a disagreement problem in financial markets: gradual information flow, limited attention, and heterogeneous priors. Based on the disagreement theory, this study reveals the mechanisms of how the information of sunspots causes disagreement problems among investors in the soybean futures market.

\subsubsection{Information and Disagreement}

\subsubsection{Gradual Information Flow}

Gradual information flow is an important way to cause disagreement. Due to geographical segmentation, professionalization, and also access to the media or internet, information always flows gradually in our daily life. Thus, it is common in financial markets that some investors always acquire value-relevant information 
before others. With the formation of two groups of investors that receive the information at a different time, disagreement happens. For instance, when the information is positive, those investors who receive the information immediately tend to increase their valuations of the asset price, while those who do not receive the information would again remain the valuation of the asset price. This kind of disagreement would shape the behaviors, that is, the former group would buy the asset from the latter group, causing the volatility of the asset price.

In addition, overconfidence, mainly mentioned in the field of behavioral finance, also causes disagreement problem under the condition of gradual information flow. Specifically, overconfidence means that investors cannot always realize they may be in the situation of informational disadvantage and hence do not learn from the others. Rather, they only take the trade action when the information comes to them. There are several recent studies provide some evidence for this phenomenon (Hong, Torous, and Valkanov 2006).

\subsubsection{Limited Attention}

Limited attention means that cognitively-overloaded investors only focus on publicly-available information (Zhang and Wang 2015; Han et al. 2018). Compared with gradual information flow, limited attention stresses less on the diffusion of information. In particular, limited attention indicates that the information released in an "attention-grabbing" way would result in the larger response of the volatility of asset prices, which implies that the media would play a vital role in affecting the investors' behaviors. Also, the limited attention mechanism also occurs when 
investors are distracted for some reason. The research of DellaVigna and Pollet (2006) claims that the information released on Friday would have less effect on the volatility of the stock price than on the other days, as investors are distracted over the weekend and then ignore the influence of the information to some extension. Furthermore, just as gradual information flow, the mechanism of limited attention also requires the assumption of overconfidence, that is, investors only have the belief on the information they own and do not adjust their behaviors when trades with others.

\subsubsection{Heterogeneous Priors}

Heterogeneous priors, the third mechanism of disagreement, refers to the situation that even if the information flows simultaneously and all investors pay attention to the information, the information still causes the disagreement on the valuation of asset prices. The interpretation of this phenomenon is that every investor has a different behavioral orientation, which would generate different understandings for the information (Gizatulina and Hellman 2019). For instance, when a firm releases profit information, there might be three groups of investors. The first group might regard this information as good news, as it excesses the profit level they expected; the second group might regard it as common news, as it just reaches the level they expected; while the third group might regard it as bad news, as it does not reach the level they expected. Under this disagreement, they would choose different trading behaviors, which naturally lead to the volatility of the stock price. Regarding the impacts of sunspots information on the commodity futures market, it can be assumed that there is a similar mechanism. 


\subsubsection{Information of Sunspots and Disagreement}

In this study, we mainly focus on whether the information of sunspots causes the disagreement on soybeans futures prices. Thus, we use the disagreement theory to reveal the mechanism of information of sunspots and disagreement. Clearly, if traders disagree on the implications of sunspots, the price volatility would be high. This is the empirical foundation.

First, the information of sunspots causes disagreement by its gradual flow. The information of sunspots, reflecting solar activity, is more scientific than public information. Regularly, such kind of information would be published in scientific journals originally, like Nature or Science. As a result, scientific researchers or those people who pay more attention to these scientific journals would capture the information of sunspots timely. Yet, for most people, they can only get the information of sunspots from social media or magazine, which has been reported in scientific journals before. If the information of sunspots is positive for soybeans futures prices, the investors of the former group will increase the valuation of soybeans futures prices while the latter group would maintain the valuation, resulting in disagreement.

Second, the information of sunspots causes disagreement by investors' limited attention. A large literature has claimed that a series of economic indicators can predict the market effectively (Novy-Marx 2014). Some investors in the agricultural commodity futures market are more sensitive to and would like to pay more attention to such economic or public information so as to predict the soybeans futures prices. However, the information of sunspots refers to the natural phenomenon of solar 
activity, which may draw less attention from other investors. Thus, the existence of investors with limited attention would lead to disagreement on the information of sunspots.

Third, the information of sunspots causes disagreement by heterogeneous interpretation. As we discussed above, sunspots, the indicator of solar activity, contains lots of complicated information, as it affects a series of the economic, natural, and behavioral phenomenon, though different channels, some positive, some negative. It is very difficult to determine whether the variation of sunspots, in general, is good news or a bad one to the soybeans futures prices. Moreover, it is well-known that "One thousand readers, one thousand Hamlets". Investors of the agricultural commodity futures market, heterogeneous individuals, always have different economic behavior models, leading them to interpret the information of sunspots diversely. With the heterogeneous interpretation of the information of sunspots, the disagreement forms. When the information of sunspots comes, investors would have a different valuation of soybeans futures and then adopt different trading behaviors, which cause the volatility of soybeans futures prices.

By and large, if the information of sunspots forms investors' disagreement in the soybeans futures market, the volatility of soybeans futures prices would be high. Consequently, this could help forecast futures market prices better. To test this hypothesis, the following section of this study conducts the econometric analysis. 


\subsection{Data and Methodological Approach}

\subsubsection{Data}

This study tests the disagreement on sunspots and soybeans futures prices by employing the monthly data from Dec. 1988 to Dec. 2018. Specifically, the sunspot activity data is available from several authorized organizations, including NASA (National Aeronautics and Space Administration), NOAA (National Oceanic and Atmospheric Administration). In this study, we use the data from WDC-SILSO (World Data Center- Sunspot Index and Long-term Solar Observations) for the reason that the WDC-SILSO, found in Royal Observatory of Belgium, Brussels, has recorded the longest period of solar activity, which spans four centuries. Specifically, we measure sunspot activity by the number of sunspots. The sunspot number is equal to $10 g+t$, where $g$ is the number of sunspot groups and $t$ is the total number of sunspots on the sun. This formula was introduced by Rudolf Wolf in 1849, so it is also named as Wolf Sunspot Number. Furthermore, we obtain the soybeans futures price data from CME Group Inc. (Chicago Mercantile Exchange \& Chicago Board of Trade), which is the world's leading and most diverse derivatives marketplace.

Table 3.1 reports the descriptive statistics of both sunspot activity and soybean prices, and Figure 3.1 shows their trends. Clearly, the price of soybeans is negatively correlated with sunspot activity. This is consistent with our common wisdom. More sunspot activities could lead to lower soybeans futures prices. Hence, more sunspot 
activities imply milder weather globally, which leads to better harvest and lower prices.

However, the effect of sunspots on the volatility of market prices cannot be simply inferred from Figure 3.1, while volatility is an important parameter for market risks related to hedging behavior. We hence employ the GARCH models to test it quantitatively.

\section{[Place Table 3.1 \& Figure 3.1 here]}

\subsubsection{Methodological Approach}

The theoretical framework reveals that if disagreement exists on the information of sunspots, it will lead to high volatility of soybeans futures prices. Considering the different assumption of volatility patterns, this study employs three econometric methods: the GARCH, GJR-GARCH, and Markov-switching GARCH models. Sunspots can affect not only the first-order moment of commodity prices (mean equation), but also the second-order moment (variance equation). That means, if there is disagreement on the sunspots information, on the one hand, the trade volume increases, which has been proved by Hong and Stein (2007), one the other hand, this could change the variance of the prices. We use several GARCH models to test our hypothesis.

- ARCH model 
Engle (1982) proposes the ARCH model (Autoregressive Conditional Heteroscedasticity), which is the pioneer of the GARCH model. The univariate ARCH model is specified as follows:

$$
\begin{gathered}
y_{t}=a_{0}+\sum_{i=1}^{q} a_{i} y_{t-i}+\varepsilon_{t} \\
\sigma_{t}^{2}=\alpha_{0}+\alpha_{1} \varepsilon_{t-1}^{2}+\alpha_{2} \varepsilon_{t-2}^{2}+\ldots+\alpha_{p} \varepsilon_{t-p}^{2}
\end{gathered}
$$

Where $y_{t}$ denotes the soybeans futures prices, $\varepsilon_{t}$ denotes the error terms of the mean equation, $\sigma_{t}$ denotes the time-dependent standard deviation of the soybeans futures prices. $\alpha_{i}$ are the coefficients for error terms.

\section{- GARCH model}

Based on the ARCH model, Bollerslev (1986) develops it to the Generalized ARCH model, that is, the GARCH model, which can be formulated by, i.e., GARCH (p, q):

$$
\sigma_{t}^{2}=\alpha_{0}+\alpha_{1} \varepsilon_{t-1}^{2}+\alpha_{2} \varepsilon_{t-2}^{2}+\ldots+\alpha_{p} \varepsilon_{t-q}^{2}+\beta_{1} \sigma_{t-1}^{2}+\beta_{2} \sigma_{t-2}^{2}+\ldots+\beta_{p} \sigma_{t-p}^{2}
$$

where $\beta_{i}$ are the coefficients for the variances.

In practice, the $\operatorname{GARCH}(1,1)$ is the most popular model in the time series analysis of the financial market. That is:

$$
\sigma_{t}^{2}=\alpha_{0}+\alpha_{1} \varepsilon_{t-1}^{2}+\beta_{1} \sigma_{t-1}^{2}
$$

The purpose of this study again is to test whether the information of sunspots has a significant effect on the volatility of soybeans futures prices. In this context, we hypothesize that the disagreement on sunspots information impacts price variance (See Section 3.3). Thus, we further develop the GARCH $(1,1)$ with an exogenous covariate of sunspots, we could have two specifications: 


$$
\sigma_{t}^{2}=\alpha_{0}+\alpha_{1} \varepsilon_{t-1}^{2}+\beta_{1} \sigma_{t-1}^{2}+\gamma \text { sunspot }
$$

(3.5a) is a linear specification which means that disagreement level is correlated with the level of sunspot activity.

$$
\sigma_{t}^{2}=\alpha_{0}+\alpha_{1} \varepsilon_{t-1}^{2}+\beta_{1} \sigma_{t-1}^{2}+\gamma \text { sunspot }+\theta \text { sunspot }^{2}
$$

This is a more generalized specification. It implies that the disagreement level is a nonlinear function of sunspots.

\section{- GJR-GARCH model}

Though the negative correlation between the shocks and the returns has been widely observed, the sign and the magnitude of the shocks might be asymmetric. Glosten, Jagannathan, and Runkle (1993) introduce a GARCH model (GJR-GARCH) which considers different effects of negative and positive shocks. Corresponding to Equation (3.4), (3.5a) and (3.5b), we have

$$
\sigma_{t}^{2}=\alpha_{0}+\left(\alpha_{1}+r_{1} I_{t-1}\right) \varepsilon_{t-1}^{2}+\beta_{1} \sigma_{t-1}^{2}
$$

and

$$
\sigma_{t}^{2}=\alpha_{0}+\left(\alpha_{1}+r_{1} I_{t-1}\right) \varepsilon_{t-1}^{2}+\beta_{1} \sigma_{t-1}^{2}+\gamma \text { sunspot }
$$

and

$$
\sigma_{t}^{2}=\alpha_{0}+\left(\alpha_{1}+r_{1} I_{t-1}\right) \varepsilon_{t-1}^{2}+\beta_{1} \sigma_{t-1}^{2}+\gamma \text { sunspot }+\theta \text { sunspot }^{2}
$$

where $I_{t-1}=1$ if $\varepsilon_{t-1} \leq 0 ; I_{t-1}=0$ if $\varepsilon_{t-1}>0$.

$I_{t-1}$ is an index function. Particularly, when the shock is negative, $I_{t-1}=1$, and its coefficient $r_{1}$ then captures asymmetric effect.

- Markov- switching GARCH model 
Recent studies find that when regime changes in the volatility dynamics, GARCH-type models might fail to capture the true variation of volatility (Bauwens, Backer, and Dufays 2014). In this case, Markov- switching GARCH model provides a solution to this problem, as it allows the parameters to vary over time. The conditional variance dynamics can be formulated as:

$$
h_{k, t}=h\left(y_{t-1}, h_{k, t-1}, \boldsymbol{\delta}_{k}\right)
$$

where $h(\bullet)$ defines the filter for the conditional variance and ensures it is positive, $y_{t-1}$ is the variable of interest at time $t-1, k$ denotes regimes, $h_{k, t-1}$ denotes past variance, and $\boldsymbol{\delta}_{k}$ is the regime-dependent vector of parameters. Similarly, in order to capture the impact of sunspots, we have

$$
\begin{aligned}
& h_{k, t}=h\left(y_{t-1}, h_{k, t-1}, \boldsymbol{\delta}_{k}\right)+\gamma_{k} \text { sunspot }
\end{aligned}
$$

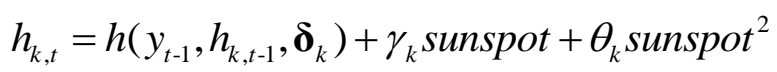

\subsection{Empirical Results and Discussion}

\subsubsection{Stationarity and ARCH Effect Tests}

Before estimating GARCH models with exogenous covariates, it is necessary to test the stationary of soybeans futures prices as well as the ARCH effect. Table 3.2 reports the Augmented Dickey-Fuller tests for unit root. The values of the test statistic are statistically significant at 5\% regardless of considering structural breaks or not, indicating that soybeans futures prices variable is stationary. 
We also tested the ARCH effect, which is also reported in Table 3.2. The result of the LM test is statistically significant at 5\%, rejecting the null hypothesis of no ARCH effect. It implies that ARCH or GARCH is legitimate.

\section{[Place Table 3.2 here]}

\subsubsection{GARCH $(1,1)$ Results}

Table 3.3 reports the estimated results of the $\mathrm{GARCH}(1,1)$ with an exogenous covariate (sunspots). GARCH $(1,1)$ is the simplest but a powerful model and often outperforms other sophisticated models. Hansen and Lunde (2005) compare 330 ARCH-type models in terms of their ability to describe the conditional variance using DM- $\$$ exchange rate, which turns out that there is no evidence that a GARCH $(1,1)$ is outperformed by more sophisticated models. Miah and Rahman (2016) also find that GARCH $(1,1)$ outperforms other GARCH $(p, q)$ models in modeling volatility of USE returns.

Table 3.3 reports three different models for the sake of comparison. Model (1) is an estimation of GARCH $(1,1)$ without considering sunspots information (Equation 4). The coefficients of the ARCH term and the GARCH term are both statistically significant at $1 \%$, implying that $\mathrm{ARCH}$ and $\mathrm{GARCH}$ effects exist in the volatility of soybeans futures prices. Specifically, the coefficients of the ARCH term and GARCH term are 0.225 and 0.745 , respectively. Summing up the two effects, it is equal to 0.970, which means that the past shock has a long-term impact on the future conditional variance of soybeans futures prices. 
After adding the information of sunspots, we re-estimate the GARCH $(1,1)$ with an exogenous covariate. The estimation result of Equation (3.5a) (Model 2 in Table 3.3) shows that the ARCH and GARCH effects are both significant. Importantly, the coefficient of sunspots is -0.009 and statistically significant at $1 \%$. That is, traders' disagreement levels on sunspot activities are diminishing as sunspot activity levels increase. As a potential explanation for this, traders might have a relatively high disagreement on the impact of low-level sunspot activity on market prices but might agree to a greater extent with the impact on high-level sunspot activity. Besides, the results of the mean function of Model (2) suggest that the soybeans futures prices are decreasing as sunspot activity levels increase (the coefficient is -0.0354). When the activity of sunspots is low, it is correlated with low global temperature. Low temperature is often linked to low harvest and high prices of food products. However, the degree of low solar activity might be disagreed by traders, so that high market volatility can be observed.

Yet considering the disagreement levels is a nonlinear function of sunspots, we further estimate the Equation (3.5b). Using the Likelihood-ratio test to compare Model (2) and Model (3), the result is not statistically significant, which means that the nonlinear form would not necessarily outperform the linear one. However, the second-order term is statistically significant. It may result from different regimes in this data so that a Markov-switching GARCH will be used later.

[Place Table 3.3 here] 


\subsubsection{GJR-GARCH Results}

The shocks might be asymmetric so that we use GJR-GARCH, which captures the asymmetric effect. Table 3.4 reports the results of Equation (3.6), (3.6a), and (3.6b).

First, we look at the threshold effect $\left(r_{1}\right)$, which captures the asymmetric effect as well. The estimation for $r_{1}$ is statistically significant in all three models. It confirms asymmetric shocks in the variance equation. That is, GJR-GARCH performs better than the ordinary GARCH $(1,1)$ model.

The coefficients for both first-order and second-order terms of sunspots are not statistically significant in Equation (3.6b). Besides, the LR test between Equations (3.6a) and (3.6b) is not statistically significant as well. We hence believe that Equation (3.6a) is the best model. The following discussion is based on the results of Equation (3.6a) (Model 2 in Table 3.4).

Consistent with the results of Equation (3.5a), sunspots could significantly decrease both the mean and variance of soybeans futures prices. When the activity of sunspots is low, the weather condition is not good. Though the mean prices could be high, the disagreement on the information is also high. It leads to high volatility of prices. Still, the second-order term of sunspots in Model 3 of Table 3.4 is marginally significant (at 10\%). Once again, it shows that there are different regimes in the GARCH process. Hence, we further use a Markov-switching GARCH to test it.

[Place Table 3.4 here] 


\subsubsection{Markov-switching GARCH Results}

Previous results indicate that GJR-GARCH performs better than the ordinary GARCH $(1,1)$ model. Therefore, we define the conditional variance specification as GJR-GARCH, that is

$$
h_{k, t}=\alpha_{o, k}+\left(\alpha_{1, k}+\alpha_{2, k} I_{t-1}\right) y_{t-1}^{2}+\beta_{k} h_{k, t-1}
$$

Table 3.5 shows the results of the double-regime model. It is clear that the estimated parameters are different between regime 1 and regime 2. Specifically, the volatility of regime 1 is lower than regime 2 , as the value $\alpha_{01}+\alpha_{11}$ is smaller than $\alpha_{02}+\alpha_{12}$. This confirms the regime changes in the volatility dynamics of soybeans futures prices. Specifically, the probability of the first regime is 0.6618 , and the second one is 0.3382 .

In light of this, we analyze the effect of sunspots on soybeans futures prices under different volatility regimes. The LR test of regime 1 suggests that the linear form outperforms the non-linear form, while the result of regimes 2 finds that the non-linear form would be better. Thus, we can find that, in the low volatility regime (regime 1), sunspots could significantly decrease the variance of soybeans futures prices. However, in the high volatility regime (regime 2), the impact of sunspots is more complicated. Specifically, the disagreement of traders is high under both low and high sunspot activity. It is reasonable that the higher the volatility, the more traders believe the soybeans futures prices will move, especially under the information of extreme sunspot activity.

\section{[Place Table 3.5 here]}




\subsubsection{Discussion of Economic Mechanism}

Soybean is an important agricultural commodity traded in the global market, as it provides an important source of protein as a food for humans and as a feed for livestock. High price volatility would cause welfare loss for both farmers and consumers (Bellemare, Barrett, and Just 2013). The empirical results highlight the effect of sunspots information on the volatility of soybeans futures prices. Based on the disagreement theory, the underlying mechanism of this phenomenon is that the disagreements exist on the information of sunspot activity among investors of the soybeans futures market. When the sunspots are in normal status, the weather would be mild for soybean production, and the disagreement on the effects would be small. When the sunspot activities are in an extreme status, either extremely low or extremely high, the disagreement would be high as well.

Generally, there are three main channels that can link the sunspots information to market price volatility. First, the information of sunspots flows gradually in the soybeans futures market. If the information of sunspots is positive for soybeans futures prices, investors who capture the information earlier will increase the valuation of soybeans futures prices while the others would maintain the valuation, resulting in the volatility of soybeans futures prices due to disagreement. Second, some investors of the soybeans futures market pay limited attention to the information of sunspots activity, while others pay much attention. It also could cause the volatility of soybeans futures prices due to the disagreement. Third, investors of the soybeans futures market have heterogeneous interpretations on the information of sunspot 
activity, as the information is quite complicated, and investors have different risk preferences. Hence, the heterogeneous interpretation would certainly increase the volatility of soybeans futures prices.

These three channels function simultaneously in the market, and the disagreement increases in extreme cases, so do the price volatility.

\subsection{Robustness check}

As we find above that, in general, low sunspot activity links to both high soybeans price and high volatility. There are a few methods in finance to measure market volatility. We use two prevalent measures here to check the robustness of our results: realized volatility and historical volatility. With the use of monthly data, we obtain annual volatility measures ${ }^{16}$. Figures 3.2 and 3.3 show their relationships with the sunspots.

\section{[Place Figure 3.2 \& Figure 3.3 here]}

Table 3.6 reports simple regression results of volatility on sunspots. We confirm that sunspot activity is negatively correlated with market volatility both in the equation of realized volatility and historical volatility functions, and the results are $10 \%$ statistically significant. However, we cannot confirm any nonlinear relationship between them ${ }^{17}$, perhaps due to different regimes in the GARCH process.

\section{[Place Table 3.6 here]}

\footnotetext{
${ }^{16}$ We use 12 months to calculate the realized and historical volatilities. The aggregation of monthly data may lose some properties of price volatility.

${ }^{17}$ However, the regressions do not consider time series properties.
} 
Overall, these results are consistent with the GARCH, GJR-GARCH, and Markov-switching GARCH results in Section 3.5. It evidences the robustness of our results.

\subsection{Conclusions}

Food price volatilities could lead to significant welfare loss for both farmers and consumers, and sunspots are regarded as a fundamental driving factor behind the volatility. Different from the existing literature, from the perspective of behavioral finance, this study uses disagreement theory to analyze how the information of sunspots affects the volatility of soybeans futures prices. Moreover, we use the GARCH, GJR-GARCH, and Markov-switching GARCH model with exogenous covariates to test the theoretical hypothesis empirically. Generally, the three models are consistent regarding the results of sunspot shocks. Low sunspots are linked to both high price and high price volatility for soybeans. Low temperature is often linked to low harvest and high prices of food products. However, the degree of low solar activity might be disagreed by traders, so that high market volatility can be observed.

This study shows that, theoretically, the information of sunspots causes disagreement in the soybeans futures market mainly by three channels: gradual information flow, limited attention, and heterogeneous priors, which would finally lead to the volatility of soybeans futures prices. Using time series monthly data from Dec. 1988 to Dec. 2018, the empirical study finds low sunspot activities are linked to both high soybean prices and price volatility. Particularly, the price variances are 
negatively correlated with sunspots level. It implies that traders particularly have a high disagreement on the impact of extremely low sunspot activity on market prices. In addition, the disagreement level is nonlinear in the high volatility regime. That is, traders have a high disagreement on both extremely low and high sunspot activity. This study hence provides evidence that the information of sunspots leads to disagreement levels on the impacts, shaping the investors' trading behaviors in the soybeans futures market.

Disagreement theory provides a new perspective to analyze the influence of sunspots, especially in the field of behavioral finance. Furthermore, the theoretical and empirical findings are of potential interest to traders and policymakers. This study could help better understand the mechanism of soybeans futures price volatility from a theoretical perspective and better forecast market prices from an empirical perspective with considering sunspots shocks. A better forecast of market price could help traders make better investment strategies, and help governments make better food security policies. 


\section{Tables}

Table 3.1 Descriptive Statistics

\begin{tabular}{|c|c|c|c|c|c|}
\hline Variables & Obs & Mean & S.D. & Min & Max \\
\hline Soybeans Price & 360 & 336.055 & 119.134 & 183 & 684 \\
\hline Sunspots & 360 & 82.088 & 67.729 & 0 & 284.5 \\
\hline
\end{tabular}

Table 3.2 Test Results for Stationarity

\begin{tabular}{|c|c|c|}
\hline \multicolumn{3}{|c|}{ Test 1: Unit Root Test } \\
\hline \multirow{2}{*}{ unit root without break test } & \multicolumn{2}{|c|}{ unit root with break test } \\
\hline & Type1: Innovational Outlier & Type 2: Additive Outlier \\
\hline$-1.964^{*}$ & $-4.498^{*}$ & $-4.488^{*}$ \\
\hline Test 2: LM test for ARCH & \multicolumn{2}{|c|}{$6.399^{*}$} \\
\hline
\end{tabular}

Note: $* *$ and $*$ denote $1 \%$ and $5 \%$ statistical significance, respectively.

Table 3.3 Estimation Results for $\operatorname{GARCH}(1,1)$

\begin{tabular}{|c|c|c|c|c|c|c|}
\hline \multirow[t]{2}{*}{ Variables } & \multicolumn{2}{|c|}{$\begin{array}{l}\text { Model } 1 \\
\text { (Eq. 3.4) }\end{array}$} & \multicolumn{2}{|c|}{$\begin{array}{l}\text { Model } 2 \\
\text { (Eq. 3.5a) }\end{array}$} & \multicolumn{2}{|c|}{$\begin{array}{l}\text { Model } 3 \\
\text { (Eq. 3.5b) }\end{array}$} \\
\hline & Coefficient & Z-value & Coefficient & Z-value & Coefficient & Z-value \\
\hline \multicolumn{7}{|c|}{ Mean Function } \\
\hline 1.price & $0.9741^{* *}$ & 148.51 & $0.9567^{* *}$ & 142.98 & $0.9592^{* *}$ & 131.04 \\
\hline Sunspot & & & $-0.0354^{* *}$ & -3.42 & $-0.0330^{* *}$ & -3.66 \\
\hline Constant & $6.9293^{* *}$ & 3.05 & $15.8722^{* *}$ & 5.48 & $14.9388^{* *}$ & 4.86 \\
\hline \multicolumn{7}{|c|}{ Variance Function } \\
\hline $\operatorname{ARCH}\left(\alpha_{1}\right)$ & $0.225^{* *}$ & 4.86 & $0.241^{\text {*** }}$ & 4.46 & $0.2328^{* *}$ & 4.21 \\
\hline $\operatorname{GARCH}\left(\beta_{1}\right)$ & $0.745^{* *}$ & 16.97 & $0.693^{* *}$ & 12.93 & $0.7057^{* *}$ & 12.59 \\
\hline $\operatorname{Sunspot}(\gamma)$ & & & $-0.009^{* *}$ & -3.34 & 0.0120 & 1.33 \\
\hline $\operatorname{Sunspot}^{2}(\theta)$ & & & & & $-0.0001^{*}$ & -2.20 \\
\hline Constant & $16.873^{* *}$ & 4.00 & $3.929^{* *}$ & 13.10 & $3.3102^{* *}$ & 7.35 \\
\hline Distribution & \multicolumn{2}{|c|}{ Gaussian } & \multicolumn{2}{|c|}{ Gaussian } & \multicolumn{2}{|c|}{ Gaussian } \\
\hline Observations & \multicolumn{2}{|c|}{360} & \multicolumn{2}{|c|}{360} & \multicolumn{2}{|c|}{360} \\
\hline LR-Test & \multicolumn{2}{|c|}{----} & \multicolumn{4}{|c|}{3.33} \\
\hline
\end{tabular}

Note: $* *$ and $*$ denote $1 \%$ and $5 \%$ statistical significance, respectively. 
Table 3.4 Estimation Results of GJR-GARCH

\begin{tabular}{|c|c|c|c|c|c|c|}
\hline \multirow[t]{2}{*}{ Variables } & \multicolumn{2}{|c|}{$\begin{array}{l}\text { Model } 1 \\
\text { (Eq. 3.6) }\end{array}$} & \multicolumn{2}{|c|}{$\begin{array}{l}\text { Model } 2 \\
\text { (Eq. 3.6a) }\end{array}$} & \multicolumn{2}{|c|}{$\begin{array}{l}\text { Model } 3 \\
\text { (Eq. 3.6b) }\end{array}$} \\
\hline & Coefficient & Z-value & Coefficient & Z-value & Coefficient & Z-value \\
\hline \multicolumn{7}{|c|}{ Mean Function } \\
\hline 1.price & $0.9759^{* *}$ & 135.88 & $0.9640^{* *}$ & 114.48 & $0.9639^{* *}$ & 109.63 \\
\hline Sunspot & & & $-0.0311^{* *}$ & -3.02 & $-0.0301^{* * *}$ & -3.08 \\
\hline Constant & $7.4322^{* *}$ & 3.69 & $14.2472^{* *}$ & 4.67 & $14.1768^{* *}$ & 4.42 \\
\hline \multicolumn{7}{|c|}{ Variance Function } \\
\hline $\operatorname{ARCH}\left(\alpha_{1}\right)$ & -0.0236 & -1.67 & -0.0161 & -0.96 & -0.0127 & -0.76 \\
\hline $\operatorname{GARCH}\left(\beta_{1}\right)$ & $0.8318^{* *}$ & 26.3 & $0.8077^{* *}$ & 22.98 & $0.8091^{* * *}$ & 23.8 \\
\hline TARCH $\left(r_{1}\right)$ & $0.3261^{* *}$ & 5.21 & $0.3094^{* *}$ & 5.02 & $0.3110^{* *}$ & 4.83 \\
\hline $\operatorname{Sunspot}(\gamma)$ & & & $-0.0072^{* *}$ & -2.77 & 0.0077 & 0.86 \\
\hline $\operatorname{Sunspot}^{2}(\theta)$ & & & & & -0.0001 & -1.73 \\
\hline Constant & $10.7305^{* *}$ & 4.23 & $3.3741^{* *}$ & 11.02 & $2.8476^{* *}$ & 5.56 \\
\hline Distribution & \multicolumn{2}{|c|}{ Gaussian } & \multicolumn{2}{|c|}{ Gaussian } & \multicolumn{2}{|c|}{ Gaussian } \\
\hline Observations & \multicolumn{2}{|c|}{360} & \multicolumn{2}{|c|}{360} & \multicolumn{2}{|c|}{360} \\
\hline LR-Test & \multicolumn{2}{|c|}{--.- } & \multicolumn{4}{|c|}{2.13} \\
\hline
\end{tabular}

Note: $* *$ and $*$ denote $1 \%$ and $5 \%$ statistical significance, respectively. 
Table 3.5 Estimation Results of Markov-switching GARCH

\begin{tabular}{|c|c|c|}
\hline Variables & \multicolumn{2}{|c|}{ Coefficient } \\
\hline$\alpha_{01}$ & \multicolumn{2}{|c|}{$\begin{array}{c}0.0001^{* * * *} \\
(8.87)\end{array}$} \\
\hline$y_{t-1}^{2}\left(\alpha_{11}\right)$ & \multicolumn{2}{|c|}{$\begin{array}{c}0.0041^{* * * *} \\
(4.99)\end{array}$} \\
\hline$I_{t-1} y_{t-1}^{2}\left(\alpha_{21}\right)$ & \multicolumn{2}{|c|}{$(5.00)$} \\
\hline$h_{1, t-1}\left(\beta_{1}\right)$ & \multicolumn{2}{|c|}{$\begin{array}{c}0.4357^{* * *} \\
(3.67)\end{array}$} \\
\hline$\alpha_{02}$ & \multicolumn{2}{|c|}{$\begin{array}{c}0.0002^{* *} \\
(2.19)\end{array}$} \\
\hline$y_{t-1}^{2}\left(\alpha_{12}\right)$ & \multicolumn{2}{|c|}{$\begin{array}{c}0.2060^{\text {**** }} \\
(4.49)\end{array}$} \\
\hline$I_{t-1} y_{t-1}^{2}\left(\alpha_{22}\right)$ & \multicolumn{2}{|c|}{$\begin{array}{c}0.0003 \\
(1.08)\end{array}$} \\
\hline$h_{2, t-1}\left(\beta_{2}\right)$ & \multicolumn{2}{|c|}{$\begin{array}{c}0.7239^{* * * *} \\
(5.07)\end{array}$} \\
\hline \multicolumn{3}{|c|}{ Regime 1} \\
\hline $\operatorname{Sunspot}\left(\gamma_{1}\right)$ & $\begin{array}{c}-0.0001^{* * *} \\
(-3.10)\end{array}$ & $\begin{array}{l}-0.0001 \\
(-1.22) \\
\end{array}$ \\
\hline $\operatorname{Sunspot}^{2}\left(\theta_{1}\right)$ & --- & $\begin{array}{c}0.0000 \\
(0.39)\end{array}$ \\
\hline LR-test & \multicolumn{2}{|c|}{0.16} \\
\hline Probability for Regime 1 & \multicolumn{2}{|c|}{0.6618} \\
\hline \multicolumn{3}{|c|}{ Regime 2} \\
\hline $\operatorname{Sunspot}\left(\gamma_{2}\right)$ & $\begin{array}{c}-0.0001 \\
(-1.59)\end{array}$ & $\begin{array}{c}-0.0002^{* * *} \\
(-3.94)\end{array}$ \\
\hline $\operatorname{Sunspot}^{2}\left(\theta_{2}\right)$ & & $\begin{array}{c}0.0001^{\text {**** }} \\
(3.61)\end{array}$ \\
\hline LR-test & \multicolumn{2}{|c|}{$12.71^{* * * *}$} \\
\hline Probability for Regime 2 & \multicolumn{2}{|c|}{0.3382} \\
\hline
\end{tabular}

Note: $* * *, * *$, and $*$ denote $1 \%, 5 \%$ and $10 \%$ statistical significance, respectively. The numbers in parentheses are t-values. 
Table 3.6 Robustness Check between Sunspots and Volatility

\begin{tabular}{|c|c|c|c|c|c|c|c|c|}
\hline & \multicolumn{4}{|c|}{ Realized Volatility } & \multicolumn{4}{|c|}{ Historical Volatility } \\
\hline & \multicolumn{2}{|c|}{ Model 1} & \multicolumn{2}{|c|}{ Model 2} & \multicolumn{2}{|c|}{ Model 3} & \multicolumn{2}{|c|}{ Model 4} \\
\hline & Coefficient & t-value & Coefficient & t-value & Coefficient & t-value & Coefficient & t-value \\
\hline Sunspots & -0.0001 & -0.29 & -0.0001 & $-1.74^{*}$ & -11.9827 & -0.66 & -7.1199 & $-1.86^{*}$ \\
\hline Sunspots $^{2}$ & 0.0000 & -0.10 & & & 0.0242 & 0.32 & & \\
\hline Intercept & 0.0806 & $5.75^{* * *}$ & 0.0814 & $9.29^{* * *}$ & 1769.2440 & $2.04^{* *}$ & 1631.4760 & $3.12^{* * *}$ \\
\hline
\end{tabular}

Note: $* * *, * *$, and $*$ denote $1 \%, 5 \%$ and $10 \%$ statistical significance, respectively. 


\section{Figures}

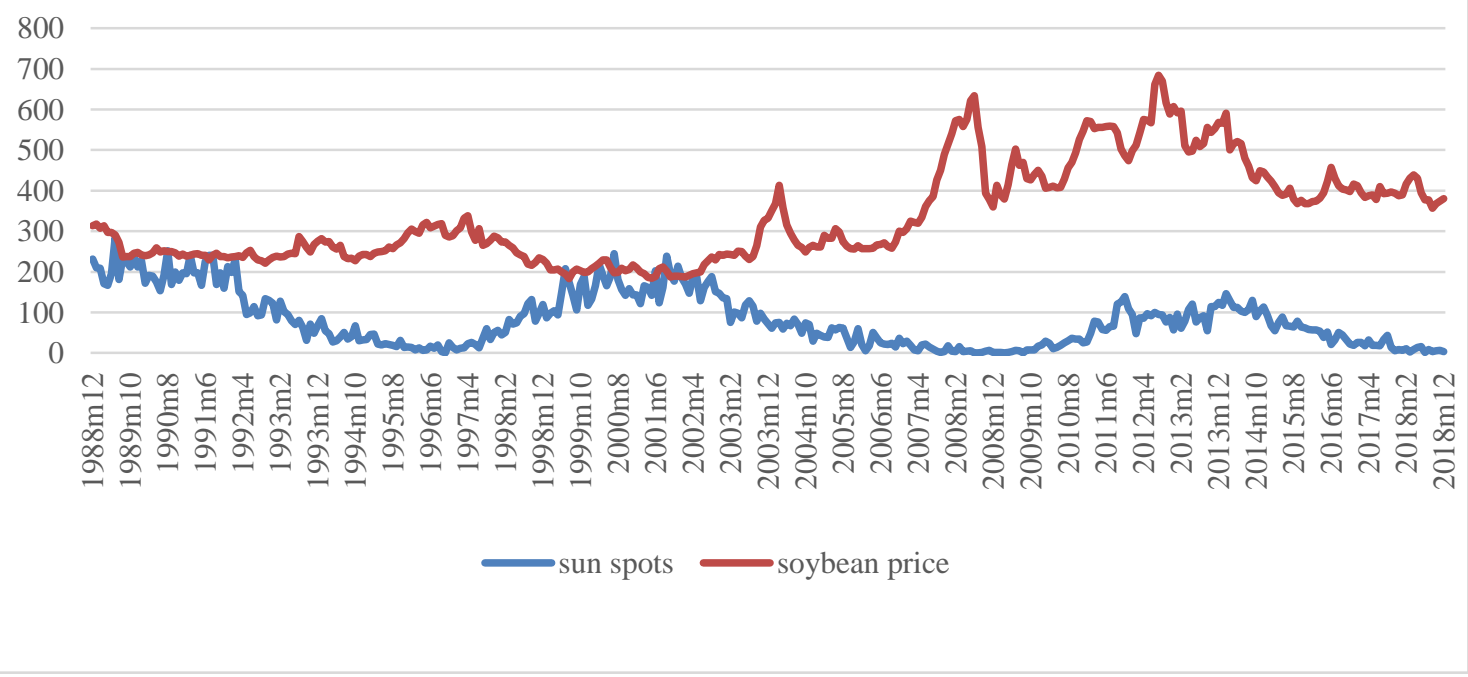

Figure 3.1 Sunspots and Soybean Prices

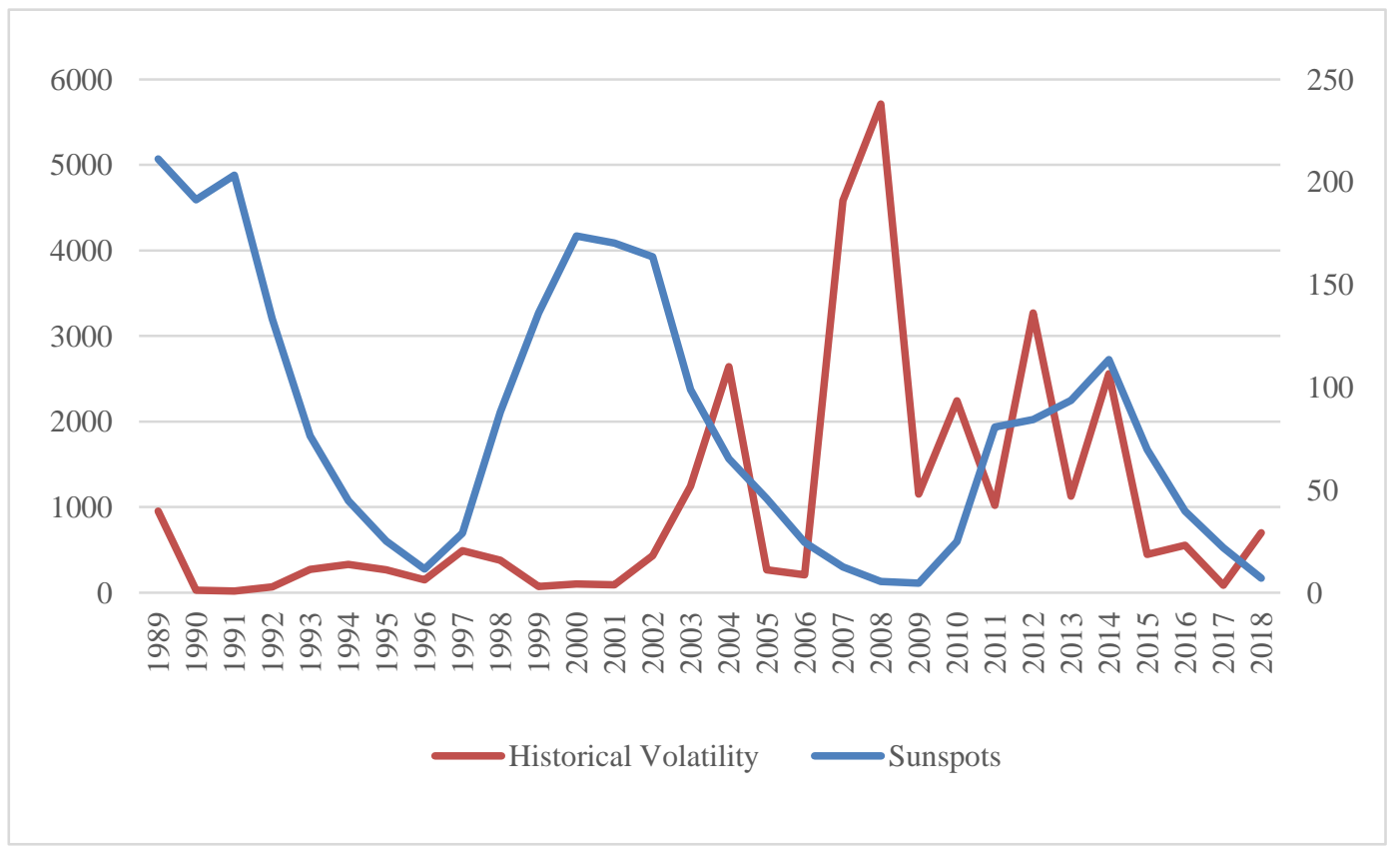

Figure 3.2 Historical Volatility and Sunspots 


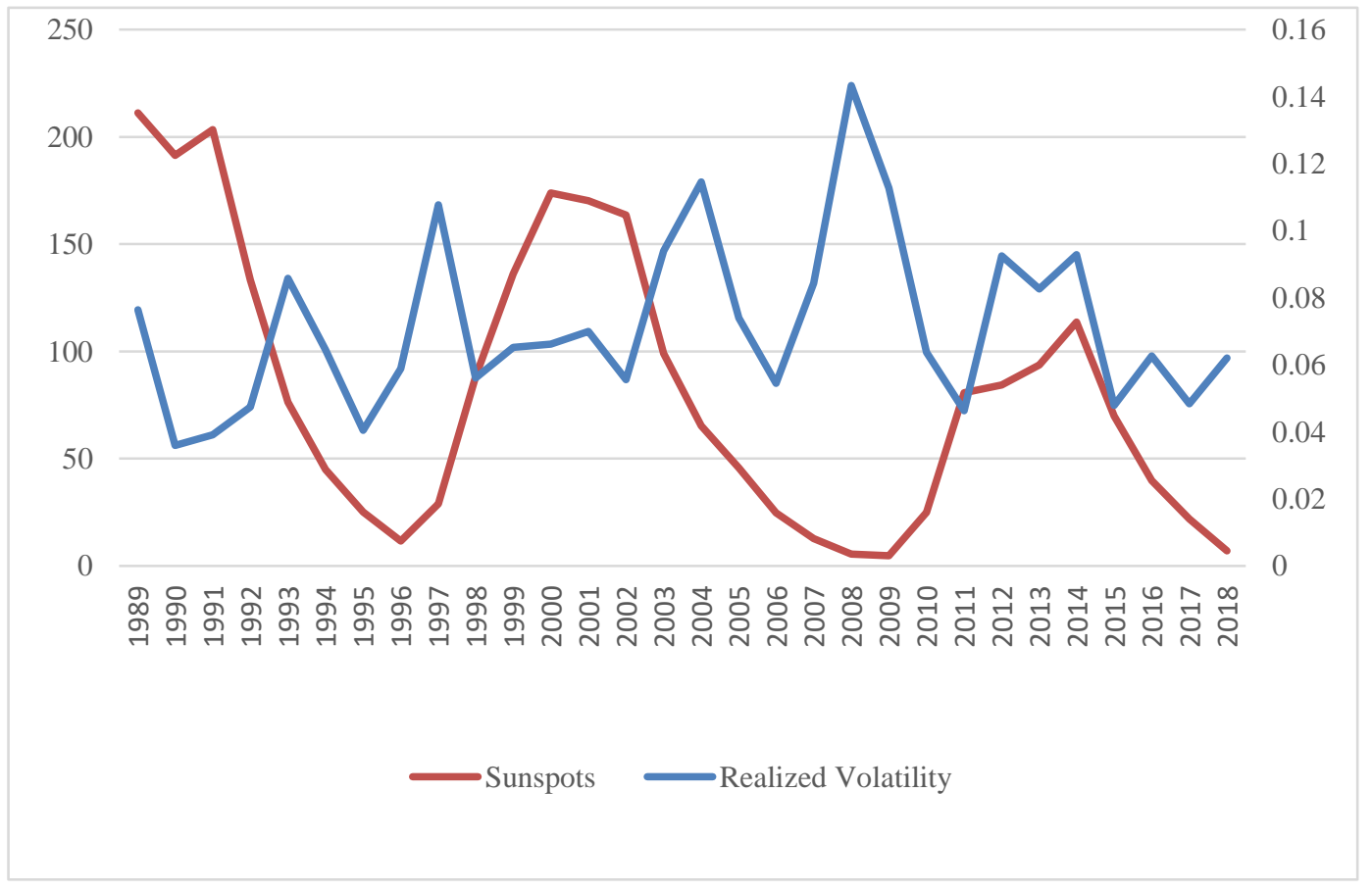

Figure 3.3 Realized Volatility and Sunspots 


\section{Chapter 4 Climate Change and Agricultural Trade in Central Asia: Evidence from Kazakhstan ${ }^{18}$}

Abstract: International agricultural trade is a potential adaption to climate change. However, little attention has been paid to the impact of climate change on cereal trade in Central Asia. This study takes Kazakhstan as an example to empirically analyze the impact of climate change on cereal trade by including them as determinants in the gravity model. Our results show that climate changes in Kazakhstan, measured by precipitation and temperature, could increase the export of wheat and rice and the import of maize, and decrease the import of wheat. Specifically, as a major crop in Kazakhstan, increasing precipitation by 1 millimeter during the major cropping season from May to August, will significantly enhance export of wheat by $0.7 \%$ and reduce the import by $1.7 \%$; increasing temperature by $1{ }^{\circ} \mathrm{C}$ during the same cropping season will significantly increase export of wheat by $21.9 \%$ and reduce the import by $49.4 \%$. As an important cereal trade country in the world, the dramatic adjustments of cereal trade patterns resulting from climate change in Kazakhstan might affect global food security.

Keywords: climate change, cereal trade, adaptation, gravity model, Kazakhstan

JEL: Q54, Q17, F18

\footnotetext{
18 This chapter has been published in Ecosystem Health and Sustainability. I contributed to the data collection and empirical analysis, and took the lead in writing the manuscript under the guidance of Prof. Yu. All authors provided critical feedback and contributed to the research.

Yu, X., Luo, H., Wang, H. (Corresponding Author), \& Feil, J. H. (2020). Climate change and agricultural trade in central Asia: evidence from Kazakhstan. Ecosystem Health and Sustainability, 6(1), 1766380. https://doi.org/10.1080/20964129.2020.1766380
} 


\subsection{Introduction}

It is widely known that climate plays a vital role in agricultural production (Brown and Funk 2008; Crost et al. 2018; Holst et al. 2013). According to the OECD-FAO Agricultural Outlook (2016-2025), the global cereal use will grow by $14 \%$, reaching 2818 Mt by 2025 . Given the fundamental function of agriculture in food security, there is a growing concern on the potential impact of climate change on agricultural productivity (Adams et al. 1998; Olesen and Bindi 2002; Baldos et al. 2014). Specifically, climate change would undoubtedly change the natural conditions of crop growth, such as temperature and precipitation (Rosenzweig and Parry 1994; Huang et al. 2011; Zhang, Zhang, and Chen 2017). To project the impact of climate change on crop yield scientifically, a series of crop-simulation models, including the SOYGRO model, the CERES-wheat model, and the CERES-maize model, are well-developed (Raj, Shekhar, and Mani 2010; Ahmed et al. 2016). In general, the mainstream findings have not reached a general conclusion on the impact of climate change on agricultural production, which is the primary determinant of trade.

Central Asia, an important partner of the Belt and Road Initiative (BRI), its agriculture development faces tremendous challenges of climate change. Although agriculture sector is one of the most important sectors of the five Central Asian countries $^{19}$, accounting for $10 \%$ to $45 \%$ of their GDP, employing $20 \%$ to $50 \%$ of total employment (Hamidov 2016), the natural environment of Central Asia might not be ideal for agricultural production. Explicitly, most of the farming land in Central Asia

\footnotetext{
${ }^{19}$ It refers to Kazakhstan, Kyrgyzstan, Tajikistan, Turkmenistan, and Uzbekistan.
} 
is desert. For example, the share of deserts of Turkmenistan and Uzbekistan is up to $80-90 \%$. Likewise, the shortage of water for agricultural production is a critical challenge in Central Asia. According to the estimation of the European Parliamentary Research Service, four of the five Central Asian countries are under water-stress ${ }^{20}$. In particular, most of the agricultural land of Kazakhstan, nearly 35 million hectares, is rain-fed, while only 6\% is irrigated (Mizina et al. 1999). This makes agricultural production in Central Asia vulnerable to climate change. Consequently, climate change would undoubtedly increase natural risk and uncertainty in agriculture sectors. Using SRES scenarios from IPCCAR4, 23 models, the Intergovernmental Panel on Climate Change (IPCC) points out that projected increases in temperature could exacerbate the water shortage in Central $\mathrm{Asia}^{21}$. Thus, how to cope with climate change is the priority of policy agenda in Central Asia.

Theoretically, adaption is one of the effective approaches that respond to climate change in the agriculture sector (Chen et al. 2015). Extensive studies show that climate change would be problematic for agricultural production without adaption, while the vulnerability of agricultural production could be alleviated with adaption (Mendelsohn et al. 1994; Wheaton and Maciver 1999; Burk and Emerick 2016). In practice, numerous agricultural adaptation options coping with climate change have been proposed, ranging from technical, financial, political, and also managerial approaches (Chen et al. 2015, Schwan and Yu 2018). For example, the U.S. has undertaken several new agricultural adaptive approaches, such as the development of

\footnotetext{
20 Source: www.europarl.europa.eu

21 Source: www.ipcc.ch
} 
resilient agricultural production systems, the connection between climate knowledge and decision-making by farmers, and technical advisors (Walthall et al. 2013). Schwan and Yu (2017) find that migration is another adaptive strategy for climate change. However, the five Central Asian countries, all developing countries, are more vulnerable to climate change, as they lack financial and technical capability coping with increased variability (Barrios et al. 2008; Kahsay and Hansen 2016).

While a large body of literature generally discusses a series of adaptations, only a few studies evaluate the potential of international agriculture trade. Huang et al. (2011) point out that a well-functioning agriculture trade system could be a supportive adaptation to climate change. Although the impact of climate change on agricultural production is significant, it varies among different regions. Generally, the consensus is that low latitudes, tropical regions, facing extreme temperatures, would experience a reduction of crop yield. Such a scenario, international agriculture trade, accompanying the transfer of virtual water, could be an effective adaptation to reduce climate-induced environmental stress (Konar et al. 2011). Nevertheless, international agriculture trade would also increase climate-induced vulnerability, as some regions are specialized in producing certain agricultural products in which they have a comparative advantage (Ouraich et al. 2018).

Although a few studies have realized the potential adaptation of agriculture trade, to the best of our knowledge, far too little attention has been paid to the impact of climate change on cereal trade in Central Asia. Given the importance of the potential adaptation of international agriculture trade, it is necessary to understand how climate 
change affects the agriculture trade patterns in Central Asia. Particularly, agriculture plays an essential role in their livelihood, but food production particularly suffered from political and economic turmoil after the collapse of the Soviet Union even though these countries traditionally had a favorable endowment of natural resources and well-organized facilities for agricultural production. How to incorporate themselves into the global food trade system, particularly after the transition from a planned economy to a market system, has not been well studied.

Thus, the main contribution of this study is that we use the gravity model, a widely used trade model in the field of international trade (Hasiner and Yu 2019), to empirically reveal the relationship between climate change and cereal trade, which provide the empirical evidence for the impact of climate change on cereal trade. Furthermore, Kazakhstan, a dominant economy in Central Asia, more than $70 \%$ of its land is occupied by agriculture, and its agricultural trade ranks first among the five Central Asian countries, though the share of agriculture in total GDP is only 5\%. This study hence takes Kazakhstan as an example to analyze how climate change affects cereal trade in Central Asia.

\subsection{Background: Cereal trade and climate change in Kazakhstan}

Cereal is one of the most important agricultural products in Kazakhstan. According to the Ministry of Agriculture of Kazakhstan, the total crop area is up to 19 million hectares, in which cereal crops occupy 14.5 million hectares. The country's major cereal crops include wheat, rice, and maize. In particular, wheat production is 
officially estimated at 14 million tonnes, accounting for $70 \%$ of the total cereal production $^{22}$. In terms of cereal trade, Kazakhstan, a major global wheat producer, exports cereal products to over 70 countries, ranked in the top 10 grain exporters. For instance, in 2018, wheat exports of Kazakhstan were valued at $\$ 965.4$ million, accounting for $2.3 \%$ of the global total.

Nevertheless, sustainable cereal productivity in Kazakhstan is increasingly challenged by climate change, which might affect cereal trade. According to the UNDP, nearly $75 \%$ of the territory in Kazakhstan is under high-risk ecological destabilization. Additionally, the country's agricultural production is facing a series of climate change risks, including water shortage, increased aridity, and also extreme weather events. Worse still, climate trends in Kazakhstan are expected to exacerbate these risks. For instance, the temperature rose approximately by $2^{\circ} \mathrm{C}$ from 1936 to 2005 in Kazakhstan, double the global average. Since 2000, the temperature increased by $0.31{ }^{\circ} \mathrm{C}$ in ten years ${ }^{23}$. Moreover, heavy precipitation and redistribution of precipitation also contribute to the vulnerability of agriculture in Kazakhstan, though it is possible that increasing precipitation could somehow benefit agricultural production.

Considering the vital role of wheat exports in Kazakhstan, we show the trend of wheat production, wheat trade, and climate change. In particular, climate change related to cereal production in this study mainly refers to the change of precipitation and temperature. Figure 4.1 depicts the trends of precipitation, wheat production, and

\footnotetext{
${ }^{22}$ Source: FAO, Global Information and Early Warning System (GIEWS).

${ }^{23} \mathrm{https}$ ://www.adaptation-undp.org/explore/central-asia/kazakhstan
} 
wheat exports in Kazakhstan from 2001 to 2017, while Figure 4.2 captures the trends of temperature, wheat production, and wheat exports. It is clear that wheat production and exports show similar trends with the variation of precipitation. However, the relationship between temperature, wheat production, and wheat exports is rather complicated as it manifests both positive and negative correlations. It is possible that crop yields have a non-linear relationship with temperature (Holst, Yu, and Gruen 2013). Figures 4.1 and 4.2 cannot mirror the accurate quantitative relationship between them, which will be studied by the gravity model in the rest of the study.

\section{[Place Figure 4.1 \& Figure 4.2 here]}

\subsection{Data and Descriptive Statistics}

To empirically reveal the impact of climate change on cereal trade in Kazakhstan, this study employs a panel dataset of 158 countries from 2001 to 2017. As discussed above, the major cereals produced in Kazakhstan mainly include wheat, rice, and maize. For this reason, we define the cereal trade as imports and exports of wheat, rice, and maize, which come from the FAO (Food and Agriculture Organization of the United Nations) database ${ }^{24}$.

Regarding climate variables in Kazakhstan, we use the following two proxies in this study: precipitation and temperature. It is widely admitted that water and temperature are the necessary conditions for cereal production (Holst et al. 2013). Specifically, the precipitation data, measured by millimeter per hour $(\mathrm{mm} / \mathrm{hr})$, is available from the GPM (Global Precipitation Measurement) data products. The GPM,

\footnotetext{
${ }^{24}$ Source: http://www.fao.org/faostat/en/\#data/TM
} 
an international network of satellites initiated by NASA (the National Aeronautics and Space Administration) and JAXA (the Japan Aerospace Exploration Agency), provides the global observations of raining. The "Core" satellite of GPM carries advanced radar (radiometer system), having the extended capability to measure light rain $(<0.5 \mathrm{~mm} / \mathrm{hr})$. Besides, the temperature data, defined as land surface temperature, is obtained from the MERRA2 (the second Modern-Era Retrospective analysis for Research and Applications). The MERRA2, a NASA atmospheric reanalysis, provides remote sensing data beginning in 1980. It uses GEOS-5, which equipped with the newer microwave sounders and hyperspectral infrared radiance instruments. Importantly, according to the crop calendar of Kazakhstan reported by FAO-GIEWS, the cultivating and growing period of cereal mainly takes place from May to August. Thus, it would be reasonable to use the precipitation and temperature data of this period, which is consistent with the growth of cereal in Kazakhstan. Specifically, we use the total precipitation (Millimeters) and average temperature $\left({ }^{\circ} \mathrm{C}\right)$ during these four months as the climate measures.

Additionally, in order to fit the gravity model consistently, the empirical study further includes some other variables. For example, the GDP (constant 2010 US\$) and the land under the cereal production of exporters and importers come from the World Development Indicators database of the World Bank. While the distance variable, measured by the great circle distance between two capitals, is taken from CEPII. Besides, we also access two proxies for bilateral covariates from CEPII: common language and contiguous border, which are measured by dummy variables. These 
three variables are widely used as economic distance variables in the literature (Hasiner and Yu 2016; 2019). Table 4.1 presents the detailed definition of variables, and Table 4.2 reports the descriptive statistics.

\section{[Place Table $4.1 \&$ Table 4.2 here]}

\subsection{Gravity Model and Econometric Approach}

The gravity model of international trade, inspired by Newton's gravity equation, relates bilateral trade flows to the economic size and distance of two trade partners. This model was first proposed by Isard (1954) in the field of economics. The basic model for two partners' trade can be formulated by the following equation:

$$
Y_{i j}=C \frac{E_{i} E_{j}}{D_{i j}}
$$

Where $Y_{i j}$ denotes trade flows (export or import) from country $i$ to country $j$; $E_{i}$ and $E_{j}$ denote the economic size of two countries respectively, measured by their GDP's; $D_{i j}$ is the geographical distance between the two countries; and $C$ is constant. Theoretically, this model indicates that trade flows are determined by the exporter's productivity, the importer's purchasing power, and also the trade cost measured by geographical and economic distance. In addition, Linnemann (1996), Bergstrand (1989), and Tian and Yu (2017) further consider a set of bilateral trade covariates as trade costs, mainly including contiguous border, common language, and so on. Empirically, for the sake of econometric analyses, we can easily transfer the gravity model to a linear form by taking logarithms, that is:

$$
\ln Y_{i j}=\alpha+\beta_{1} \ln E_{i}+\beta_{2} \ln E_{j}+\beta_{3} \ln D_{i j}+\varepsilon_{i j}
$$


Regarding the estimation strategies for the gravity model, some disputes exist. Traditionally, OLS could be a feasible way to estimate Equation (4.2) as it has been transferred to linear form, which is based on the homoscedasticity assumption. However, this approach has been subjected to considerable criticism due to its several limitations. First, Silva and Tenreyro (2006) argue that the parameter of the gravity equation estimated by OLS would be biased under heteroskedasticity, and then suggest that nonlinear estimation would perform better. The second challenge is the problem of zero values, as there are always some countries do not trade all products with their partners (Haveman and Hummels 2004). Gómez-Herrera (2013) points out that the econometric models that do not consider the zero values would perform worse than others. In practice, given the theoretical foundation of firm heterogeneity (Chaney 2008), Helpman et al. (2008) employ the two-stage Heckman sample selection model to avoid inconsistent estimation. However, the disadvantage of the Heckman sample selection model is that it might be difficult to find an identification restriction (Gómez-Herrera 2013). In this study, we use the PPML (Poisson Pseudo Maximum Likelihood) to estimate the gravity model. Compared with other econometric methods, the advantage of PPML is that it could not only deal with the problem of zero trade flows but also obtain unbiased estimation under heteroskedasticity (Silva and Tenreyro 2006; An and Puttitanun 2009; Prehn et al. 2016). The third challenge for a gravity model is the identification problem. GDP could be endogeneity. However, as the share of agriculture in total GDP is less than 5\% in Kazakhstan, and export value for a single cereal is far less than $1 \%$ in GDP. GDP, 
which measures the economic scale, can, therefore, be regarded as exogeneity. Endogeneity could also be caused by the unchanged heterogeneity in the error terms, such as scale and institution, and we use a fixed-effects model to control for it.

In the last few decades, the gravity model is widely used in international trade researches. For instance, Anderson and Marcouiller (2002) employ a gravity model and corruption data to study the effect of institutional weakness on trade. And their results show that institutional weakness dramatically reduces international trade. Similarly, Hasiner and Yu (2016 \& 2019) also draw a conclusion that the institutions of exporters have a significant positive effect on meat exports to China. Besides, some literature pays more attention to the trade partnerships and trade barriers, including Regional Trade Agreement (TRA) (Baier and Bergstrand 2005; Tian and Yu 2017), Non-Tariff Barriers to Trade (NTB) (Fontagné et al. 2005), cost of the border (Anderson and Van Wincoop 2003), single currency on trade (Frankel and Rose 2000), trade patterns (Fontagné et al. 1998), and so on.

Nevertheless, to the best of our knowledge, although a few studies realize the importance of agriculture trade in climate change, little attention has been paid to the impact of climate change on cereal trade empirically by employing gravity model. Climate variables could be regarded as essential resource variables that significantly affect agricultural productivity (Holst et al. 2013). Of course, it is an important determinant of agricultural trade. Given the dramatic trend of climate change and the importance of food security, this study empirically studies the potential impact of climate change on cereal trade in Kazakhstan by incorporating the climate variables in 
the gravity model. Moreover, as the proxies for climate change are strictly exogenous, we could simply construct the econometric model as follow:

$$
\ln T_{i j}=\alpha+\beta_{1} C m_{i}+\beta_{2} \ln G D P_{i}+\beta_{3} \ln G D P_{j}+\beta_{4} \ln Z_{i j}+\varepsilon_{i j}
$$

Where $T_{i j}$ denotes the cereal trade between Kazakhstan and other countries, $C m_{i}$ denotes the precipitation and land surface temperature of Kazakhstan, $G D P_{i}$ denotes the GDP of Kazakhstan while $G D P_{j}$ denotes the GDP of trade partners, $Z_{i j}$ stands for bilateral covariates, including the distance of two capitals, land under cereal production, common language, and contiguous border. Note that we did not take logs for the climate variables so that the coefficient will be explained as the percentage of trade volume (export or import) in response to one unit increase in climate variables.

\subsection{Results and Discussion}

In order to tackle zero trade flows, we ad hoc adopt the Poisson Pseudo Maximum Likelihood (PPML) to estimate the gravity model of Equation (4.3). As aforementioned, the proxies for climate change in this study include precipitation and land surface temperature, while cereal trade is defined as cereal exports and imports, which are estimated separately below.

\subsubsection{Climate Change and Cereal Exports in Kazakhstan}

Table 4.3 reports the impact of climate change on cereal exports. Specifically, we mainly discuss three major crops in Kazakhstan: wheat, rice, and maize. In column (1), column (3), and column (5) of Table 4.3, we present the estimated results of the basic 
gravity model incorporating climate variables for the purpose of comparison, while column (2), column (4), and column (6) are the results of the full gravity model incorporating climate change and control variables as well (Equation (4.3)). It is clear that the estimated results are robust.

Overall, the coefficients of precipitation and temperature are positive, although the impact of climate change on maize exports is not significant. The general conclusions indicate that a marginal increase in precipitation would significantly increase exports of wheat and rice and has no significant impact on the export of maize. Specifically, increasing precipitation by one millimeter during the major cropping season from May to August will significantly promote the export of wheat and rice by $0.7 \%$ and $0.5 \%$, respectively, in the full model. A marginal increase in temperature only significantly increase the export of wheat, while no significant impact is found for rice and maize. The marginal impact of temperature for wheat is 0.219 in the full model. It indicates that a $1{ }^{\circ} \mathrm{C}$ increase would lead to $21.9 \%$ more export of wheat.

A possible explanation for this might be that marginally increasing precipitation and temperature are likely to result in cereal production increase as the climate becomes milder for grain production, which is consequently transmitted to trade. Also, it indicates that the decreasing precipitation might reduce the wheat export in Kazakhstan. Landscape in Kazakhstan is characterized by mountain and desert areas in the whole nation except in the north and northwest regions. Water shortage is one of the main challenges to agricultural production in Kazakhstan. Specifically, most of 
the agricultural land of Kazakhstan, nearly 35 million hectares, is rain-fed, while only $6 \%$ is irrigated (Mizina et al. 1999). Hence, the increase of precipitation might increase cereal production so as to promote cereal exports, which is consistent with the trend we depict in Figure 4.1. Nevertheless, the maize plant is highly sensitive to moisture surplus and deficit (Rashid and Rasul 2011). As a result, the impact of climate change on maize export is not significant.

Besides, the coefficients of the GDP of Kazakhstan are almost negative and statistically significant, while the coefficients are positive regarding the importers. It is comprehensible that economic growth would demand more food domestically and could lead to less export of food. Furthermore, the distance plays a negative impact on cereal exports, which is consistent with the basic assumption of the gravity model.

\section{[Place Table 4.3 here]}

\subsubsection{Climate Change and Cereal Imports in Kazakhstan}

Now we look at the impact of climate change on cereal imports. Many countries simultaneously import and export certain products, such as cereal products. Table 4.4 reports the impact of climate change on cereal imports. Specifically, column (1), (3), and (5) of Table 4.4 are the estimation results of Equation (4.2) with climate variables, while column (2), (4), and (6) for Equation (4.3) are the results for the full model. In column (2) of Table 4.4, we can find that the coefficients of precipitation and temperature are negative and statistically significant, suggesting that the increase in precipitation and temperature would reduce wheat imports. The coefficients are -0.017 
and -0.494 , respectively. It implies that increasing precipitation by one millimeter during the period from May to August will reduce the import of wheat by $1.7 \%$, while a $1{ }^{\circ} \mathrm{C}$ increase will reduce the import of wheat by $49.4 \%$.

This result is consistent with those of the export function and might be due to the fact that the increase of precipitation and temperature promote wheat production, reducing wheat imports from other countries. Similarly, corresponding to earlier findings, the coefficient of precipitation of column (6) is 0.006 and statistically significant, indicating that increasing precipitation by one millimeter during the period from May to August could increase the maize imports by $0.6 \%$ in Kazakhstan. This might be due to the reason that the variation of climate change decreases maize production in Kazakhstan. The most likely cause is the flood caused by increased precipitation deteriorates the growing environment of maize. Consequently, to cope with the impact of climate change on maize production, maize trade is a feasible adaption. However, the coefficients of climate variables are not significant in terms of rice imports.

Likewise, the GDP of Kazakhstan plays a negative effect on cereal imports except for maize imports, while the GDP of exporters plays a positive effect. In addition, the increase in distance between importers and exporters significantly decreases the cereal imports of Kazakhstan. The results are consistent with the existing literature.

[Place Table 4.4 here] 


\subsubsection{Robustness Check}

Considering the fact that some variables are constant across entities but vary over time, this study further controls the time fixed effect to check the robustness of estimation results. The results of Tables $4.5 \& 4.6$ show that, after controlling the year fixed effect, the major conclusions of this study remain unchanged. It indicates that our econometric results are robust.

\section{[Place Table $4.5 \& 4.6$ here]}

\subsection{Conclusions and Implications}

International cereal trade is a potential adaption to climate change. Given the background of increasing challenges of climate change on agricultural production in Central Asia, international food trade should be taken into consideration for coping with climate change. However, little attention has been paid to the relationship between climate change and cereal trade. In light of this, this study takes Kazakhstan as an example to empirically analyze the impact of climate change on cereal trade in central Asia by employing the gravity model incorporating PPML (Poisson Pseudo Maximum Likelihood) approach.

Generally, the empirical results show that climate change in Kazakhstan plays a significant impact on cereal trade. On the one hand, the precipitation and temperature in Kazakhstan significantly increase wheat and rice exports, while such an impact is not significant in terms of maize exports. Specifically, increasing precipitation by one millimeter during the period from May to August will significantly promote the export 
of wheat and rice by $0.7 \%$ and $0.5 \%$, respectively. Considering the water shortage situation in Kazakhstan, it is comprehensible that the increase of precipitation could positively affect wheat and rice production. On the other hand, the increase in precipitation and temperature in Kazakhstan reduce wheat imports significantly, while the increase in precipitation significantly increases maize imports.

Overall, our conclusions indicate that under the increased challenges of climate change, international cereal trade could be an effective adaption to ensuring food supply in Kazakhstan. Thus, a well-functioning international cereal trade system should be taken into consideration so as to support the adaption to climate change. Nevertheless, as an important cereal trade country around the world, the dramatic adjustments of cereal trade patterns resulting from climate change in Kazakhstan might affect global food security. For this reason, it is necessary to integrate international food trade into the other climate change adaption approaches in the future. 


\section{Tables}

Table 4.1 Variables Definition

\begin{tabular}{ll}
\hline Variable & Definition \\
\hline Precipitation & Total precipitation during major crop season \\
& (May-August) $(\mathrm{mm})$ \\
Temperature & Land surface temperature $\left({ }^{\circ} \mathrm{C}\right)$ \\
Wheat trade & Exports and imports of wheat (1000 MT), log \\
Rice trade & Exports and imports of rice (1000 MT), log \\
Maize trade & Exports and imports of maize (1000 MT), log \\
GDP of Kazakhstan & Constant 2010 US\$, log \\
GDP of trade partners & Constant 2010 US\$, log \\
Land of Kazakhstan & Land under cereal production (hectares), log \\
Land of trade partners & Land under cereal production (hectares), log \\
Distance & Distance between two capitals (kilometer), log \\
Common language & Trading partners share a common language, dummy \\
Contiguous border & Trading partners share a common border, dummy \\
\hline
\end{tabular}


Table 4.2 Descriptive Statistics

\begin{tabular}{ccccc}
\hline Variable & Mean & SD & Min & Max \\
\hline Precipitation & 117.155 & 24.809 & 80.980 & 170.264 \\
Temperature & 23.106 & 0.718 & 21.991 & 24.332 \\
Wheat export & 1.515 & 3.761 & 0 & 14.340 \\
Wheat import & 0.108 & 0.891 & 0 & 14.720 \\
Rice export & 0.263 & 1.404 & 0 & 11.080 \\
Rice import & 0.261 & 1.185 & 0 & 10.430 \\
Maize export & 0.113 & 0.932 & 0 & 10.460 \\
Maize import & 0.138 & 0.764 & 0 & 9.641 \\
GDP of Kazakhstan & 25.630 & 0.294 & 25.050 & 26.000 \\
GDP of trade partners & 24.500 & 2.179 & 18.620 & 30.480 \\
Land of Kazakhstan & 16.501 & 0.059 & 16.383 & 16.623 \\
Land of trade partners & 13.337 & 2.582 & 3.332 & 18.473 \\
Distance & 8.693 & 0.586 & 6.857 & 9.7160 \\
Common language & 0.028 & 0.166 & 0 & 1 \\
Contiguous border & 0.023 & 0.149 & 0 & 1 \\
\hline & & & & \\
\hline & & 0.363 & 0 & \\
\hline
\end{tabular}


Table 4.3 the Impact of Climate Change on Cereal Exports

\begin{tabular}{ccccccc}
\hline \multirow{2}{*}{ Variables } & $(1)$ & $(2)$ & $(3)$ & $(4)$ & $(5)$ & $(6)$ \\
& Wheat & Wheat & Rice & Rice & Maize & Maize \\
\hline \multirow{2}{*}{ Precipitation } & $0.005^{* * *}$ & $0.007^{* * *}$ & $0.004^{*}$ & $0.005^{* *}$ & 0.000 & -0.001 \\
& $(0.001)$ & $(0.001)$ & $(0.002)$ & $(0.002)$ & $(0.003)$ & $(0.003)$ \\
Temperature & $0.120^{* * *}$ & $0.219^{* * *}$ & 0.052 & 0.128 & -0.156 & -0.237 \\
& $(0.030)$ & $(0.033)$ & $(0.072)$ & $(0.079)$ & $(0.110)$ & $(0.131)$ \\
GDP_Kaz & $-0.891^{* * *}$ & $-1.296^{* * *}$ & -0.155 & -0.443 & $-2.362^{* * *}$ & $-2.106^{* * *}$ \\
& $(0.071)$ & $(0.100)$ & $(0.229)$ & $(0.281)$ & $(0.480)$ & $(0.597)$ \\
GDP_Par & $0.514^{* * *}$ & $0.503^{* * *}$ & $1.625^{* * *}$ & $1.669^{* * *}$ & $2.407^{* * * *}$ & $2.471^{* * *}$ \\
& $(0.071)$ & $(0.077)$ & $(0.225)$ & $(0.270)$ & $(0.481)$ & $(0.504)$ \\
Distance & $-2.895^{* * *}$ & $-2.980^{* * *}$ & $-10.644^{* * *}$ & $-11.212^{* * *}$ & $-21.483^{* * *}$ & $-20.489^{* * *}$ \\
& $(0.297)$ & $(0.319)$ & $(1.745)$ & $(1.839)$ & $(5.061)$ & $(4.477)$ \\
Land_Kaz & & $2.450^{* * *}$ & & $1.969^{* *}$ & & -1.816 \\
& & $(0.392)$ & & $(0.895)$ & & $(1.529)$ \\
Land_Par & & 0.043 & & 0.011 & & -0.354 \\
& & $(0.072)$ & & $(0.272)$ & & $(0.393)$ \\
Language & & 0.278 & & 0.661 & & -2.692 \\
& & $(1.134)$ & & $(1.931)$ & & $(3.280)$ \\
Border & & -1.085 & & -3.053 & & 0.944 \\
& & $(1.068)$ & & $(2.043)$ & & $(2.092)$ \\
Constant & $30.815^{* * *}$ & -1.234 & $45.878^{* * *}$ & 22.247 & $166.380^{* * * *}$ & $187.464^{* * *}$ \\
Country & $(2.869)$ & $(5.988)$ & $(14.098)$ & $(19.154)$ & $(38.517)$ & $(37.888)$ \\
Observations & $\mathrm{Y}$ & $\mathrm{Y}$ & $\mathrm{Y}$ & $\mathrm{Y}$ & $\mathrm{Y}$ & $\mathrm{Y}$ \\
\hline & 2627 & 2627 & 2627 & 2627 & 2627 & 2627 \\
\hline
\end{tabular}

Note: $* * * * *$ and $*$ denote $1 \%, 5 \%$ and $10 \%$ statistical significance, respectively. 
Table 4.4 the Impact of Climate Change on Cereal Imports

\begin{tabular}{|c|c|c|c|c|c|c|}
\hline Variables & $\begin{array}{c}(1) \\
\text { Wheat }\end{array}$ & $\begin{array}{c}(2) \\
\text { Wheat }\end{array}$ & $\begin{array}{c}(3) \\
\text { Rice }\end{array}$ & $\begin{array}{c}(4) \\
\text { Rice }\end{array}$ & $\begin{array}{c}(5) \\
\text { Maize }\end{array}$ & $\begin{array}{c}(6) \\
\text { Maize }\end{array}$ \\
\hline Precipitation & $\begin{array}{c}-0.016^{* * *} \\
(0.003)\end{array}$ & $\begin{array}{c}-0.017^{* * *} \\
(0.003)\end{array}$ & $\begin{array}{c}0.001 \\
(0.002)\end{array}$ & $\begin{array}{c}0.002 \\
(0.002)\end{array}$ & $\begin{array}{l}0.007^{\text {**** }} \\
(0.003)\end{array}$ & $\begin{array}{l}0.006^{* * *} \\
(0.003)\end{array}$ \\
\hline Temperature & $\begin{array}{c}-0.398^{* * *} \\
(0.114)\end{array}$ & $\begin{array}{c}-0.494^{* * *} \\
(0.131)\end{array}$ & $\begin{array}{l}-0.057 \\
(0.071)\end{array}$ & $\begin{array}{c}0.016 \\
(0.080)\end{array}$ & $\begin{array}{c}0.151 \\
(0.100)\end{array}$ & $\begin{array}{c}0.091 \\
(0.111)\end{array}$ \\
\hline GDP_Kaz & $\begin{array}{l}-0.107 \\
(0.233)\end{array}$ & $\begin{array}{c}0.383 \\
(0.312)\end{array}$ & $\begin{array}{l}-0.374^{* *} \\
(0.150)\end{array}$ & $\begin{array}{l}-0.474^{* *} \\
(0.217)\end{array}$ & $\begin{array}{l}1.016^{* * * *} \\
(0.217)\end{array}$ & $\begin{array}{l}1.379^{* * * *} \\
(0.274)\end{array}$ \\
\hline GDP_Par & $\begin{array}{l}0.896^{\text {**** }} \\
(0.211)\end{array}$ & $\begin{array}{l}0.653^{* * *} \\
(0.220)\end{array}$ & $\begin{array}{l}0.432^{* * *} \\
(0.103)\end{array}$ & $\begin{array}{c}0.187 \\
(0.120)\end{array}$ & $\begin{array}{c}0.822^{* * *} \\
(0.209)\end{array}$ & $\begin{array}{l}0.491^{* *} \\
(0.242)\end{array}$ \\
\hline Distance & $\begin{array}{c}-2.639^{* * * *} \\
(0.633)\end{array}$ & $\begin{array}{c}-2.008^{* * *} \\
(0.709)\end{array}$ & $\begin{array}{c}-1.586^{* * * *} \\
(0.366)\end{array}$ & $\begin{array}{c}-1.323^{* * * *} \\
(0.355)\end{array}$ & $\begin{array}{c}-2.156^{* * * *} \\
(0.559)\end{array}$ & $\begin{array}{l}-1.589^{* *} \\
(0.642)\end{array}$ \\
\hline Land_Kaz & & $\begin{array}{l}-2.336 \\
(1.429)\end{array}$ & & $\begin{array}{l}1.722^{*} \\
(0.907)\end{array}$ & & $\begin{array}{l}-1.618 \\
(1.313)\end{array}$ \\
\hline Land_Par & & $\begin{array}{l}0.384^{*} \\
(0.215)\end{array}$ & & $\begin{array}{l}0.395^{* * *} \\
(0.124)\end{array}$ & & $\begin{array}{l}0.617^{\text {*** }} \\
(0.275)\end{array}$ \\
\hline Language & & $\begin{array}{l}3.173^{* * *} \\
(1.574)\end{array}$ & & $\begin{array}{c}0.137 \\
(1.801)\end{array}$ & & $\begin{array}{c}3.958 \\
(4.286)\end{array}$ \\
\hline Border & & $\begin{array}{l}-0.382 \\
(1.672)\end{array}$ & & $\begin{array}{c}0.691 \\
(1.632)\end{array}$ & & $\begin{array}{l}-3.184 \\
(3.905)\end{array}$ \\
\hline Constant & $\begin{array}{c}9.836 \\
(7.149)\end{array}$ & $\begin{array}{c}33.122 \\
(21.069)\end{array}$ & $\begin{array}{c}11.401^{* *} \\
(4.610)\end{array}$ & $\begin{array}{l}-18.101 \\
(13.058)\end{array}$ & $\begin{array}{c}-35.327^{* * *} \\
(6.658)\end{array}$ & $\begin{array}{l}-21.831 \\
(20.328)\end{array}$ \\
\hline Country & Y & Y & $\mathrm{Y}$ & Y & Y & $\mathrm{Y}$ \\
\hline Observations & 2627 & 2627 & 2627 & 2627 & 2627 & 2627 \\
\hline
\end{tabular}

Note: $* * *, * *$ and $*$ denote $1 \%, 5 \%$ and $10 \%$ statistical significance, respectively. 
Table 4.5 Robustness Check of Cereal Exports

\begin{tabular}{|c|c|c|c|c|c|c|}
\hline Variables & $\begin{array}{c}(1) \\
\text { Wheat }\end{array}$ & $\begin{array}{c}(2) \\
\text { Wheat }\end{array}$ & $\begin{array}{c}(3) \\
\text { Rice }\end{array}$ & $\begin{array}{c}(4) \\
\text { Rice }\end{array}$ & $\begin{array}{c}(5) \\
\text { Maize }\end{array}$ & $\begin{array}{c}(6) \\
\text { Maize }\end{array}$ \\
\hline Precipitation & $\begin{array}{l}0.008^{* * *} \\
(0.001)\end{array}$ & $\begin{array}{l}0.008^{* * *} \\
(0.001)\end{array}$ & $\begin{array}{l}0.004^{* *} \\
(0.002)\end{array}$ & $\begin{array}{l}0.005^{* *} \\
(0.002)\end{array}$ & $\begin{array}{c}0.000 \\
(0.003)\end{array}$ & $\begin{array}{l}-0.001 \\
(0.003)\end{array}$ \\
\hline Temperature & $\begin{array}{c}0.098^{* * * *} \\
(0.029)\end{array}$ & $\begin{array}{c}0.095^{* * *} \\
(0.036)\end{array}$ & $\begin{array}{c}0.041 \\
(0.072)\end{array}$ & $\begin{array}{c}0.112 \\
(0.089)\end{array}$ & $\begin{array}{l}-0.157 \\
(0.110)\end{array}$ & $\begin{array}{l}-0.318^{* * *} \\
(0.142)\end{array}$ \\
\hline GDP_Kaz & $\begin{array}{l}1.935^{\text {*** }} \\
(0.286)\end{array}$ & $\begin{array}{c}2.106^{* * *} \\
(0.404)\end{array}$ & $\begin{array}{c}1.007 \\
(0.712)\end{array}$ & $\begin{array}{l}-0.050 \\
(1.053)\end{array}$ & $\begin{array}{l}-2.095^{* *} \\
(0.974)\end{array}$ & $\begin{array}{l}-0.165 \\
(1.433)\end{array}$ \\
\hline GDP_Par & $\begin{array}{c}0.567^{* * *} \\
(0.073)\end{array}$ & $\begin{array}{l}0.551^{* * * *} \\
(0.079)\end{array}$ & $\begin{array}{l}1.677^{* * *} \\
(0.233)\end{array}$ & $\begin{array}{l}1.682^{* * * *} \\
(0.273)\end{array}$ & $\begin{array}{l}2.479^{* * * *} \\
(0.537)\end{array}$ & $\begin{array}{l}2.765^{* * * *} \\
(0.557)\end{array}$ \\
\hline Distance & $\begin{array}{c}-2.926^{* * *} \\
(0.296)\end{array}$ & $\begin{array}{c}-3.012^{* * *} \\
(0.319)\end{array}$ & $\begin{array}{c}-10.916^{* * *} \\
(1.800)\end{array}$ & $\begin{array}{c}-11.274^{* * *} \\
(1.855)\end{array}$ & $\begin{array}{c}-21.948^{* * *} \\
(5.358)\end{array}$ & $\begin{array}{c}-22.219^{* * * *} \\
(4.868)\end{array}$ \\
\hline Land_Kaz & & $\begin{array}{l}-0.127 \\
(0.493)\end{array}$ & & $\begin{array}{c}1.653 \\
(1.212)\end{array}$ & & $\begin{array}{l}-3.473^{*} \\
(1.895)\end{array}$ \\
\hline Land_Par & & $\begin{array}{c}0.044 \\
(0.073)\end{array}$ & & $\begin{array}{c}0.008 \\
(0.272)\end{array}$ & & $\begin{array}{l}-0.433 \\
(0.416)\end{array}$ \\
\hline Language & & $\begin{array}{c}0.267 \\
(1.139)\end{array}$ & & $\begin{array}{c}0.649 \\
(1.938)\end{array}$ & & $\begin{array}{l}-3.252 \\
(3.428)\end{array}$ \\
\hline Border & & $\begin{array}{l}-1.116 \\
(1.073)\end{array}$ & & $\begin{array}{l}-3.086 \\
(2.054)\end{array}$ & & $\begin{array}{c}0.983 \\
(2.166)\end{array}$ \\
\hline Constant & $\begin{array}{c}313.135^{* * *} \\
(27.768)\end{array}$ & $\begin{array}{c}328.898^{* * *} \\
(38.357)\end{array}$ & $\begin{array}{c}156.370^{* *} \\
(65.451)\end{array}$ & $\begin{array}{c}59.922 \\
(99.059)\end{array}$ & $\begin{array}{l}202.355^{*} \\
(120.713)\end{array}$ & $\begin{array}{l}412.183^{\text {*** }} \\
(156.132)\end{array}$ \\
\hline Country & Y & Y & Y & Y & $\mathrm{Y}$ & Y \\
\hline Year & Y & Y & $\mathrm{Y}$ & $\mathrm{Y}$ & $\mathrm{Y}$ & $\mathrm{Y}$ \\
\hline Observations & 2627 & 2627 & 2627 & 2627 & 2627 & 2627 \\
\hline
\end{tabular}

Note: $* * *, * *$ and $*$ denote $1 \%, 5 \%$ and $10 \%$ statistical significance, respectively. 
Table 4.6 Robustness Check of Cereal Imports

\begin{tabular}{|c|c|c|c|c|c|c|}
\hline \multirow{2}{*}{ Variables } & (1) & (2) & (3) & (4) & (5) & (6) \\
\hline & Wheat & Wheat & Rice & Rice & Maize & Maize \\
\hline \multirow{2}{*}{ Precipitation } & $-0.018^{* * *}$ & $-0.018^{* * * *}$ & 0.002 & 0.002 & $0.005^{*}$ & $0.006^{* *}$ \\
\hline & $(0.003)$ & $(0.003)$ & $(0.002)$ & $(0.002)$ & $(0.003)$ & $(0.003)$ \\
\hline \multirow{2}{*}{ Temperature } & $-0.380^{* * * *}$ & $-0.397^{* * *}$ & -0.069 & -0.048 & $0.199^{*}$ & $0.336^{* * *}$ \\
\hline & $(0.116)$ & $(0.142)$ & $(0.071)$ & $(0.087)$ & (0.103) & $(0.128)$ \\
\hline \multirow{2}{*}{ GDP_Kaz } & $-2.558^{* * *}$ & -2.106 & $1.379^{* *}$ & 1.222 & $-2.463^{* * *}$ & $-4.330^{* * *}$ \\
\hline & $(0.990)$ & $(1.443)$ & $(0.672)$ & $(0.969)$ & $(0.946)$ & $(1.477)$ \\
\hline \multirow{2}{*}{ GDP_Par } & $0.916^{* * *}$ & $0.668^{* * *}$ & $0.451^{* * *}$ & 0.198 & $0.827^{* * *}$ & $0.490^{* *}$ \\
\hline & $(0.213)$ & $(0.221)$ & $(0.104)$ & $(0.121)$ & $(0.209)$ & $(0.241)$ \\
\hline \multirow{2}{*}{ Distance } & $-2.671^{* * *}$ & $-2.017^{* * *}$ & $-1.573^{* * *}$ & $-1.321^{* * *}$ & $-2.163^{* * *}$ & $-1.589^{* *}$ \\
\hline & $(0.641)$ & $(0.710)$ & $(0.363)$ & $(0.354)$ & $(0.560)$ & $(0.640)$ \\
\hline \multirow{2}{*}{ Land_Kaz } & & -0.369 & & 0.426 & & $3.264^{*}$ \\
\hline & & $(1.810)$ & & (1.159) & & (1.803) \\
\hline \multirow{2}{*}{ Land_Par } & & $0.370^{*}$ & & $0.390^{* * * *}$ & & $0.613^{* *}$ \\
\hline & & $(0.213)$ & & $(0.124)$ & & $(0.273)$ \\
\hline \multirow{2}{*}{ Language } & & $3.148^{* *}$ & & 0.150 & & 3.942 \\
\hline & & $(1.574)$ & & (1.804) & & $(4.275)$ \\
\hline \multirow{2}{*}{ Border } & & -0.375 & & 0.678 & & -3.176 \\
\hline & & $(1.671)$ & & (1.634) & & (3.894) \\
\hline \multirow{2}{*}{ Constant } & $-220.065^{* *}$ & -199.350 & $181.630^{* * * *}$ & 143.811 & $-345.085^{* * *}$ & $-548.137^{* * *}$ \\
\hline & $(90.596)$ & $(133.651)$ & $(63.694)$ & (90.976) & $(82.837)$ & $(136.303)$ \\
\hline Country & Y & Y & Y & $\mathrm{Y}$ & Y & $\mathrm{Y}$ \\
\hline Year & $\mathrm{Y}$ & Y & $\mathrm{Y}$ & $\mathrm{Y}$ & Y & $\mathrm{Y}$ \\
\hline Observations & 2627 & 2627 & 2627 & 2627 & 2627 & 2627 \\
\hline
\end{tabular}

Note: $* * *, * *$ and $*$ denote $1 \%, 5 \%$ and $10 \%$ statistical significance, respectively. 


\section{Figures}

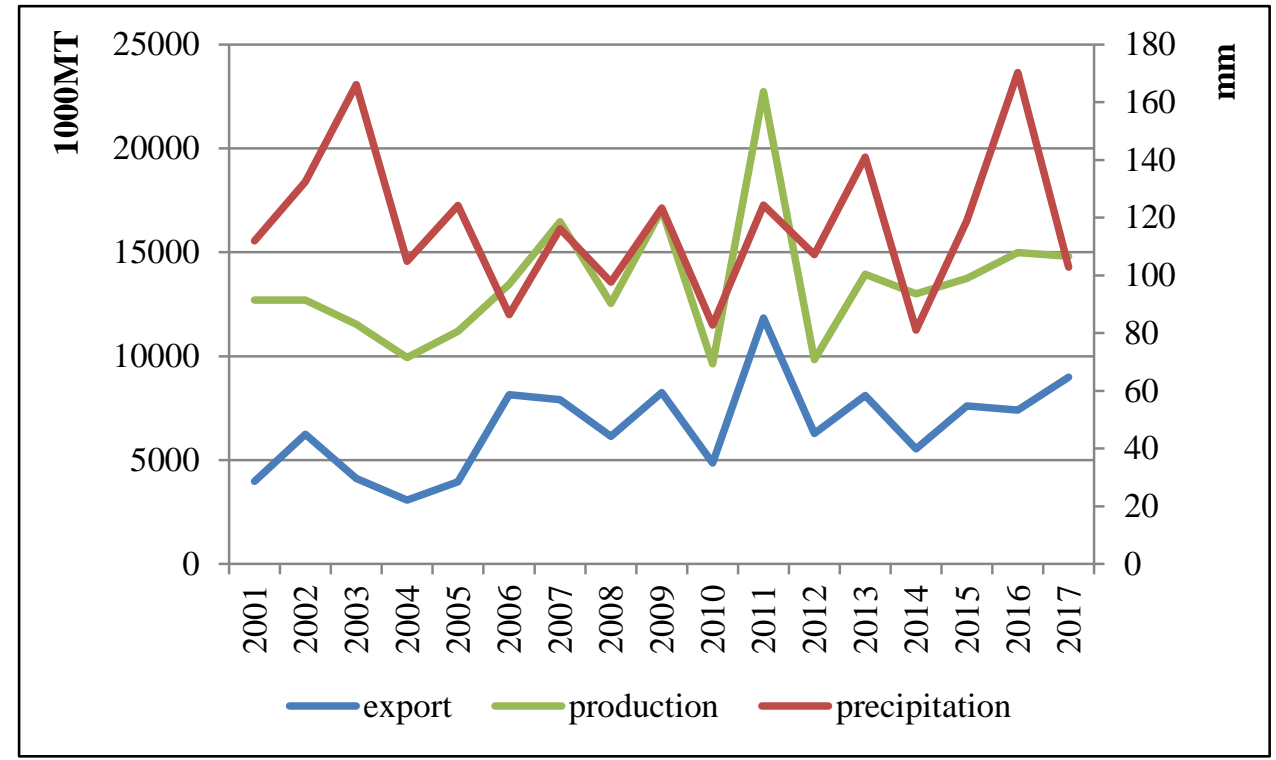

Figure 4.1 Precipitation and Wheat Exports

Data sources: FAOSTAT: http://www.fao.org/faostat/en/\#home

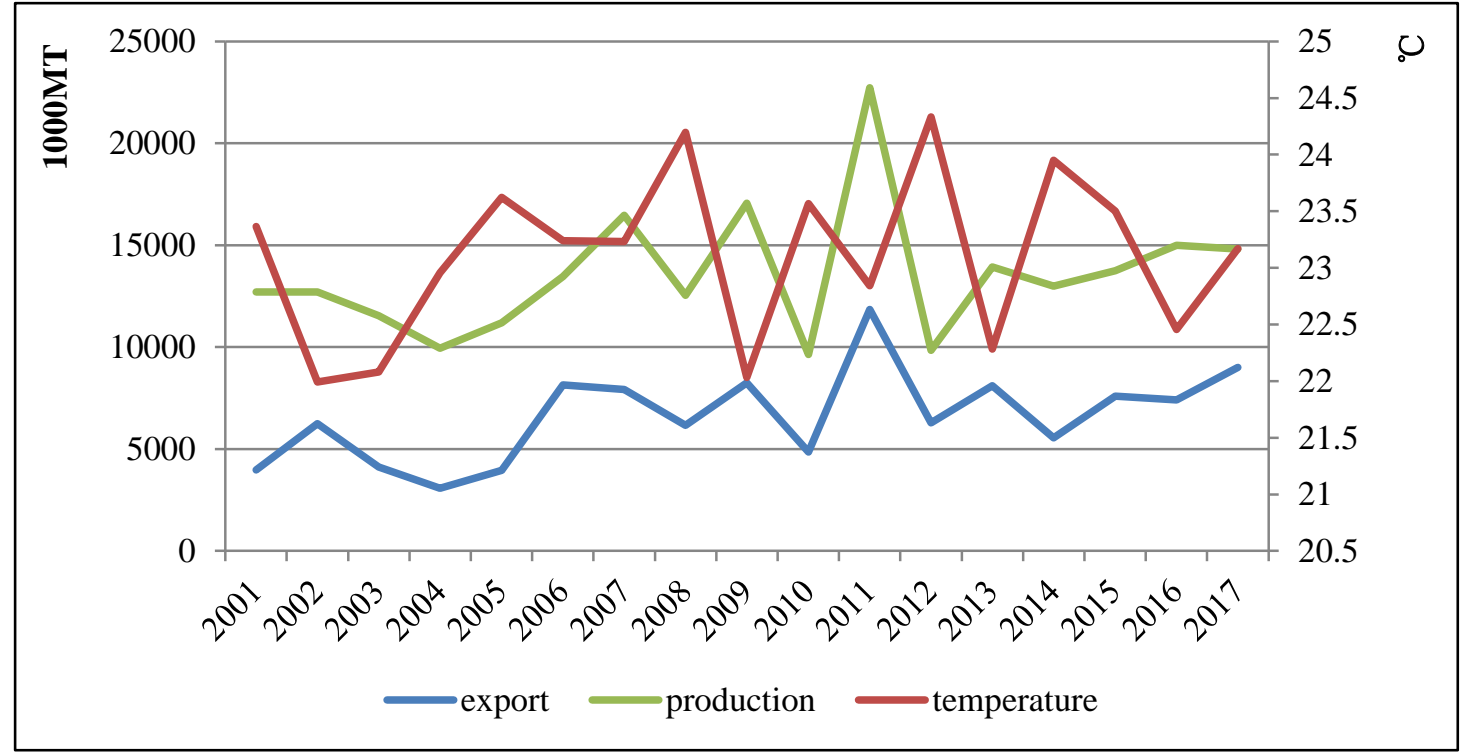

Figure 4.2 Temperature and Wheat Exports

Data sources: FAOSTAT: http://www.fao.org/faostat/en/\#home 


\section{Chapter 5 General Conclusion}

\subsection{Conclusions from Empirical Studies}

How to achieve sustainable development is an important issue. Among all of the 17 Sustainable Development Goals (SDGs), rural poverty and climate change are the most significant challenges for the agricultural economy and rural development as it relates to the basic living needs of rural households and agricultural production activities. In light of this, this dissertation aims to shed light on rural poverty and the impact of climate change on agriculture. Regarding the rural poverty issue, this dissertation tends to reveal the subjective poverty in rural China beyond 2020 when extreme poverty is expected to be eliminated. In terms of the impact of climate change, we reveal the impact from two perspectives. First, high food price volatility could incur severe welfare loss, especially for the poor (Bellemare, Barrett, and Just 2013; Yu 2014b). Thus, we reveal the impact of sunspots on soybeans futures prices from the behavioral finance perspective by using the disagreement theory. Second, international agricultural trade is a potential adaption to climate change. Accordingly, this dissertation empirically substantiates the impact of climate change on agricultural trade in Central Asia so as to provide some insightful policy implications. Generally, the conclusions of the three topics are as follows:

In Chapter 2, the most significant finding is that the objective poverty line cannot well mirror the subjective poverty comprehensively in rural China. Statistically, the results show that the mean subjective poverty standard for rural households is 8297 
yuan per capita, which is much higher than the national poverty line and the global poverty line. More importantly, $82 \%$ of the objective poor in rural China report higher subjective poverty standards or feel subjectively poor, while $29 \%$ of the rural household who are not the objective poor feel subjectively poor. Empirically, the results substantiate that demographic and socioeconomic characteristics have significant effects on subjective poverty. On the one hand, the wealthy level of a household, measured by per capita income and house value, etc. can reflect the life quality. It is understandable that wealthier families expect a better life quality so that a high subjective poverty line for them is comprehensible. On the other hand, irregular expenditures due to imperfections of social security systems in rural China (mainly medical and education expenses) and traditional culture of a cash gift, are also positively correlated with the subjective poverty lines.

In Chapter 3, we provide a new perspective to understand how the information of sunspots affects the soybeans futures price volatility both theoretically and empirically. The theoretical framework shows that the information of sunspots causes disagreement in the soybeans futures market mainly by three channels: gradual information flow, limited attention, and heterogeneous priors, which would finally lead to the volatility of soybeans futures price. Using time series monthly data from Dec. 1988 to Dec. 2018, the empirical study finds that low sunspot activities are linked to both high soybean prices and price volatility. Particularly, the price variances are negatively correlated with sunspots level. It implies that traders particularly have a high disagreement on the impact of extremely low sunspot activity on market prices. 
In addition, the disagreement level is nonlinear in the high volatility regime. That is, traders have a high disagreement on both extremely low and high sunspot activity. This Chapter hence provides evidence that the information of sunspots leads to disagreement levels on the impacts, shaping the investors' trading behaviors in the soybeans futures market.

In Chapter 4, we empirically substantiate the impact of climate change on agricultural trade. Generally, the empirical results show that climate change in Kazakhstan has a significant impact on cereal trade. On the one hand, the precipitation and temperature in Kazakhstan significantly increase wheat and rice exports, while such an impact is not significant in terms of maize exports. Specifically, increasing precipitation by 1 millimeter during the period from May to August will significantly promote the export of wheat and rice by 0.7 percent and 0.5 percent, respectively. Considering the water shortage in Kazakhstan, it is comprehensible that the increase in precipitation could positively affect wheat and rice production. On the other hand, the increase in precipitation and temperature in Kazakhstan reduce wheat imports significantly, while the increase in precipitation significantly increases maize imports.

\subsection{Policy Implications}

This dissertation offers some policy implications as follows:

First, the objective poverty line cannot well mirror the subjective poverty in rural China. Compared with the objective poverty line, the measurement of subjective poverty is a more flexible method to reflect the poverty perception, particularly when 
extreme poverty is not an important issue, such as in China. This will be increasingly important for China's poverty and welfare policymaking beyond 2020 when extreme poverty is eliminated. Besides, medical expenditure and education expenditure are found to play an important role in subjective poverty in rural China. The government should enhance the coverage of medical insurance, increase the education expenditure, and change the culture of a cash gift, to reduce insecurity and enhance life satisfaction for rural households ${ }^{25}$. Moreover, the subjective poverty standard is correlated with income level, and it should increase gradually if there is a national subjective poverty line. In order to evaluate the efficiency of the policies more scientifically, it is necessary to integrate subjective poverty into the policy evaluation system and combine both subjective and objective poverty to show a full picture of poverty reduction in rural China. Also, sustainable growth of income is an effective way to alleviate both subjective and objective poverty and to increase the life satisfaction of the citizens (Zhou and Yu 2017).

Second, high food price volatility could incur severe welfare loss (Bellemare, Barrett, and Just 2013; Yu 2014b), while solar phenomena, often measured by $\operatorname{sunspots}^{26}$, are regarded as a fundamental factor that drives the volatility. It is widely known that the agricultural commodity futures market plays an important role in the development of the agriculture sector and traders' decision-making. Capturing the

\footnotetext{
${ }^{25}$ Chinese government has issued several regulations for the culture of cash gift. For instance, No. 1 Central Document of 2018 has proposed the policies to restrict the culture of cash gift.

${ }^{26}$ Sunspots form on the surface of the Sun due to strong magnetic field lines coming up from within the Sun trough the solar surface and appear visibly as dark spots compared to their surroundings (see www.spaceweatherlive.com).
} 
volatility of agricultural commodity futures price enables policymakers to stabilize the domestic agricultural commodity market in time so as to protect agriculture sectors.

Given the fact that the information of sunspots could cause soybeans futures price, projecting food prices, and making food policies should consider sunspot activities. A better forecast of market price could help traders make better investment strategies and help governments make better food security policies.

Third, under the increasing challenges of climate change, international cereal trade could be an effective adaption to ensuring food supply in Kazakhstan. Thus, a well-functioning international cereal trade system should be taken into consideration so as to support the adaption to climate change. Nevertheless, as an important cereal trade country around the world, the dramatic adjustments of cereal trade patterns resulting from climate change in Kazakhstan might affect global food security. For this reason, it is necessary to integrate international food trade into the other climate change adaption approaches in the future.

\subsection{Limitations}

Generally, although this dissertation provides new insights into the rural poverty in China and the impact of climate change on agriculture, there are some limitations.

In Chapter 2, to the best of our knowledge, this is the first study comprehensively reveal the subjective poverty in rural China. Nevertheless, the subjective approach we use to measure subjective poverty is the Minimum Income Question (MIQ), which may not well reflect the happiness of the rural household. As we know, one of the 
most famous arguments is that "rich does not mean happiness". For instance, the study of Easterlin (1974) investigates the association of income and happiness, and the results show that the happiness differences between rich and poor countries are uncertain. In light of this, it would be better to further incorporate psychological perception into the subjective poverty measure approach.

In Chapter 3, the mechanism of how the information of sunspots affects soybean futures price volatility needs to be further empirically substantiated. Based on the disagreement theory, we theoretically reveal that the information of sunspots could cause disagreement in the soybeans futures market by three channels: gradual information flow, limited attention, and heterogeneous priors, which would finally lead to the volatility of soybeans future price. However, due to the lack of individual-level data, we cannot identify the channels that the information of sunspots affects soybeans futures prices, as well as the differences among the three channels. Further studies could combine the individual-level data and the market level data to clarify the specified channels.

In Chapter 4, we evaluate the impact of climate change by using two proxies: precipitation and temperature, which are essential conditions for agricultural production. The general findings show that climate change in Central Asia significantly affects the international cereal trade. However, we should admit that the impact of climate change on agriculture is rather complicated. Accordingly, the impact of climate change on agricultural trade should be further studied. For instance, it is important to understand how the natural disasters induced by climate change, such as 
droughts, floods, fire hazards, etc. affect agricultural trade, as it might cause a dramatic decrease in agricultural production and then threaten food security. 


\section{Bibliography}

Adams, R. M., Hurd, B. H., Lenhart, S., \& Leary, N. (1998). Effects of global climate change on agriculture: an interpretative review. Climate Research, 11(1), 19-30.

Ahmed, M., Akram, M. N., Asim, M., Aslam, M., Hassan, F. U., Higgins, S., \& Hoogenboom, G. (2016). Calibration and validation of APSIM-Wheat and CERES-Wheat for spring wheat under rainfed conditions: Models evaluation and application. Computers and Electronics in Agriculture, 123, 384-401.

Alkire, S., and Foster, J., "Counting and Multidimensional Poverty Measurement," Journal of public economics, 95, 476-487, 2011.

Alkire, S., and Seth, S., "Multidimensional poverty reduction in India between 1999 and 2006: Where and how?" World Development, 72, 93-108, 2015.

Allen, R. C., "Absolute Poverty: When Necessity Displaces Desire," American Economic Review, 107, 3690-3721, 2017.

An, G., \& Puttitanun, T. (2009). Revisiting McCallum's Border Puzzle. Economic Development Quarterly, 23(2), 167-170.

Anderson, J. E., \& Marcouiller, D. (2002). Insecurity and the pattern of trade: An empirical investigation. Review of Economics and Statistics, 84(2), 342-352.

Anderson, J. E., \& Van Wincoop, E. (2003). Gravity with gravitas: a solution to the border puzzle. American Economic Review, 93(1), 170-192.

Andrade, P., Gaballo, G., Mengus, E., et al., 2019. Forward guidance and heterogeneous beliefs. Amer. Econ. J. Macr. 11(3), 1-29.

Aouadi, A., Arouri, M., Teulon, F., 2013. Investor attention and stock market activity: Evidence from France. Econ. Model. 35, 674-681.

Arifovic, J., Evans, G.W., Kostyshyna, O., 2019. Are sunspots learnable? an experimental investigation in a simple macroeconomic model. J. Econ. Dyna. Cont. 103775.

Ascari, G., Bonomolo, P., Lopes, H. F., 2019. Walk on the wild side: Temporarily 
unstable paths and multiplicative sunspots. Amer. Econ. Revi. 109(5), 1805-42.

Baldos, U. L. C., \& Hertel, T. W. (2014). Global food security in 2050: the role of agricultural productivity and climate change. Australian Journal of Agricultural and Resource Economics, 58(4), 554-570.

Barrios, S., Ouattara, B., \& Strobl, E. (2008). The impact of climatic change on agricultural production: is it different for Africa?. Food Policy, 33(4), 287-298.

Bauwens, L., De Backer, B., Dufays, A., 2014. A Bayesian method of change-point estimation with recurrent regimes: Application to GARCH models. J. Emp. Fina., 29, 207-229.

Bellemare M. F., C. B. Barrett, D. R. Just, 2013. "The Welfare Impacts of Commodity Price Volatility: Evidence from Rural Ethiopia”,American Journal of Agricultural Economics, Vol.95 (4), 877-899.

Benhabib, J., Spiegel, M.M., 2018. Sentiments and economic activity: Evidence from US states. Econ. J. 129(618), 715-733.

Benhabib, J., Wang, P., 2015. Private information and sunspots in sequential asset markets. J. Econ. Theo. 158, 558-584.

Bergstrand, J. H. (1985). The gravity equation in international trade: some microeconomic foundations and empirical evidence. The Review of Economics and Statistics, 474-481.

Bishop, J. A., Luo, F., and Pan, X., "Economic Transition and Subjective Poverty in Urban China," Review of Income and Wealth, 52, 625-641, 2006.

Bollerslev, T., 1986. Generalized autoregressive conditional heteroskedasticity. J. Econometric. 31(3), 307-327.

Bordalo, P., Gennaioli, N., Shleifer, A., 2013. Salience and asset prices. Amer. Econ. Revi. 103(3), 623-28.

Brown, M. E., \& Funk, C. C. (2008). Food security under climate change. Science, 319(5863), 580-581.

Burakov, D., 2017. Do sunspots matter for cycles in agricultural lending: A VEC approach to Russian wheat market. Econ. Info. 9(665-2017-1565), 17-31.

Burke, M., \& Emerick, K. (2016). Adaptation to climate change: Evidence from US 
agriculture. American Economic Journal: Economic Policy, 8(3), 106-40.

Chaney, T. (2008). Distorted gravity: the intensive and extensive margins of international trade. American Economic Review, 98(4), 1707-21.

Chen M., Sun F., Berry P. M., Tinch R., Ju H., and E. Lin. (2015). Integrated assessment of China's adaptive capacity to climate change with a capital approach. Climatic Change. 128:367-380.

Chen, X., "Gift-giving and Network Structure in Rural China: Utilizing Long-term Spontaneous Gift Records," PloS one, 9, 1-14, 2014.

Cherrier, B., Saïdi, A., 2018. The indeterminate fate of sunspots in economics. Hist. Poli. Econ. 50(3), 425-481.

Colasanto, D., Kapteyn, A., and Van der Gaag, J., "Two Subjective Definitions of Poverty: Results from The Wisconsin Basic Needs Study," The Journal of Human Resources, 19, 127-138, 1984.

Crost, B., Duquennois, C., Felter, J. H., \& Rees, D. I. (2018). Climate change, agricultural production and civil conflict: Evidence from the Philippines. Journal of Environmental Economics and Management, 88, 379-395.

Danziger, S., Van der Gaag, J., Taussig, M. K., and Smolensky, E., “The Direct Measurement of Welfare Levels: How Much Does It Cost to Make Ends Meet?" The Review of Economics and Statistics, 500-505, 1984.

Deaton, A., “Computing Prices and Poverty Rates in India, 1999-2000,” Princeton, Research Programme in Development Studies. 2001

Deaton, A., "Price Indexes, Inequality, and the Measurement of World Poverty," American Economic Review, 100, 5-34, 2010.

Deaton, A., "What Do Self-reports of Well-being Say About Life-cycle Theory and Policy?" Journal of Public Economics. 2018.

Deaton, A., and Drèze, J., "Food and nutrition in India: facts and interpretations," Economic and political weekly, 44, 42-65, 2009.

Deaton, A., and Dupriez, O., "Purchasing power parity exchange rates for the global poor," American Economic Journal: Applied Economics, 3, 137-66, 2011.

Deaton, A., and Heston, A., "Understanding PPPs and PPP-based national 
accounts," American Economic Journal: Macroeconomics, 2, 1-35, 2010.

Deleeck, H., and Van den Bosch, K., "Poverty and adequacy of social security in Europe: a comparative analysis," Journal of European Social Policy, 2, 107-120, 1992.

DellaVigna, S., Pollet, J.M., 2009. Investor inattention and Friday earnings announcements. J. Fina. 64(2), 709-749.

Dodamani, B.M., Anoop, R., Mahajan, D.R., 2015. Agricultural drought modeling using remote sensing. Inte. J. Envir. Scie. Deve. 6(5), 326-331.

Duffy, J., Fisher, E.O.N., 2005. Sunspots in the Laboratory. Amer. Econ. Revi. 95(3), $510-529$.

Engle, R.F., 1982. Autoregressive Conditional Heteroscedasticity with Estimates of Variance of United Kingdom Inflation. Econometr. 50 (4), 987-1008

Farmer, R.E.A., 2015. Global sunspots and asset prices in a monetary economy. Nati. Bure. Econ. Rese.

Fehr, D., Heinemann, F., Llorente-Saguer, A., 2019. The power of sunspots: An experimental analysis. J. Mone. Econ. 103, 123-136.

Fontagné, L., Freudenberg, M., \& Péridy, N. (1998). Intra-industry trade and the single market: quality matters. London: Centre for Economic Policy Research.

Foster, E., "Absolute versus relative poverty." The American Economic Review, 88.2, 335-341, 1998

Frankel, J., \& Rose, A. (2000). An estimate of the effect of currency unions on trade and growth. NBER Working Study, 7857.

Garcia-Mata, C., Shaffner, F.I., 1934. Solar and economic relationships: a preliminary report. Quar. J. Econ. 49(1), 1-51.

Garner, T. I., and Short, K. S., "Personal assessments of minimum income and expenses: what do they tell us about 'minimum living thresholds and equivalence scales?" Inequality, Welfare and Poverty: Theory and Measurement. Emerald Group Publishing Limited. 191-243, 2003

Glosten, L.R, R. Jagannathan and D.E. Runkle., 1993. Relationship between the expected value and the volatility of the nominal excess return on stocks, J. Fina. 
48(5), 1779-1801.Gizatulina, A., Hellman, Z., 2019. No trade and yes trade theorems for heterogeneous priors. J. Econ. Theo. 182, 161-184.

Goedhart, T., Halberstadt, V., Kapteyn, A., and Van Praag, B., "The poverty line: concept and measurement," Journal of Human Resources, 12, 503-520, 1977.

Gómez-Herrera, E. (2013). Comparing alternative methods to estimate gravity models of bilateral trade. Empirical Economics, 44(3), 1087-1111.

Gu, C., Mattesini, F., Monnet, C., Wright, R., 2013. Endogenous credit cycles. J. Polit. Econ. 121(5), 940-965.

Guo, Y., Zhou, Y., \& Cao, Z. (2018). Geographical patterns and anti-poverty targeting post-2020 in China. Journal of Geographical Sciences, 28(12), 1810-1824.

Gupta, A., 2019. Climate Change and Global Warming: A Critical Analysis. Nati. J. Envi. Law. 1(2), 37-41.

Gupta, R., Gil-Alana, L.A., Yaya, O.S., 2015. Do sunspot numbers cause global temperatures? Evidence from a frequency domain causality test. Appl. Econ. 47(8), 798-808.

Gustafsson B, Shi L, and Sato H., "Can a subjective poverty line be applied to China? Assessing poverty among urban residents in 1999," Journal of International Development, 16, 1089-1107, 2004.

Hamidov, A., Helming, K., \& Balla, D. (2016). Impact of agricultural land use in Central Asia: a review. Agronomy for Sustainable Development, 36(1), 6.

Han, L., Xu, Y., Yin, L., 2018. Does investor attention matter? The attention-return relationships in FX markets. Econ. Model. 68, 644-660.

Hansen, P.R., Lunde, A., 2005. A forecast comparison of volatility models: does anything beat a GARCH $(1,1)$ ? J. Appl. Econ. 20(7), 873-889.

Harrison, S.G. Weder, M., 2006. Did sunspot forces cause the Great Depression?. J. Mone. Econ. 53(7), 1327-1339.

Hasiner E. and X. Yu (2016) “ Meat Consumption and Democratic Governance: A CrossNational Analysis ", Forthcoming in China Economic Review. DOI: 10.1016/j.chieco.2016.06.008.

Hasiner, E., \& Yu, X. (2019). When institutions matter: A gravity model for Chinese 
meat imports. International Journal of Emerging Markets, 14(1), 231-253.

Haveman, J., \& Hummels, D. (2004). Alternative hypotheses and the volume of trade: the gravity equation and the extent of specialization. Canadian Journal of Economics, 37(1), 199-218.

Helpman, E., Melitz, M., \& Rubinstein, Y. (2008). Estimating trade flows: Trading partners and trading volumes. The Quarterly Journal of Economics, 123(2), 441-487.

Herschel, W.XIII., 1801. Observations tending to investigate the nature of the sun, in order to find the causes or symptoms of its variable emission of light and heat; with remarks on the use that may possibly be drawn from solar observations[J]. Phil. Tran. Roya. Soci. Lond. (91), 265-318.

Ho, S.K.M., 2015. Uni-economics: impact of sunspot on human behaviour and strategic business alliances. Inte. J. Stra. Busi. Alli. 4(1), 24-38.

Holst R., Yu. X. and C. Gruen (2013): "Climate Change, Risk and Grain Yields in China”. Journal of Integrative Agriculture, 12(7) 1279-1291.

Hong, H., Stein, J.C., 2007. Disagreement and the stock market. J. Econ. Pers. 21(2), 109-128.

Hong, H., Torous, W., Valkanov, R., 2007. Do industries lead stock markets?. J. Fina. Econ. 83(2), 367-396.

Huang, H., von Lampe, M., \& van Tongeren, F. (2011). Climate change and trade in agriculture. Food Policy, 36, S9-S13.

Huhtamaa, H., Helama, S., Holopainen, J., et al., 2015. Crop yield responses to temperature fluctuations in 19th century Finland: provincial variation in relation to climate and tree-rings. Bore. Envi. Rese. 20, 707-722.

Isard, W. (1954). Location theory and trade theory: short-run analysis. The Quarterly Journal of Economics, 305-320.

Jevons, W.S., 1879. Sun-spots and commercial crises. Natu. 19, 588-590.

Ji, Y., Xiao, W., 2018. Instability of Sunspot Equilibria in Real Business Cycle Models under Infinite Horizon Learning. Macr. Dyna. 22(8), 1978-2006.

Kahsay, G. A., \& Hansen, L. G. (2016). The effect of climate change and adaptation 
policy on agricultural production in Eastern Africa. Ecological Economics, 121, 54-64.

Kang, M. 2015. Price-level volatility and welfare in incomplete markets with sunspots. J. Math. Econ. 56, 58-66.

Kang, M., 2019. The welfare cost of excess volatility in incomplete markets with sunspots. Macr. Dyna. 23(3), 1062-1073.

Kashiwagi, M., 2014. Sunspots and self-fulfilling beliefs in the US housing market. Revi. Econ. Dyna. 17(4), 654-676.

Kim, J M., Jun, M., Kim, C K., “The Effects of Culture on Consumers' Consumption and Generation of Online Reviews," Journal of Interactive Marketing, 43, 134-150, 2018.

Kingdon, G. G., and Knight, J., "Subjective well-being poverty vs. income poverty and capabilities poverty?" The Journal of Development Studies, 42(7), 1199-1224, 2006.

Klasen, S., Krivobokova, T., Greb, F., et al., "International income poverty measurement: which way now?" The Journal of Economic Inequality, 14(2), 199-225, 2016

Konar, M., Dalin, C., Suweis, S., Hanasaki, N., Rinaldo, A., \& Rodriguez-Iturbe, I. (2011). Water for food: The global virtual water trade network. Water Resources Research, 47(5).

Lan, Y., Huang, Y., Yan, C., 2020. Investor sentiment and stock price: Empirical evidence from Chinese SEOs. Forthcoming in Econ. Model. https://doi.org/10.1016/j.econmod.2020.02.012

Linnemann, H. (1966). An econometric study of international trade flows (No. 42). North-Holland Pub. Co..

Liu, M., Feng, X., Wang, S., \& Qiu, H. (2020). China's poverty alleviation over the last 40 years: successes and challenges. Australian Journal of Agricultural and Resource Economics, 64(1), 209-228.

Liu, Y., Guo, Y., \& Zhou, Y. (2018). Poverty alleviation in rural China: policy changes, future challenges and policy implications. China Agricultural Economic Review. 
Lockwood, M., 2012. Solar influence on global and regional climates. Surv. Geop. 33(3-4), 503-534.

Mahmood T., X. Yu and S. Klasen., "Do the Poor really Feel Poor? Comparing Objective Poverty with Subjective Poverty in Pakistan," Social Indicators Research. 1-38, 2018.

Malmendier, U., Nagel, S., 2016. Learning from inflation experiences. Quar. J. Econ. 131(1), 53-87.

Marinescu, I.I., Horobet, A., Lupu, R., 2018. Dichotomous stock market reaction to episodes of rules and discretion in the US monetary policy. Econ. Model. 70, $56-66$.

Mason, R. L., Gunst, R. F. \& Hess, J. L. (1989). Statistical Design and Analysis of Experiments: Applications to Engineering and Science. New York: Wiley

Mendelsohn, R., Nordhaus, W. D., \& Shaw, D. (1994). The impact of global warming on agriculture: a Ricardian analysis. American Economic Review, 753-771.

Miah, M., Rahman, A., 2016. Modelling Volatility of Daily Stock Returns: Is GARCH $(1,1)$ Enough?. Amer. Scie. Rese. J. Engi. Tech. Scie. 18(1), 29-39.

Mizina, S. V., Smith, J. B., Gossen, E., Spiecker, K. F., \& Witkowski, S. L. (1999). An evaluation of adaptation options for climate change impacts on agriculture in Kazakhstan. Mitigation and Adaptation Strategies for Global Change, 4(1), $25-41$.

Modis, T., 2007. Sunspots, GDP and the stock market. Tech. Fore. Soci. Chan. 74(8), 1508-1514.

Novy-Marx, R., 2014. Predicting anomaly performance with politics, the weather, global warming, sunspots, and the stars. J. Fian. Econ. 112(2), 137-146.

Olesen, J. E., \& Bindi, M. (2002). Consequences of climate change for European agricultural productivity, land use and policy. European Journal of Agronomy, 16(4), 239-262.

Ormes, J.F., 2018. Cosmic rays and climate. Adva. Spac. Rese. 62(10), 2880-2891.

Ouraich, I., Dudu, H., Tyner, W. E., \& Cakmak, E. H. (2018). Agriculture, trade, and climate change adaptation: a global CGE analysis for Morocco and Turkey. The 
Journal of North African Studies, 1-31.

Posel, D., and Rogan, M., "Measured as poor versus feeling poor: Comparing objective and subjective poverty rates in South Africa. WIDER Working Study. 133, 2014.

Pradhan, M., and Ravallion, M., "Measuring poverty using qualitative perceptions of consumption adequacy," Review of Economics and Statistics, 82, 462-471, 2000.

Prehn, S., Brümmer, B., \& Glauben, T. (2016). Gravity model estimation: fixed effects vs. random intercept Poisson pseudo-maximum likelihood. Applied Economics Letters, 23(11), 761-764.

Pryor, S. C., Scavia, D., Downer, C., Gaden, M., Iverson, L., Nordstrom, R., ... \& Robertson, G. P. (2014). Midwest. Climate change impacts in the United States: The third national climate assessment. In: Melillo, JM; Richmond, TC; Yohe, GW, eds. National Climate Assessment Report. Washington, DC: US Global Change Research Program: 418-440., 418-440.

Pustilnik, L.A., G, Yom.Din., 2013. On Possible Influence of Space Weather on Agricultural Markets: Necessary Conditions and Probable Scenarios. Astr. Bull. 68(1), 107-124.

RAJ SINGH, D. S., Shekhar, C., \& MANI, J. K. (2010). Evaluation of 'SOYGRO'model for soybean crop under Hisar conditions. Journal of Agrometeorology, 12(1), 121-122.

Rashid, K., \& Rasul, G. (2011). Rainfall variability and maize production over the Potohar Plateau of Pakistan. Pakistan Journal of Meteorology, 8(15), 63-74.

Ravallion, M., "On testing the scale sensitivity of poverty measures," Economics Letters, 137, 88-90, 2015.

Ravallion, M., and Lokshin, M., "Self-rated economic welfare in Russia," European Economic Review, 46, 1453-1473, 2002.

Reyes-García, V., Babigumira, R., Pyhälä, A., et al., "Subjective wellbeing and income: Empirical patterns in the rural developing world," Journal of happiness studies, 17(2), 773-791, 2016.

Rosenzweig, C., \& Parry, M. L. (1994). Potential impact of climate change on world 
food supply. Nature, 367(6459), 133.

Rozelle, S., "Stagnation without equity: patterns of growth and inequality in China's rural economy," The China Journal, 35, 63-92, 1996.

Ruan, Q., Wang, Z., Zhou, Y., Lv, D., 2019. A new investor sentiment indicator (ISI) based on artificial intelligence: A powerful return predictor in China. Econ. Model.

Schwan S. and X. Yu (2018) "Social protection as a strategy to address climate-induced migration", International Journal of Climate Change Strategies and Management. 10(1):43-64.

Sen, A., "Development as freedom," Oxford University Press, 1996.

Silva, J. S., \& Tenreyro, S. (2006). The log of gravity. The Review of Economics and Statistics, 88(4), 641-658.

Stevenson, B., and Wolfers, J., "Subjective well-being and income: Is there any evidence of satiation?" American Economic Review, 103, 598-604, 2013.

Sun, F., Yun, D., Yu, X., 2017. Air pollution, food production and food security: A review from the perspective of food system. J. Inte. Agri. 16(12), 2945-2962.

Tchijevsky, A.L., 1971. Physical factors of the historical process. Cycl. 22, 11-27.

Thaler, R. H., 2016. Behavioral economics: Past, present, and future. Amer. Econ. Revi. 106(7), 1577-1600.

Tian X., and X. Yu (2017) "The Quality of Imported Fruits in China". Emerging Markets Finance \& Trade. 53:1603-1618, 2017

Townsend, P., "Poverty in the United Kingdom: a survey of household resources and standards of living," University of California Press. 1979.

Van Praag, B. M., "Individual welfare functions and consumer behavior: A theory of rational irrationality" North-Holland Pub. Co. 1968

Van Praag, B. M., Spit, J. S., and Van de Stadt, H., “A comparison between the food ratio poverty line and the Leyden poverty line," The Review of Economics and Statistics, 64, 691-694, 1982.

Veenhoven, R., "Why social policy needs subjective indicators," Social indicators research, 58, 33-46, 2002. 
Vermeir, I., and Verbeke, W., "Sustainable food consumption: Exploring the consumer “attitude-behavioral intention" gap," Journal of Agricultural and Environmental ethics, 19, 169-194, 2006.

Wall, S.B., Jenkins, S.H., 2003. Reciprocal pilferage and the evolution of food-hoarding behavior. Beha. Ecol. 14(5), 656-667.

Walsh, B., 1993. Economic Cycles and Changes in the Earth's Geomagnetic Field. Cycl. Maga. 44(2).

Walthall, C. L., Anderson, C. J., Baumgard, L. H., Takle, E., \& Wright-Morton, L. (2013). Climate change and agriculture in the United States: Effects and adaptation.

Wang, H., Zhao, Q., Bai, Y., Zhang, L., \& Yu, X. (2020). Poverty and Subjective Poverty in Rural China. Social Indicators Research, 1-24.

Wheaton, E. E., \& Maciver, D. C. (1999). A framework and key questions for adapting to climate variability and change. Mitigation and Adaptation Strategies for Global Change, 4(3-4), 215-225.

Withbroe, G.L., 1989. Solar activity cycle-History and predictions. J. Spac. Rock. 26(6), 394-402.

Yang, C., Li, J., 2013. Investor sentiment, information and asset pricing model. Econ. Model. 35, 436-442.

Yang, H.J., Park, C.G., Cho, K.S., et al., 2019. Solar activities and climate change during the last millennium recorded in Korean chronicles. J. Atom. Sola. Phys. $186,139-146$.

Yu, X., and Abler, D., "Matching food with mouths: A statistical explanation to the abnormal decline of per capita food consumption in rural China," Food Policy, 63, 36-43, 2016.

Yu. X., 2014a. Monetary Easing Policy and Long-Run Food Prices in China. Econ. Model, 40:175-183.

Yu. X.,2014b. "Raising Food Prices and Welfare Change: A Simple Calibration". Applied Economics Letters. Vol. 21(9):643-645.

Zhang P., Zhang J., and M. Chen. 2017. Economic impacts of climate change on 
agriculture: The importance of additional climatic variable other than temperature and precipitation. Journal of Environmental Economics and Management. 83: 8-31.

Zhang, B., Wang, Y., 2015. Limited attention of individual investors and stock performance: Evidence from the ChiNext market. Econ. Model. 50, 94-104.

Zhang, D., Lei, L., Ji, Q., et al., 2019. Economic policy uncertainty in the US and China and their impact on the global markets. Econ. Model. 79, 47-56.

Zhou S. and X. Yu, "Regional Heterogeneity of Life Satisfaction in Urban China: Evidence from Hierarchical Ordered Logit Analysis," Social Indicators Research, 132, 25-45, 2017.

Zhou, D., and Yu, X., "Calorie elasticities with income dynamics: evidence from the literature," Applied Economic Perspectives and Policy, 37, 575-601, 2014.

Zhou, Yang, et al., "Targeted poverty alleviation and land policy innovation: Some practice and policy implications from China." Land Use Policy, 74, 53-65, 2018.

Zuo, T., and Yang, Y., "Reshaping the cognition of poverty," Guizhou social science, 285, 43-49, 2013. 